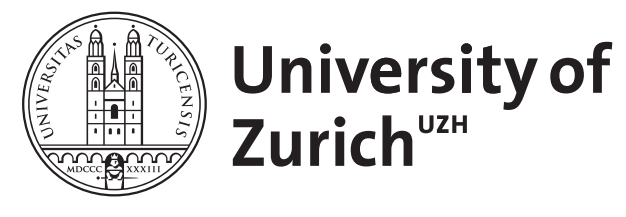

\title{
Recent progress in histochemistry
}

Zuber, Christian ; Taatjes, Douglas J ; Roth, Jürgen

\begin{abstract}
The progress in discerning the structure and function of cells and tissues in health and disease has been achieved to a large extent by the continued development of new reagents for histochemistry, the improvement of existing techniques and new imaging techniques. This review will highlight some advancements made in these fields
\end{abstract}

DOI: https://doi.org/10.1007/s00418-007-0350-2

Posted at the Zurich Open Repository and Archive, University of Zurich

ZORA URL: https://doi.org/10.5167/uzh-156656

Journal Article

Published Version

Originally published at:

Zuber, Christian; Taatjes, Douglas J; Roth, Jürgen (2007). Recent progress in histochemistry. Histochemistry and Cell Biology, 128(6):557-594.

DOI: https://doi.org/10.1007/s00418-007-0350-2 


\title{
Recent progress in histochemistry
}

\author{
Christian Zuber · Douglas J. Taatjes · Jürgen Roth
}

Accepted: 19 October 2007 / Published online: 31 October 2007

(c) Springer-Verlag 2007

\begin{abstract}
The progress in discerning the structure and function of cells and tissues in health and disease has been achieved to a large extent by the continued development of new reagents for histochemistry, the improvement of existing techniques and new imaging techniques. This review will highlight some advancements made in these fields.
\end{abstract}

Keywords Nucleus · Apoptosis · Stem cells .

Angiogenesis $\cdot$ Cartilage $\cdot$ Regeneration $\cdot$ Muscle $\cdot$

Adipocyte

\section{Introduction}

Histochemistry for the most part has become an applied discipline and as such is indispensible for research in cell and molecular biology as well as pathology. This is impressively documented by various labeling techniques for the in situ detection of cellular and extracellular constituents. The use of colloidal gold has revolutionized immunolabeling (Roth 1983) and immunogold labeling became a most widely used technique. Initially introduced as an immunocolloid for cell surface labeling by Faulk and Taylor (1971), the preparation of protein A-gold complexes by Roth et al. (1978) for the detection of intracelluar antigens

C. Zuber $(\square) \cdot$ J. Roth

Division of Cell and Molecular Pathology,

Department of Pathology, University of Zurich,

CH-8091 Zurich, Switzerland

e-mail: christian.zuber@usz.ch

D. J. Taatjes

Department of Pathology, and Microscopy Imaging Center,

College of Medicine, University of Vermont,

Burlington, VT 05405, USA in ultrathin tissue sections permitted an astounding farrago of applications for the analysis of cell and tissue constituents at both the light and electron microscopic level. It is safe to say that the enormous spectrum of available molecular techniques in combination with rapid progress in microscopy techniques permits unprecedented possibilities for the analysis of even the most complex cellular processes. This review is intended to summarize multifarious articles highlighting progress made in histochemical techniques and their manifold applications.

\section{Methods and hardware developments}

A number of papers were published detailing advances in techniques and protocols and reporting new tools. Live-cell imaging is required to study the generation and maintenance of polarity in epithelial cells. Wakabayashi et al. (2007) described a novel procedure using commercially available Transwell filter inserts in which cells were observed using an inverted microscope with the possibility of separately or individually accessing apical and basolateral surfaces. Using fluorescence imaging approaches, unprecedented resolution of dynamics of early endosomes and the Golgi apparatus without perturbing the monolayer was obtained. Visualization of endocytic tracer uptake when added to either apical or basolateral membranes was also possible. Thus, the underside filter culturing method should have wide applicability to four-dimensional live-cell imaging of fully polarized epithelial cells.

Laser microdissection (LMD) techniques have become routine tool for the procurement of a purified population of cells obtained from a complex tissue section for subsequent molecular analyses. The method using immunohistochemistry coupled with LMD (immuno-LMD) enables selective 
sampling of immunopositive cells for RNA extraction. However, RNA degradation largely due to RNase activity in the solutions for immunostaining is inevitable. Kase et al. (2007) developed an efficient method for selective sampling of specific cell populations using immunohistochemistry coupled with LMD. Sections of cerebral cortex were immunostained for parvalbumin and adjacent sections were mounted on Cell Support Film for LMD and stained with neutral red. By comparison of the adjacent sections, neuronal profiles representing parts of parvalbumin-immunopositive somata were identified in the neutral red stained sections. These neuronal profiles were safely captured with LMD and analyzed on reverse transcription-PCR using extracted RNA. The method can be applied to cell-type specific characterization using fixed cells under RNase-free conditions. LMD in conjunction with RT-PCR was applied to quantify ovarian gene expression in granulosa cells (Sakurada et al. 2006). This study revealed that granulosa cells express stable amounts of inhibin- $\alpha$ subunit mRNA independently of antral formation in immature rat ovaries. An interesting application of the LMD technique is to induce cell injury as reported in an in vitro model of vascular injury (Fujita et al. 2006). Capillary-like tubes formed in culture were injured by a precisely focused laser pulse, making LMD an ideal tool for inducing and studying aspects of vascular injury.

Tissue microarray (TMA)-based immunohistochemistry enables to profile comprehensive protein localization and distribution in a high-throughput manner. Peroxisome proliferator-activated receptor-delta (PPAR-delta) is a transcription factor involved in the regulation of fatty acid oxidation and mitochondrial biogenesis in several tissues. PPAR-delta protein localization and distribution profiles in adult mice were analyzed by TMA-based immunohistochemistry (Higashiyama et al. 2007). PPAR-delta immunoreactivity was generally localized on the nucleus, although cytoplasmic localization was observed on several cell types including neurons in the nervous system and cells of the islet of Langerhans. These expression profiling data indicate various physiological roles of PPAR-delta in the studied organ systems.

Unger et al. (2007) evaluated the utility of human placental alkaline phosphatase (hPLAP) as a genetic marker for cell tracking in bone and cartilage, using transgenic Fischer 344 rats expressing hPLAP under the control of the ubiquitous R26 promoter [F344- $\mathrm{Tg}$ (R26-hPLAP)]. hPLAP enzyme activity was retained during paraffin and methylmethacrylate (MMA) embedding, and was best preserved using $40 \%$ ethanol as fixative. In addition, sensitive detection of hPLAP was also possible using immunohistochemistry. F344- $\mathrm{Tg}(\mathrm{R} 26-\mathrm{hPLAP})$ rats demonstrated ubiquitous expression of hPLAP in hematopoietic bone marrow cells and stromal cells such as osteoblasts, osteocytes, and chon- drocytes. Osteoclasts only weakly expressed hPLAP. In conclusion, hPLAP in paraffin and plastic tissue sections constitutes an excellent genetic marker for cell tracking in hard and soft tissues. Hypertrophic chondrocytes in the growth plate play a key role in preparing growth plate cartilage for replacement by bone. Gebhard et al. (2007) reported on the construction of a BAC reporter mouse expressing lac $Z$ under the control of the Col10a1 gene specifically in hypertrophic cartilage. The Col10a1 specific $\mathrm{BAC}$ recombination vector was shown to permit the specific analysis of effector gene functions in hypertrophic cartilage during skeletal development, endochondral ossification, and fracture callus healing. Bender et al. (2007) have optimized the efficiancy of a lentiviral-based transfection protocol in cultures of primary motoneurons. High transfection efficiancy ( $>50 \%$ ) was combined with optimal preservation of morphology and unaltered motoneuron survival. Nilsson (2006) described the development of a technique for genotyping individual DNA molecules utilizing oligonucleotide probes (called padlock probes) circularized by a DNA ligase. Potentially, this technique is suitable for detecting deletions and multiplications of genes with allelic resolution, for investigating the distribution of point mutations, and for $\mathrm{X}$-inactivation patterns and allelic imbalances of gene transcripts.

Most adult organs display low proliferation rates and mitotic figures are rarely encountered due to the short duration of the M-phase. Schmidt et al. (2007), while studying the mTor pathway in tubulo-epithelial cells of rat kidney, observed that S6 kinase became strongly phosphorylated in mitotic cells not only of kidney but also of liver and various human cell lines. Immunofluorescence was weak during the interphase and increased during the prophase in both the nucleus and the cytoplasm and remained strong during the subsequent phases of mitosis. The authors proposed that labeling of phospho-S6 kinase represents a powerful means for the identification of mitotic cells at low magnification in tissue sections and cell cultures. The p57Kip2, a member of the CIP/KIP family of cyclin-dependent kinase inhibitors (CKIs), binds tightly to G1 cyclin/cyclin-dependent kinase complexes to block cell cycle progression. However, p57Kip2 epitopes in paraformaldehyde fixed tissues may be "masked", thus limiting their immunohistochemical detection. Ye et al. (2007) have developed a protocol to circumvent this difficulty. It employs a DNAse I digestion step, which significantly increased not only the detection of p57Kip2 but also of incorporated BrdU.

A novel dual staining method for identification of apoptotic cells in infarcted myocardium was reported by Taatjes et al. (2007). They employed the apoptosis-specific anticleaved caspase 3 antibody and an anti-ssDNA antibody, singly and in a novel dual immunostaining combination, to determine whether cardiomyocyte apoptosis is a generally 
occurring phenomenon following persistent coronary artery ligation in the plasminogen activator inhibitor (PAI)-1 knockout mouse. With the use of the dual immunostaining protocol only scattered cells were found displaying both markers in the zones of infarction, suggesting that persistent ischemia results in a robust necrotic response, but only a very minor apoptotic response in the PAI 1 knockout mouse model.

A novel slit scanning confocal microscope with a CCD camera image sensor and a virtual slit aperture for descanning that can be adjusted during post-processing was reported by Fiolka et al. (2007). Furthermore, they introduced a method to reduce the anisotropic lateral resolution of slit scanning microscopes. Wang et al. (2006) presented a technique using two-photon fluorescence and second harmonic generation from Ti:sapphire laser systems in conjunction with a high numerical aperture, diffraction-limited objective lens. This technique should be especially useful as a non-invasive method to perform a three-dimensional analysis of tissue in a research and potentially clinical diagnostic environment. Bouchet-Marquis et al. (2006) reported the use of cryoelectron microscopy of vitrified sections for investigating the structure of the interphase nucleus. Their observations showed that individual nuclear structural domains could be resolved with high degree of structural detail. An "in vivo cryotechnique" (IVCT) to examine living mouse liver by histochemical, immunohistochemical, and ultrastructural analyses was reported (Ohno et al. 2006). Comparison of results obtained with the IVCT technique with those obtained by perfusion fixation, immersion fixation and quick-freezing methods showed absence of protein dislocation. An application of IVCT to study soluble proteins (passage of albumin, $\mathrm{IgG}$, Ig $\kappa$ light chain and IgG1 heavy chain through the glomerular capillary loops) by immunohistochemistry showed its usefulness for studies of proteins under dynamic conditions (Li et al. 2006).

Dahan (2006) reviewed the use of quantum dots as fluorescent probes for live-cell imaging and pointed to their potential, in combination with ultrasensitive imaging techniques, for the analysis of single molecules. Other small molecules can be used in live-cell imaging such as the fluorescein arsenical helix binder (FlAsH) which has been used for investigating the dynamics of reggie-1/flotillin- 2 protein in cell culture (Langhorst et al. 2006). They found that the biarsenical staining reagent FlAsH/Lumio Green accumulated in active mitochondria, resulting in mitochondrial swelling which limits the usefulness of this reagent for livecell imaging. In a modified protocol, however, the authors were able to eliminate this side effect. A quantitative structure-activity relations (QSAR) model for specifying the physicochemical characteristics of fluorescent probes, which accumulate preferentially in the nuclei of living cells, was reported (Horobin et al. 2006). The QSAR model was demonstrated to be useful for the selection of anti-cancer drugs, for the minimization of dye and drug toxicity, and for the designed synthesis of fluorescent probes.

By combining immunohistochemical and RT-PCR techniques, the effects of gonadotropins and gonadotropin releasing hormone $(\mathrm{GnRH})$ on the pathophysiology of the side effects of spaying of dogs could be analyzed (Welle et al. 2006). Galectin histochemistry with the use of biotinylated galectins was applied for the analysis of diethylstilbestrol-induced renal tumors in Syrian hamster (Saussez et al. 2006).

SDS-digested freeze-fracture replicas have been used as a substrate for immunoelectron microscopy to determine localization of membrane proteins and lipids. This procedure involves the use of cells, which are rapidly cryofixed and freeze-fractured. The fracture plane is physically stabilized by evaporation of platinum/carbon. The detergent dissolves the remains of cellular material with the exception of components of the protoplasmic and the exoplasmic membrane halves, which are in direct contact to the replica film. It was noticed that replicas prepared by first evaporating carbon are labeled more efficiently than conventional preparations in which platinum/carbon is evaporated first followed by carbon (Fujita and Fujimoto 2007; Schlormann et al. 2007). The reason why this improvement occurs by changing the order of evaporation has remained enigmatic but most probably is not due to differences in the capacity of the different replicas to retain lipids.

An anti-serum against an unknown human placental antigen complex X-P2 (hPAXP2) specifically labels the stigmoid body (STB), a distinct, spherical-to-ovoidal and nonmembrane-bound neuronal cytoplasmic inclusion, which also contains huntingtin-associated protein 1 (HAP1). In order to clarify the relationship between hPAX-P2S and HAP1 isoforms (A/B), Fujinaga et al. (2007) performed Western blotting, immunohisto/cytochemistry and preadsorption tests with HAP1 deletion fragments. They showed that the anti-hPAX-P2 anti-serum recognizes $\mathrm{HAP}^{474-577}$ of HAP1A/B in Western blotting and strongly immunostains HAP1A-induced STB-like inclusions and can be used to detect and stain STB inclusions in the rat brain.

Zarnani et al. (2006) have developed purification techniques to isolate murine splenic dendritic cells (DCs) for subsequent characterization. Following methods to establish the purity of cells, they examined DC functional properties using an in vivo antigen presentation assay. They used myeloperoxidase and non-specific esterase to determine the purity of the DCs compared with more conventional assays. They recommend the use of the non-specific esterase activity as a simple and inexpensive means for the accurate evaluation of the purity of isolated murine splenic DCs.

The permanent porcine intestinal cell line IPEC-J2 was shown to be a useful in vitro model system for the 
investigation of swine-specific bacterial infections (Schierack et al. 2006).

Since peroxidase inhibitors are routinely employed to quench endogenous peroxidase activity, Liu et al. (2006a) compared several compounds for their efficacy as peroxidase inhibitors. They recommend the use of hydrochloric acid as a potent peroxidase inhibitor.

\section{Aspects of functional organization of tissues}

The Dickkopf (Dkk) gene family of secretory modulators of canonical Wnt/beta catenin signals is involved in the control of stem cell proliferation, homeostasis and differentiation. Bioinformatic data on dkk-1/3 gene expression indicated high expression levels in the human pancreas. Consequently, Hermann et al. (2007) have analyzed these two proteins in adult human pancreatic tissue. Dkk-1/3 mRNA levels and protein distribution were analyzed in isolated human islets versus the exocrine/ductal pancreatic cells and in paraffin sections of adult human pancreata. Using real-time PCR only lowest amounts of dkk-1 mRNA were detectable in the endocrine fractions. Immunohistochemistry did not reveal any Dkk-1 protein in adult human pancreatic tissue. Interestingly, Dkk-3 mRNA and protein were clearly present in adult human pancreatic islets. Messenger RNA levels for Dkk-3 were significantly higher in isolated islets as compared to the exocrine/ductal fraction. Double staining with and insulin antibody identified the beta cells as the Dkk-3-positive cells. Notably, only a subset of beta cells contained Dkk-3. As shown by Western blot analysis Dkk-3 seems to be proteolytically processed in beta cells. This is the first study describing a molecule with which the pool of pancreatic beta cells can be further subdivided.

Glucose-6 phosphatase (Glc6Pase) is a crucial enzyme in the control of glucose homeostasis. Rajas et al. (2007) performed an immunohistochemical analysis to define the precise cell-specific localization of Glc6Pase and the cytosolic form of the phosphoenolpyruvate carboxykinase (PEPCK-C) in the digestive system (liver, small intestine and pancreas) and kidney. Co-expression of Glc6Pase and PEPCK-C was found in hepatocytes, in proximal tubules of the cortex kidney and at the top of the villi of the small intestine suggesting that these tissues are able to perform complete gluconeogenesis. Other tissue elements such as intrahepatic bile ducts, collecting tubules of the nephron and the urinary epithelium in the calices of the kidney, as well as the crypts of the small intestine, expressed Glc6Pase without significant levels of PEPCK-C. Here, the function of Glc6Pase was proposed to be related to the transepithelial transport of glucose, rather than to the neoformation of glucose. Lastly, isolated PEPCK-C expression was noted in both the exocrine pancreas and the endocrine islets of Langerhans. In exocrine pancreas it might be involved in the provision of gluconeogenic intermediates for further conversion into glucose in the liver, whereas in islets it could be instrumental in pyruvate cycling, which has been suggested to play a regulatory role in insulin secretion by the $\beta$-cells of the islets.

Bile acids are important in the absorptive process of dietary lipids in the small intestine and their synthesis is confined to the hepatocytes. Wang et al. (2007) have evaluated by immunohistochemistry the expression pattern within the liver of the rate-limiting enzyme of the neutral pathway, cholesterol $7 \alpha$-hydroxylase (Cyp7a1), and sterol 12 $\alpha$-hydroxylase (Cyp8b1), the enzyme necessary for the synthesis of cholic acid. They observed Cyp8b1 expression mainly in the hepatocytes in a zonal pattern surrounding the central vein while the areas surrounding the portal zones showed much lower levels. The zonation was maintained in cholic acid-depleted mice. Cyp7a1 also showed a zonal distribution pattern, although less distinct, with a maximal expression within a 1-2 cell thick layer of hepatocytes surrounding the central vein. In Cyp8b1 null mice, a more intense staining was obtained, although the overall expression pattern was maintained. These results obtained in mice indicate possible differences in the regulation of the cellular zonation of Cyp7a1 and Cyp8b1. Stenzinger et al. (2005) have analyzed the expression of the novel protein tyrosine phosphatase interacting protein 51 (PTPIP51) on mRNA and protein level in the liver of adult Wistar rats. PTPIP51 protein was detected in specific non-parenchymal cells: stellate cells, KC and NK cells. Sinusoidal endothelial cells were unreactive, whereas endothelium of blood vessels within the liver showed a positive reaction. PTPIP51 could also be detected in hepatocytes and cholangiocytes lining portal ducts, interlobular ducts and in the smaller branches of the biliary tree.

Gustducin-expressing brush cells scattered throughout the gastrointestinal (GI) mucosa and represent candidate sensory cells for precise chemosensory monitoring of luminal contents. Hass et al. (2007) have investigated a large cluster of gustducin-positive cells that is located exactly at the boundary between the fundic and the oxyntic mucosa of the mouse stomach, at the so-called "limiting ridge". In close association with the candidate chemosensory cluster, they found two populations of enteroendocrine cells: one containing the satiety regulating hormone ghrelin, the other comprising serotonin-secreting enterochromaffin cells. The particular arrangement of gustducin-expressing cells and enteroendocrine cells at the limiting ridge suggests a direct interplay between these cell types with immediate implications, not only for digestive processes in the stomach, but also for parameters controlling the satiety status.

Suzuki-Yamamoto et al. (2007) investigated the prostaglandin F synthase and cyclooxygenase- 1 that are essential 
for the production of prostaglandin $\mathrm{F}_{2 \alpha}$, and prostaglandin $\mathrm{F}_{2 \alpha}$ receptor in mouse testis. By double histochemical staining, co-localization of cyclooxygenase-1, prostaglandin $\mathrm{F}$ synthase and prostaglandin $\mathrm{F}_{2 \alpha}$ receptor was observed in the Leydig cells. These findings indicated that prostaglandin F2 $\alpha$ may have an effect on the function of Leyding cells in an autocrine fashion.

Teramae et al. (2007) analyzed the cellular expression of Noc2, a Rab effector protein involved in regulated exocytosis, in endocrine and exocrine tissues in the mouse. Although Noc2 was expressed abundantly in endocrine cells, only low levels were detectable in exocrine tissues. Thus, Noc 2 could be labeled in endocrine cells in the adrenal medulla and adenohypophysis, pancreatic islet cells, thyroid parafollicular cells, and gut endocrine cells, supporting the notion that Noc 2 is a Rab effector protein shared by amine/peptide-secreting endocrine cells. Besides endocrine tissues, granular ducts in salivary glands were reactive for Noc2. Although Noc2 was undetectable by immunostaining in acinar cells of all exocrine glands examined, reverse transcriptase-polymerase chain reaction analysis detected the mRNA expression in exocrine pancreas.

Podocalyxin (PC) was initially identified as a major sialoprotein on the apical surface of glomerular podocytes important for the filtration barrier function. Subsequently, it was reported to be expressed in other cell types such as endothelial cells, megakaryotes/platelets, and hemangioblasts. Lin et al. (2007) have conducted an immunohistochemical study on various tissues of healthy adult beagle dogs. By the use of two different anti-podocalyxin antibodies recognizing distinct epitopes in PC, they could demonstrate that (1) PC is expressed in renal tubules, mesothelium, myocardium, striated muscles in tongue, esophagus and extraocular region, myoepithelial cells in esophagus and salivary glands, neurons, and ependyma; (2) that there are at least three forms of PC proteins, depending upon the accessibility of two different PC antibodies, expressed in different organs/systems; and (3) that a particular form of PC is distributed in a vesicle-like compartment in certain organs/systems, such as the central nervous system.

MUC16 is a highmolecular mass glycoprotein of the mucin family and in addition to MUC1 and MUC4 an ocular surface mucin most probably involved in the maintenance of a healthy ocular surface. Jäger et al. (2007) have now determined the possible expression of mucin MUC16 in the lacrimal apparatus. Its expression and distribution in lacrimal gland, accessory lacrimal glands, and nasolacrimal ducts was analyzed by RT-PCR and immunohistochemistry. As in conjunctiva and cornea, it was membraneanchored in accessory lacrimal glands but in lacrimal gland acinar cells and columnar cells of the nasolacrimal ducts stored in intracytoplasmic vesicles. Subepithelial serous glands of the nasolacrimal ducts showed staining of the secretion product. MUC16 seemed to be secreted from the epithelial surface of subepithelial serous glands of the nasolacrimal ducts. Together, these results show the presence of MUC16 in the whole lacrimal apparatus although its distribution pattern varied.

Steininger et al. (2007a) studied the distribution of capillaries, sinuses and larger vessels in adult human spleens. Double staining for CD34 and CD141 (thrombomodulin) showed that capillary endothelia in the cords of the splenic red pulp and at the surface of follicles were CD34 ${ }^{(+)}$CD141 ${ }^{(-)}$, while red pulp sinus endothelia had the phenotype CD $34^{(-)}$CD $141^{(+)}$. Sinus endothelial cells in the direct vicinity of splenic follicels exhibited both antigens. It was concluded that splenic sinuses do not replace conventional capillaries, but exist in addition to such vessels. The endothelium in arterioles, venules and larger arteries and veins was uniformly $\mathrm{CD} 34^{(+)} \mathrm{CD} 141^{(+)}$. Therefore, this study showed that two types of phenotypically distinct microvessels exist in the human splenic red pulp and at the surface of the white pulp and provides the basis for further investigations of this part of the human circulatory system including its three-dimensional reconstruction.

The lymphotoxin- $\beta$ receptor (LT $\beta \mathrm{R}$ ) is required for the functioning and maintenance of structural integrity in the thymus. In LT $\beta$ R-deficient mice, the clonal deletion of autoreactive lymphocytes is impaired and the normal differentiation of thymic medullary epithelial cells is affected. Milicevic et al. (2006) used various markers to show that LT $\beta$ R-deficient mice were lacking in thymic metallophilic macrophages, while they were present at the cortico-medullary zone in controls. These results suggest that LT $\beta \mathrm{R}$ is necessary for the maintenance of metallophilic macrophages in the thymus, and furthermore that they may represent a factor involved in thymic negative selection.

The endocannaboid receptor CB1 is expressed throughout the central nervous system, equally well by neurons and by glial cells. In addition, it is also expressed at a very much lower level in several peripheral tissues, including rat adipose tissue as well as in primary fat cell cultures. The endocannaboid receptor CB2 is primarily expressed in cells of the immune system. The functionality of the CB1 receptor within peripheral tissues, including adipose tissue remains to be established. Roche et al. (2006) demonstrated $\mathrm{CB} 1$ and $\mathrm{CB} 2$ receptors in the plasma membrane of adipocytes. Whether $\mathrm{CB} 1$ and $\mathrm{CB} 2$ play a role in the homeostasis of the energy balance and/or in the regulation of adipose tissue inflammation remains to be established.

\section{Skeletal muscle, cartilage, and ECM}

Recent research suggests that estrogen receptors (ERs) are of significance in skeletal muscle function. Kalbe et al. 
(2007) have investigated whether ERalpha and ERbeta are expressed in porcine skeletal muscles and in satellite cells derived from semimembranosus muscle (SM). Immunostaining for ERalpha was detected in the nuclei of skeletal muscle cells, while the ERbeta was positive in nuclei and cytoplasm of skeletal myofibers and myoblasts derived from satellite cells. By (RT)-PCR, unambigious expression of the ERalpha mRNA and a weak expression of the ERbeta mRNA was seen in skeletal muscle tissue and SM satellite cell cultures. These results show that both ERalpha and ERbeta are expressed in porcine skeletal muscle, which than could be considered as a target tissue for estrogens or estrogen-like compounds. For further studies, the porcine SM satellite cell culture will provide a suitable in vitro model to investigate estrogenic effects on pig skeletal muscle.

In adult skeletal muscle, satellite cells and stem myoblasts represent a cellular source for regeneration following post-denervation atrophy. Following up earlier studies, Gorbe et al. (2006) now show that in differentiating perfusion myoblasts connexin43 gap junction coupling is upregulated before myoblast alignment, followed by reduction in post-mitotic cells. The synchronized exit of myoblasts from the cell cycle following extensive gap junction formation suggests a role for $\mathrm{Cx} 43$ channels in the regulation of cell cycle control.

The human vastus lateralis muscle is characterized by a mixed fiber type composition and is the muscle of choice for biopsies in research work and for clinical diagnosis. Kadi et al. (2006) have established the number and distribution of satellite cells in slow (type I fibers) and fast (type II fibers) fibers in this muscle. They were unable to establish a relationship between the mean number of satellite cells per fiber and the mean cross-sectional area of muscle fibers. It is known that skeletal muscle functions are regulated by NO. Punkt et al. (2006) have performed an analysis as to whether NO synthesis is related to a defined fiber type in human skeletal muscle. They found a correlation of NOS IIII immunoreactivity to metabolic defined fiber types with strong expression in fast-oxidative glycolytic fibers. Healthy and affected vastus medialis muscles after anterior cruciate ligament rupture revealed similar NOS expression levels.

In continuation of their studies on muscle morphology in power lifters, Eriksson et al. (2006) investigated whether hypertrophic muscle fibers with fissures in power-lifters represent fiber splitting or defect regeneration. They found that the so-called split fibers are due to defect regeneration. Obscurin is a giant multidomain muscle protein of unknown structural and regulatory functions. Borisov et al. (2006) could establish a role of obscurin in cardiac myofibrillogenesis and hypertrophic response. A vital role for obscurin in myofibrillogenesis and hypertrophic growth was demonstrated by siRNA gene silencing. Obscurin depletion caused defective lateral alignment of myofibrillar bundles, leading to their abnormal bifurcation, dispersal and multiple branching. Bending of immature myofibrils, a modified titin pattern, the absence of well-formed A-bands in newly formed contractile structures and an occasional irregular periodicity of sarcomere spacing were typical of obscurin siRNA-treated cells. Hence, the authors suggest that obscurin is indispensable for spatial positioning of contractile proteins and for the structural integration and stabilization of myofibrils, especially at the stage of myosin filament incorporation and A-band assembly. This demonstrated a vital role for obscurin in myofibrillogenesis and hypertrophic growth.

Macarak et al. (2006) utilized an animal model of urethral obstruction to study the membrane-associated structures that transfer tension across the sarcolemma of bladder smooth muscle cells (SMCs). In obstructed bladder, a pronounced disruption of the smooth muscle tension transfer apparatus was observed.

Ankyrin-repeat protein with a PEST motif and a prolinerich region (Arpp), designated asAnkrd2, is a member of the muscle ankyrin repeat proteins (MARPs). MARPs have been proposed to be involved in muscle stress response pathways. Arpp/Ankrd2 is localized mainly in the I-band of striated muscle. Tsukamoto et al. (2007) found that Arpp/ Ankrd2 accumulated in the nuclei of myofibers located adjacent to severely damaged myofibers after muscle injury. Furthermore, they found that Arpp/Ankrd2 tended to be localized in euchromatin where genes are transcriptionally activated. Based on these findings, the authors suggested that Arpp/Ankrd2 may translocate from the I-band to the nucleus in response to muscle damage and may participate in the regulation of gene expression.

The NG2 chondroitin sulfate proteoglycan interacts with extracellular and intracellular ligands and is involved in signaling events for both cell proliferation and cell migration. It is associated with several types of undifferenteiated cells including pericytes and SMCs of developing vasculature. Terada et al. (2006) observed NG2 chondroitin sulfate proteoglycan not only in the vasculature but also on the surface of intestinal subepithelial myofibroblasts (ISEMF) of human and mouse small and large intestine. They proposed that the most likely mechanisms by which NG2 might contribute to the properties of ISEMFs are responses to growth factors and interactions with integrins and extracellular matrix components. The interesting proposal is made that NG2 expression may be an indication that these cells retain a degree of developmental plasticity that allows them to de-differentiate and participate in developmental morphogenesis in cases where tissue remodeling or replacement is needed. Versican is a large chondroitin sulphate proteoglycan which is involved in ECM assembly, cell proliferation, cell survival, cell attachment, cell migration, and perhaps 
also the regulation of inflammatory and immunological reactions. Toriya et al. (2006) studied the core protein of versican during the post-natal growth of the temporomandibular joint (TMJ) discs. They were able to demonstrate that growth-related changes and regional differences in the expression of versican in the TMJ discs of growing rats reflect changes in the biomechanical environment caused by the development of orofacial functions. Aggrecan is one of the major ECM components in cartilage. Mandibular condylar cartilage acts as both articular and growth plate cartilage in the growth period, while it remains as articular cartilage after growth. Mitani et al. (2006) have shown now that functional and ECM differences between condylar and primary cartilages are associated with differences in gene expression patterns and levels of aggrecan and adamalysinthrombospondins (ADAMTS)-1, -4 , and -5 during growth and aging. Heparan sulfate proteoglycans (HSPGs) are another abundant component of the pericellular matrix of both developing and mature cartilage and their distribution during murine cartilage growth plate development was investigated by Gomes et al. (2006). By applying a panel of unique phage display antibodies specific to particular HS species, they were able to demonstrate both temporal and regional specialization in the types of HS structures within the developing growth plate and associated tissues. Furthermore, they showed an abrupt loss of HS at the chondroosseous junction.

Cartilage tissue can be broadly classified into transient cartilage (i.e., growth plate, GP) and permanent cartilage (i.e., articular cartilage, AC). Osteo(chondro)clasts are selectively induced in the GP during endochondral ossification and play central roles in the resorption of cartilagenous matrices. Kishimoto et al. (2006) established the factors determining the GP-specific recruitment of osteo(chondro)clasts. Their focus was on the expression pattern of the receptor activator of NF- $\kappa$ B ligand (RANKL), an essential factor for osteo(chondro)clast differentiation, and on that of epigenetic and transcriptional factors affecting RANKL gene expression. Together, their results suggest that Runx2, an essential transcription factor for skeletal development, is also a key regulator of RANKL expression in chondrocytes in the GP. Furthermore, a selective and sequential expression of a subset of BMP and of transcription factors may define the expression pattern of RANKL through Runx2.

The degree of mineralization in human thyroid cartilage is gender specific. Claasen et al. (2006) have applied highresolution immunohistochemistry for the localization of sexual hormone receptors. Their results suggest the involvement of androgen receptor-positive chondrocytes in thyroid cartilage mineralization, most likely by a testosterone-linked stimulation of alkaline phosphatase.

In dogs, degenerative joint diseases (DJD) have been shown to be associated with increased lactate dehydroge- nase (LDH) activity in the synovial fluid. Walter et al. (2007) have clarified the origin of LDH in synovial fluid. They suggest that (1) LDH is transferred from chondrocytes to ECM in both healthy dogs and dogs with DJD and that (2) in degenerative joints, LDH is released from chondrocytes and the ECM into synovial fluid through abrasion of cartilage as well as through enhanced diffusion as a result of increased water content and degradation of collagen.

Yamamoto et al. (2007) have used their adhesive film method to detect tissue non-specific alkaline phosphatase (TNSALP) and calcium by histochemistry, and bone sialoprotein (BSP) and osteopontin (OPN) by immunohistochemistry in developing rat molars, and to discuss the mineralization process during acellular cementogenesis. Where the epithelial sheath was intact, TNSALP reaction was observed in the dental follicle, but not in the epithelial sheath. With the onset of dentin mineralization, the BSPand OPN-immunoreactive, initial cementum layer appeared. At this point, cementoblasts showed intense TNSALP reaction and GBHA reactive particles (=calciumGBHA complex) appeared on the root surface. With further development, TNSALP and GBHA reaction became faint on the root surface. These findings were taken as evidence that during the initial cementogenesis, cementoblasts release matrix vesicles which result in calciferous spherules, corresponding to the GBHA reactive particles. Furthermore, calciferous spherules appear to trigger the mineralization of the initial cementum. After principal fiber attachment, mineralization advances along collagen fibrils without matrix vesicles.

\section{Developmental biology, differentiation, repair and stem cells}

Aspects of developmental biology and stem cell research continue to be in the center of cell biological research. Adult stem cells can be identified by the label-retaining cell (LRC) approach based on their ability to retain nucleoside analogs, such as bromodeoxyuridine (BrdU). Zhang et al. (2007a) hypothesized that mouse nasopharynx contains a small population of epithelial stem/progenitor cells. To identify them, neonatal mice were intraperitoneally injected with BrdU twice daily for three consecutive days. After an 8-week chase, long-term BrdU-labeled LRCs (approximately $2 \%$ of cells) were detected in the adult mice nasopharyngeal epithelia and some of LRCs (approximately $12 \%$ of cells) were found to be recruited into the $\mathrm{S}$ phase of cell cycle with an additional radioactive thymidine-labeling technique. This indicated that the stem cells also divide, most likely asymmetrically. Likewise, in human nasopharyngeal carcinoma cell lines (5-8F, 6-10B and TMNE) label-retaining stem cells were found. Thus, this study has 
demonstrated the presence of epithelial LRCs in mouse nasopharynx and human nasopharyngeal carcinoma tissues. These stem-like LRCs were not completely quiescent and are most likely the cause for nasopharyngeal carcinoma spread, metastasis and recurrence.

Skeletal muscle-derived stem cells (MDSCs) have been identified by several investigators. Tamaki and colleagues previously identified and purified two stem cell populations that were able to differentiate into myogenic-vasculogenic cells in the interstitial spaces of murine skeletal muscle. Now, they (Tamaki et al. 2007) have established the practical isolation and usage of skeletal MDSCs and determined the reconstitution capacity of $\mathrm{CD} 34^{(-)} / \mathrm{CD} 45^{(-)}$(Sk-DN) cells as a candidate somatic stem cell source for transplantation. Sk-DN cells were enzymatically isolated from GFP transgenic mice (C57/BL6N) skeletal muscle and sorted using FACS. Transplantation of expanded Sk-DN cells into the severe muscle damage model (C57/BL6N wild-type) resulted in the synchronized reconstitution of blood vessels, peripheral nerves and muscle fibers followed by significant recovery of total muscle mass $(57 \%)$ and contractile function $(55 \%)$. The results indicated that Sk-DN cells are capable of cell expansion, maintain multipotency and are a useful cell source for muscular, vascular and peripheral nerve reconstitution therapy. Jouvion et al. (2006) have applied morphometry to discriminate cells with different commitment properties in freshly prepared muscle derived cells (MDCs). Lineage marker analysis showed that the cell size was associated with the specific expression of myogenic markers, revealing different commitment levels. The smallest MDC exhibited limited myogenic activity, while larger MDC displayed a myogenic potential that increased with their size. Therefore, this criterion could be useful for the early separation of more or less committed cells in the myogenic program.

Follicular dendritic cells (FDC) are a population on nonimmune cells located in secondary lymphoid tissues. Insight concerning the development and maturation of these cells is currently lacking. Kasajima-Akatsuka and Maeda (2006) have performed an immunohistochemical study and found that small groups of immature FDC were within poorly-defined aggregations of B-lymphocytes in fetal lymph nodes by the 20th gestational week. As development progressed, more B-lymphocytes aggregated in compact groups and formed primary lymphoid follicles with an extending web of mature FDC (these cells expressed a variety of markers). These results suggest a process of phenotypic alteration of human FDC, and established a series of markers for determining their developmental stage and functional phase.

The renal collecting system (CS) is composed of segment-specific and intercalated (IC) cells. The latter comprise at least two subtypes (type A and non-type A). The origin and maintenance of cellular heterogeneity in the CS is unclear. It was also proposed that one subtype of IC cells represents a stem cell population from which all cell types in the CS may arise. Wehrli et al. (2007) tested the stem cell hypothesis for the adult kidney. Immunostaining for BrdU and for the proliferating cell nuclear antigen (PCNA) was used to reveal DNA synthesis. BrdU- and PCNAimmunostaining as well as mitotic figures were seen in all subtypes of CS cells and dividing cells retained the celltype specific expression of marker molecules. Thus, these data show that DNA synthesis and cell replication occur in each cell lineage of the CS and in differentiated cells. It was concluded that independent proliferation of each cell lineage might contribute to maintain the cellular heterogeneity of the CS of the adult kidney.

Jaszai et al. (2007) described the expression of the stem and progenitor cell marker Prominin-1 and those of its paralogue, Prominin-2, in the three major salivary glands, i.e., submandibular, major sublingual, and parotid glands in adult mice as well as in the extraorbital lacrimal and meibomian glands of the eyelid. Prominin-1 and Prominin-2 were differentially expressed in these major cephalic exocrine organs: Prominin-1 was found to be associated with the duct system, while Prominin-2 was mostly, but not exclusively, found in the acinar compartment of these organs with marked differences among the various glands. Furthermore, Prominin-2, like Prominin-1, was found to be released into the human saliva associated with small membrane particles holding the potential for future diagnostic applications.

Mammary anlagen and any portion of the normal mammary parenchyma are capable of regenerating a complete mammary tree. This suggests the presence of mammary epithelium stem cells. Indeed, multipotent cells residing within the luminal cell population in adult mammary epithelium of human and mouse have been observed. Han et al. (2006) have determined the exact cell composition and their orientation in embryonic mammary anlagen. Their results indicate that the putative stem cells are localized near the edge of the mammary anlagen, whereas the cell populations with different differentiation degree were localized in the central part and around the edge within the anlagen.

Tight junctions (TJ) have important functions in tubular organs. Lourenco et al. (2007) have mapped the distribution of claudins-1, 2, 3, 4, 5, 7 and 11 during development of human salivary glands and compared it with the expression of differentiation markers. All claudins, except claudin-2, were detected in the various phases of human salivary gland development, up to fully mature salivary gland. The expression of all claudins increased with the progression of salivary gland maturation. It was proposed that TJ proteins are important in the final shape and physiological functions of human salivary glands. 
In the framework of their studies on human spleen, Steiniger et al. (2007b) investigated the fetal and early postnatal development of this organ.

The fetal organ development could be divided into four stages based on the distribution of lymphocytes. At stage 0 the organ anlage contained erythrocyte precursors, few macrophages and almost no lymphocytes. At stage I arterial vascular lobules existed and lymphocytes just began colonizing the organ. At stage II, B and T lymphocytes formed periarteriolar clusters with B cell clusters predominating. B cells aggregated around the more peripheral branches of splenic arterioles, whereas $\mathrm{T}$ cells occupied the more centrally located parts of the vessels. The vascular lobules of these stages consisted of central arterioles surrounded by B cells, capillaries and peripheral venules. The lobular architecture slowly disappeared at late stage II when sinuses grew out from the peripheral venules into the centre of the lobule and at stage III before birth the lobular architecture was no longer recognized. Interestingly, the B cell accumulations around peripheral arterioles at stage II did not represent the precursors of follicles, but apparently persisted as periarteriolar B cell clusters in the adult splenic red pulp. However, follicles containing FDCs developed at late stage II from B cells in direct contact to $\mathrm{T}$ cell clusters around larger arterial vessels. The chemokine CXCL13 was already present in vascular smooth muscle and adjacent stromal cells at stage I before B cells immigrated. CCL21, on the contrary, was only demonstrated in fibroblast-like cells supporting $\mathrm{T}$ cell clusters from stage II onwards. This study provides important information regarding the ontogeny of follicles in human spleens. Their formation requires a direct interaction of B-lymphocytes with $\mathrm{T}$ lymphocytes or with stromal cells of the $\mathrm{T}$ cell region. Furthermore, periarteriolar sheaths in the centre of vascular lobules apparently represent the primordial B lymphocyte compartment and this structure would constitute a new organ compartment.

Cell-cell interactions among cell types constituting the fetal liver such as hepatoblasts, stellate cells and endothelial cells lead to functional lobule development. Sugyama et al. (2007) have investigated hepatic histogenesis in primary cultures of E12.5 mouse livers. Fetal livers were dispersed with protease and cultured. The authors demonstrated that primary cultures of fetal liver cells contained at least hepatoblasts, mesenchymal cells, endothelial cells, hemopoietic cells and Kupffer cells. Although hepatoblasts, mesenchymal cells, and endothelial cells aggregated separately in the initial step, they then formed a spheroid. Adherence of the spheroids to the glass slide led to the formation of flattened hepatic organoids. Several extracellular matrix depositions were seen in aggregates consisting of at least hepatoblasts and mesenchymal cells, but were poor in those lacking hepatoblasts. The primary culture of fetal liver cells thus may be useful for studying cell-cell interactions during liver development.

König et al. (2006) previously reported the cellular pattern of various differentiation and cell type markers in a model of liver regeneration. They suggested that the two oval cell populations are organized in a zonal hierarchy with a marker gradient from the inner, hepatocytic and biliary marker displaying zone to the outer, hepatocytic and extrahepatic progenitor marker displaying zone of the proliferating progeny clusters. Now, König et al. (2007) investigated whether pre-cultured adult rat hepatocytes adopt periportal and pericentral enzyme expression pattern following their transplantation into the regenerating rat liver. Isolated primary rat hepatocytes, representing a mixture of both periportal and pericentral origin, lost expression of carbamoyl phosphate synthetase I (CPS I) and cytochrome P450 subtype 2B1 (CYP2B1) in culture. Cultured hepatocytes from DPPIV (CD26) wild type rats were transplanted into the livers of CD26 deficient rats following prior treatment with retrorsine and partial hepatectomy to drive selective donor cell proliferation. CD26 positive donor cells engrafted in the periportal regions and grew time dependent in clusters expanding into the parenchyma. Ten weeks after transplantation, donor cells surrounding the portal veins expressed CPS I, but not CYP2B1. The reverse was true for CD26 positive cells in close proximity to the central veins. After transplantation, donor hepatocytes proliferated in the host parenchyma whilst acquiring the position-specific enzyme expression of the surrounding periportal and pericentral host hepatocytes. These results indicate the high degree of plasticity of gene expression in hepatocytes subjected to a change in microenvironment. Embryoid bodies (EBs) formed from embryonic stem cells can differentiate into multiple cell types and hepatic differentiation from mouse ES cells has been reported in vitro and in vivo. Okamura et al. (2006) have studied the potential of monkey EBs for the repopulation of injured liver of mice. They obtained good evidence that the differentiated cells in developing monkey EBs, but not contaminating ES cells, generated functional hepatocytes by cell fusion with recipient mouse hepatocytes, which repopulated the injured mouse liver.

Prospero-related homeobox 1 (Prox1) is a divergent transcription factor with two highly conserved domains, a homeobox and a prospero domain. In the endoderm, Prox 1 expression is confined to a short segment that gives rise both to the liver and pancreas, where it remains expressed into adulthood. Dudas et al. (2006) have analyzed the changes of Prox 1 gene expression in rat liver under different experimental conditions of liver injury, regeneration and acute phase reaction, and correlated it with that of markers for hepatoblasts, hepatocytes, cholangiocytes and oval cells. All together, Prox 1 gene expression represents 
the hallmark of hepatocytes and of AFP-expressing hepatoblasts, whereas it was not found in AFP expressing oval cells.

The studies performed by Lim et al. (2006) have focused on the molecular mechanism underlying the activation of hepatic stellate cells (HSC). HSCs reside normally within the perisinusoidal space of Dissé and have been identified as the principal source of increased extracellular matrix protein in chronic liver diseases resulting in liver fibrosis. The expression of E-cadherin and its switch to $\mathrm{N}$-cadherin during rat HSC activation, in vivo and in vitro, was investigated. The results suggest that HSC activation represents transdifferentiation from an epithelial to a mesenchymal phenotype.

Elmaouhoub et al. (2007) have investigated albuminand alpha-fetoprotein gene expression, and the function of the secretory apparatus during rat liver development. Synthesis and secretion of albumin and AFP were already detected in the low numbered ventral foregut endodermal cells; fibrinogen synthesis was detectable in the E12 hepatoblasts. The data suggests that the hepatocyte secretory apparatus is already functional before the emergence of the liver bud.

Keratan sulphate (KS) proteoglycans (PGs) are key molecules in the connective tissue matrix of the cornea of the eye. Keratocan is a primarily cornea-specific KS PG.

Gealy et al. (2007) investigated the tissue distribution of keratocan in the developing chick cornea as it becomes compacted and transparent in the later stages of development. Keratocan was present at all stages investigated (E10-E18), with distinct differences in localization and organization observed between early and later stages.

Thus, in embryonic chick cornea, keratocan, in common with sulphated KS chains in the E12-E14 developmental period, exhibited a preferential distribution in the anterior stroma. It underwent a striking reorganization of structure and distribution consistent with a role in relation to stromal compaction and corneal transparency.

Agrin is a HSPG involved in the organization and maintenance of postsynaptic structures at the neuromuscular junction. Hausser et al. (2007) examined the early postnatal development of agrin-deficient mice in which perinatal death was prevented by transgenic expression of neural agrin in motor neurons. Such transgenic, agrin-deficient mice exhibited severe post-natal growth retardation. These data showed that agrin is expressed in cartilage and that it plays a critical role in normal skeletal growth.

In tooth development matrix metalloproteinases (MMPs) are under the control of several regulatory mechanisms. Schwab et al. (2007) monitored the occurrence and distribution pattern of the extracellular matrix metalloproteinase inducer (EMMPRIN), the metalloproteinases MMP-2 and MT1-MMP and caveolin-1 during the cap and bell stage of rat molar tooth germs. Strong EMMPRIN immunoreactivity was detected on the cell membranes of ameloblasts and cells of the stratum intermedium in the bell stage of the enamel organ. Differentiating odontoblasts exhibited intense EMMPRIN immunoreactivity, especially at their distal ends. Caveolin-1 immunoreactivity was evident in cells of the internal enamel epithelium and in ameloblasts. The differentiation-dependent co-expression of MMPs with EMMPRIN in the enamel organ and in odontoblasts indicated that EMMPRIN takes part in the induction of proteolytic enzymes in the rat tooth germ. There is evidence that a rat autosomal-recessive mutation, whitish chalk-like teeth (wct), induces tooth enamel defects resembling those of human amelogenesis imperfecta (AI). However, the effect of the wct gene mutation on the enamel matrix synthesis and calcification remains to be elucidated. Osawa et al. (2007) investigated how the wct gene mutation influenced the synthesis of enamel matrix and its calcification by immunocytochemistry for amelogenin, ameloblastin and enamelin, and by electron probe micro-analysis (EPMA). The immunoreactivity for enamel proteins such as amelogenin, ameloblastin, and enamelin in the ameloblasts in the homozygous teeth was the same as that in the heterozygous teeth from secretory to transitional stages, although the homozygous ameloblasts became detached from the enamel matrix in the transitional stage. The flattened ameloblasts in the maturation stage of the homozygous samples contained enamel proteins in their cytoplasm. Thus, the wct mutation prevented the morphological transition of ameloblasts from secretory to maturation stages without disturbing the synthesis of enamel matrix proteins. This resulted in hypo-mineralization of incisor enamel and cyst formation between the enamel organ and matrix. The wct mutation also prevented the transfer of iron into the enamel.

The polyamines spermine and spermidine are involved in numerous important biological processes, including cell growth and differentiation. A highly regulated production of PAs appears to occur in the spermatogenic compartment of the testicles. Shin et al. (2007) undertook a study on the localization of PAs in the rat testis. They found high concentrations of PAs in spermatocytes as well as in residual bodies of the seminiferous tubules. These data suggested that PAs are compartmentalized into residual bodies which may reflect a termination of their role in spermiogenesis with respect to protein synthesis. Muller et al. (2006) have followed up previous findings showing that neurotrophins may have local functions in the developing and mature testis of rodents. They revealed the presence of nerve growth factor (NGF), brain-derived neurotrophic factor, neurotrophin-3 and 4, as well as neurotrophin receptors p75(NTR), TrkA, TrkB, and TrkC during human testis morphogenesis and in adult human testis. Remarkably, the Leydig cells 
were found to represent the predominant neurotrophin/ receptor expression sites within both fetal and adult human testes. Functional assays performed with a mouse tumor Leydig cell line revealed that NGF exposure increased cellular steroid production, indicating a role in differentiation processes. These findings provided further evidence for potential roles of neurotrophins during testis morphogenesis and in the mature testis, and demonstrated a neurotrophin-induced functional activity in Leydig cells. Based on observations that peroxisomal diseases are associated with reduced fertility, Luers et al. (2006) have searched for peroxisomes in the testis. They identified peroxisomes in Sertoli cells and in germ cells. Small-sized peroxisomes were concentrated in spermatogonia and disappeared during the course of spermatogenesis. Furthermore, it was revealed that peroxisomes of spermatogonia differ in their relative protein composition from peroxisomes of interstitial cells of Leydig. The authors propose that the disappearance of peroxisomes could serve as a suitable model system to investigate the degradation of an organelle as part of a physiological differentiation process in higher eukaryotes.

Aromatic L-amino acid decarboxylase (AADC) catalyses the decarboxylation of all aromatic L-amino acids and is expressed in many tissues besides the nervous system. Seta et al. (2007) showed that mRNA of AADC was detected in the taste bud-containing epithelium of the circumvallate papilla of mice. AADC immunostaining was detected in a subset of taste bud cells of fungiform, foliate, and circumvallate papillae. Double-label studies showed that AADC colocalized with serotonin, NCAM, PLCbeta2, and PGP9.5. However, AADC never colocalized with alphagustducin. Together, this indicates that only the type III cells could convert 5-hydroxytryptophan to serotonin within taste buds. Furthermore, in the developing circumvallate papilla, AADC was first detected in a small number of papillary epithelial cells at E14.5. By E18.5, AADC-positive epithelial cells also express PGP9.5, which is one of marker of taste cells, and these cells have been contacted by developing nerve fibers. These results suggested that AADC expression begins at early stages of taste bud cell differentiation, and biogenic amines may act on taste bud differentiation of tongue epithelial cells. Taste bud development in chick was investigated by Ganchrow et al. (2006) who found evidence that taste bud maturation, maintenance and survival are nerve-dependent.

Thyroid hormone (TH) dramatically influences inner ear development. It enhances the expression of the motor protein prestin via liganded $\mathrm{TH}$ receptor beta (TRbeta) while in contrast the expression of the potassium channel KCNQ4 is repressed by unliganded TRalpha1. Winter et al. (2007) have now analyzed other ion channels that are required for the final differentiation of OHCs. Their data support the hypothesis that proteins expressed in rodents prior to or briefly after birth like $\mathrm{Ca}(\mathrm{V}) 1.3$ and prestin are either independent of $\mathrm{TH}$ [e.g., $\mathrm{Ca}(\mathrm{V}) 1.3$ ] or enhanced through $\mathrm{TRb}$ eta (e.g., prestin). In contrast, proteins expressed in rodents later than post-natal day 6 like KCNQ4, SK2 and BK are repressed through TRalpha1. It was hypothesized that the precise regulation of expression of the latter genes requires a critical local TH level to overcome the TRalpha1 repression.

Yuan et al. (2007) have studied the expression of androgen receptor (AR) and its colocalization with estrogen receptor alpha (ERalpha) in the developing pituitary of sheep fetus. AR expression co-localized with ERalpha in the anterior pituitary of sheep fetus was detected from day 60 of gestation. Both AR immunoreactivity (AR-ir) and ERalpha immunoreactivity (ERalpha-ir) were predominantly localized in the nuclei of LH positive gonadotropes of anterior pituitary gland. Frederikse et al. (2006) have demonstrated brain-specific microRNA 124 and microRNA 7 , as well as micoRNA $125 \mathrm{~b}$ and let-7a in the eye lens. Furthermore, the presence of Dicer transcripts and proteins in the lens tissue samples was reported and the distribution of Dicer protein in late embryonic, post-natal and adult lenses. This demonstrates that key elements of microRNA biology are utilized during embryonic and adult lens development and that brain-specific miRNAs are also expressed in the lens.

The expression and tissue distribution of SPLUNC1 (short palate, lung, and nasal epithelium clone 1) in human fetuses was established by Zhou et al. (2006).

The TRIM37 protein is a member of the tripartite motif subfamily of RING finger proteins and is highly conserved between human and mouse. Mutations in the TRIM37 gene underlie mulibreynanism (muscle-liver-brain-eye nanism), a rare monogenic developmental disorder. Kallijarvi et al. (2006) showed that the mouse Trim37 gene presents several alternative splice variants, including a testis-specific transcript with an additional 3' exon. Their findings are in agreement with the clinical phenotype of the disease and should provide a basis for the analysis of Trim 37 knock-out mice as they become available.

Human placental development is established by trophoblast invasion into the uterine endometrium and its vasculature. Korgun et al. (2006) aimed to obtain information on the possible roles of cell cycle related proteins cyclin A, cyclin B1, PCNA, Ki67 and cell cycle inhibitors p21, p27 and p57 during placentation. Their data indicated different functions for p21, p27 and p57 in placental development with distinct roles for p21 and p57 in syncytiotrophoblast and EVT differentiation, respectively. p27 appears to be involved in both processes. SWAP-70 represents a new member of Rac-guanine nucleotide exchange factors (GEFs) which catalyzes PtdIns (3,4,5) P3-dependent switching of inactive GDP-Rac to active GTP-Rac. There- 
fore, it triggers the signal cascade of tyrosine kinase receptor. Liu et al. (2006b) established the spatial and temporal expression pattern of SWAP-70 on the rhesus monkey uterus during normal menstrual cycle and at the feto-maternal interface during the entire process of gestation. Together, the data indicated that SWAP-70 may be involved in regulating the motility of trophoblast cells during embryonic implantation and placentation.

\section{Histochemical techniques in the investigation of diseases and pathologies}

Reactive oxygen species are important free radicals in biology and pathology and a series of comprehensive reviews have been published (King and Loeken 2004; Kobayashi et al. 2004; Moldovan and Moldovan 2004; Myatt and Cui 2004; Nauseef 2004; Robinson et al. 2004a, b; Schrader and Fahimi 2004; Serhan 2004; Voetsch et al. 2004). The pancreatic islet beta cells are very sensitive to oxidative stress, probably due to the extremely low level of anti-oxidant enzymes, particularly catalase. In contrast to beta cells, pancreatic alpha cells are significantly more resistant to diabetogenic toxins. However, whether alpha cells express a different level of catalase is not known. Bloch et al. (2007) have evaluated catalase expression in alpha cells of diabetic and non-diabetic mice. In healthy mice, intensive catalase and glucagon immunostaining was found in the peripheral area of islets. Similar co-expression of catalase and glucagon was found in the alpha cells of diabetic animals. Thus, the high-level catalase expression in alpha cells of diabetic and non-diabetic mice may explain their resistance to oxidative stress. Some aspects of the role reactive oxygen species (ROS) and nitric oxide (NO) play in the development of pulmonary fibrosis after bleomycin administration were investigated by Inghilleri et al. (2006). They investigated histochemically ROS expression and catalase, glucose-6phosphate-dehydrogenase (G6PHD), and NOS/NADPHdiaphorase activity. Nitric oxide synthase (e-NOS and iNOS) and SOD (MnSOD, Cu/ZnSOD, ECSOD) expression was investigated immunohistochemically. Bleomycin treatment enhanced ROS production in both phagocytes and in type II alveolar epithelial cells. Mn, Cu/Zn, and ECSOD were overexpressed in parenchymal cells, whereas the interstitium expressed ECSOD. Catalase and G6PHD activity was moderately increased in parenchymal and inflammatory cells. NOS/NADPH-d activity and i-NOS expression increased in alveolar and bronchiolar epithelia and in inflammatory cells. Therefore, both inflammatory cells and epithelial cells are responsible of ROS and NO production. The authors proposed that his oxidative and nitrosative stress may be a substantial trigger in TGF- $\beta 1$ overexpression by activated type II pneumocytes, leading to fibrotic lesions. Oxidative tissue damage has been suggested to play a role in the development of stress-induced gastric lesions. Redox-active non-heme iron catalyzes hydroxyl radical generation through the Haber-Weiss reaction. Asano et al. (2006) have used highly sensitive nonheme iron histochemistry to show that the non-heme ferric and ferrous iron (NHF[III] and NHF[II]) staining increased in the oncotic parietal cells located at the erosive lesion which developed on the gastric mucosal folds after $3 \mathrm{~h}$ RWI. NHF[II] was positive in the arterial endothelium in the tela submucosa of the normal gastric wall and increased in the entire gastric mucosa after $3 \mathrm{~h} \mathrm{RWI}$. This suggested that the changes in the vascular non-heme iron metabolism were also involved in the response of the stomach to stressful conditions. Other aspects of gastric mucosa damage as they relate to Trefoil factor 2 (TFF2) were considered by Ota et al. (2006). TFF2 is a mucin-associated peptide that has a mucosal barrier function in addition to participating in repair and healing. The data indicated that the TFF2 trapped in the adherent mucins may be responsible for mucosal defense, healing, and repair.

Vitamin C (VC) is an effective scavenger for free radicals enzymatically produced in cells. The reduced form of $\mathrm{VC}$ is transported into cells by the sodium-dependent VC transporters SVCT1 and SVCT2. Lee et al. (2006b) have established the subcellular distribution of SVCT1 and SVCT2 protein in the kidney. SVCT1 immunoreactivity was observed in the brush border of proximal straight tubules, in the medullary rays of renal cortex and the outer stripe of outer medulla, while SVCT2 IR was undetectable in the kidney. These data provide the basis for a better understanding of the role of SVCT under various conditions.

Lewis antigens belong to the blood group of antigens and mediate cellular adhesion through interaction with selectins. Invasive trophoblasts use an array of adhesion molecules to facilitate cell-cell and cell-extracellular matrix interactions. Minas et al. (2007) examined immunohistochemically the expression of Sialyl Lewis a (sLe(a)), Sialyl Lewis $x(\operatorname{sLe}(x))$ and Lewis y $(\operatorname{Le}(y))$ in term placentas obtained from cases of normal, intrauterine growth retardation (IUGR), preeclamptic (PE) and hemolysis, elevated liver enzymes and low platelets syndrome (HELLP) pregnancies. Their data suggests that downregulation of sLe(x) in EVT might be associated with IUGR and PE. Furthermore, $\operatorname{Le}(\mathrm{y})$, which was recently described as a potent angiogenic factor, was upregulated in placental villi in conditions associated with placental malperfusion.

Sgambati et al. (2007) investigated the distribution of $\mathrm{N}$-glycans in placentas from pregnancies complicated by different degree of altered glycaemia. Placentas from women with physiological pregnancies, with pregnancies complicated by minor degree of glucose intolerance and 
with pregnancies complicated by gestational diabetes mellitus (GDM) treated with insulin were studied with the use of lectins (ConA, WGA, PNA, SBA, DBA, LTA, UEA I, GSL II, MAL II and SNA). Their data showed a decrease of $\alpha 2,6$-linked sialic acid and an increase of $N$-acetyl-D-glucosamine in the pathological placenta groups. Jeschke et al. (2006) observed that the gal-1 recognized appropriate glycotopes on the syncytiotrophoblast and extravillous trophoblast layer from second trimester human placenta and on BeWo chorion carcinoma cells. Gal-1 upon binding to BeWo cells also inhibited their proliferation in a concentration-dependent manner. Similar antiproliferative effects were also observed with an anti-TF monoclonal antibody which binds to the glycotope recognized by gal-1. Therefore, this kind of masking of Gal $\beta(-4 \mathrm{GlcNAc}$ and Gal $\beta(-3 \mathrm{GalNAc}$ epitopes on BeWo cells may have regulatory effects on cell proliferation.

The laminin composition (LMalpha1-alpha5, beta1beta3, gamma1 and gamma2 chains) of normal corneas and corneal buttons from keratoconus, bullous keratopathy (BKP), Fuchs' dystrophy with BKP, Fuchs' dystrophy without BKP and scar after deep lamellar keratoplasty (DLKP) was investigated by Bystrom et al. (2007). The epithelial basement membranes (BMs) of both normal and diseased corneas contained LMalpha3, alpha5, beta1, beta3, gamma1 and gamma2 chains. The epithelial BM morphology was altered in the different diseases. Scarring was associated with irregular BM and ectopic stromal localization of different laminin chains. The Descemet's membrane (DM) contained LMalpha5, beta1 and gamma1 chains in all cases and additionally LMbeta3 and gamma 2 chains in the majority of keratoconus corneas. The interface in the DLKP cornea had patches of LMalpha3, alpha4, alpha5, beta1 and beta2 chains, and an extra BM-like structure under the Bowman's membrane. These results suggest that laminin chains participate in the process of corneal scarring and in the pathogenesis of some corneal diseases. The novel finding of LMalpha3, beta3 and gamma2 in the DM of keratoconus buttons indicates that this membrane is also involved in the disease and that some cases of keratoconus may have a congenital origin, without normal downregulation of the LMbeta3 chain. KS PGs are key molecules in the corneal stroma for tissue organization and transparency. Macular corneal dystrophy (MCD) is a rare, autosomal recessive disease characterized by disturbances in $\mathrm{KS}$ expression. MCD is caused by mutations in CHST6, a gene encoding the enzyme responsible for KS sulphation. Young et al. (2007) employed four antibodies against specific KS sulphation patterns, including one against unsulphated KS, to investigate their reactivity in a case of MCD compared with normal cornea using high-resolution immunogold electron microscopy. They could demonstrate the presence of larger PG structures in MCD than normal. Unlike normal cornea,
MCD cornea showed positive labeling with antibody to unsulphated KSPG, but was not reactive with antibodies to sulphated KSPG. The use of these newly available antibodies should facilitate high-resolution investigations of phenotypic heterogeneity in support of genetic studies in MCD.

Autosomal dominant optic atrophy (adOA) is the most common form of hereditary optic neuropathy and a few cases of adOA are known to be associated with moderate progressive hearing loss. To gain insight into the pathogenesis of this hearing loss, Bette et al. (2007) performed expression analyses of OPA1 in the rat auditory and vestibular organ. In cochlear tissue, several splice variants of OPA1 were detected, which were also expressed in retinal tissue. OPA $1 \mathrm{mRNA}$ and protein was found in the hair cells and ganglion cells of the cochlea and vestibular organ. In ganglion cells, OPA1 mRNA and protein was already detectable at birth, whereas in the organ of Corti OPA1 mRNA and protein was upregulated after birth and reached mature-like expression level during the onset of hearing. The data suggest that defects in OPA1 cause hearing disorders due to a progressing metabolic disturbance of hair and ganglion cells in the inner ear.

Partial hepatectomy or carbon tetrachloride $(\mathrm{CCl}(4))$ injury, following treatment of rats with 2-acetylaminofluorene (2-AAF) to inhibit proliferation of hepatocytes, induces proliferation of oval cells and possibly their differentiation into nodular foci of hepatocytes when higher doses of 2-AAF are used. Chiu et al. (2007) have studied oval cell markers in these foci, and aimed to demonstrate a precursor-product relationship between oval cells and hepatocytes. They found $7.6 \%$ of the hepatocyte foci were positive for an oval cell marker cytokeratin 19 (CK-19). Focal hepatocyte differentiation of oval cells was characterized by cell hypertrophy, membranous CK-19, and positive hepatocyte nuclear factor 4 (HNF-4). HNF-4 positive small oval cells surrounding CK-19 positive foci were frequently seen, suggesting that a paracrine mechanism(s) may be responsible for the enlargement of CK-19 positive foci. Thus, oval cells appear to differentiate to CK-19 positive foci and then to CK-19 negative foci in the high dose 2-AAF/CCl(4) model. Jacob et al. (2007) analyzed in male wild-type (WT) and Dnase1 knockout (KO) CD-1 mice after acetaminophen (APAP)-intoxication the hepatolobular distribution of APAP-adducts in relation to DNA-damage by terminal deoxyribonucleotidyl-transferase dUTP nick end-labeling (TUNEL), the ultrastructural alterations of hepatocellular morphology and the intracellular localization of Dnase1. APAP treatment of WT-mice led to extensive pericentral necrosis. In contrast, livers from treated KO-mice exhibited almost normal structure. In WT-mice several layers of pericentral hepatocytes displayed APAPadduct formation and subsequent DNA-damage, whereas in KO-animals only few cells were affected. 
Fujiwara et al. (2007) prepared two monoclonal antibodies (ADM-1-11 and 79-31 mAbs) against daunomycin (DM) which specifically detected DM as well as its analogs doxorubicin and epirubicin, but did not react with other anticancer antibiotics, including pepleomycin, mitomycin $\mathrm{C}$, and actinomycin D. The monoclonal antibodies reacted strongly in sections of tissues from animals injected with DM. The same group (Ohara et al. 2007a) reported improved immunocytochemical detection of DM by the use of hydrogen peroxide oxidation prior to immunostaining for DM. The availability of methods to study sites of accumulation of DM offers possibilities for understanding toxic side effects of this drug on the heart and kidney. Moreover, the immunocytochemical methodology developed may prove useful for the localization of other low molecular weight drugs that can be fixed in situ by glutaraldehyde. As a case in point, Ohara et al. (2007b) studied DM distribution in the GI tract which is severely affected during DM therapy. Shortly after i.v. injection, DM was diffusely distributed in nuclei and most parts of the cytoplasm of intestinal epithelial cells. Later, DM immunostaining was by and large absent in the villous epithelium but persisted in the intestinal crypts. In addition, staining was also detected in endothelial cells, scattered cells of the lamina propria and in SMCs. Similar findings were made in the colon. The distribution of DM accumulation correlated partially with the distribution of apoptotic cells as detected by the TUNEL procedure.

Musculoskeletal diseases with osteochondrotic articular cartilage defects, such as osteoarthritis, are an increasing public health problem which necessitates the development of novel and improved therapeutic strategies. Canine mesenchymal stem cells (cMSCs) offer significant promise as a multipotent source for cell-based therapies and could form the basis for the differentiation and cultivation of tissue grafts to replace damaged tissue. Csaki et al. (2007) performed a comprehensive analysis to characterize the ultrastructure of in vitro differentiated cMSCs and to analyze their differentiation capacity. The cMSCs showed proliferative potential and were capable of osteogenic, adipogenic and chondrogenic differentiation. cMSCs treated with the osteogenic induction medium differentiated into osteoblasts, produced typical bone matrix components, beta1integrins and upregulated the osteogenic specific transcription factor Cbfa-1. cMSCs treated with the adipogenic induction medium showed typical adipocyte morphology, produced adiponectin, collagen type I and beta1-integrins, and upregulated the adipogenic specific transcription factor PPAR-gamma. cMSCs treated with the chondrogenic induction medium exhibited a round to oval shape, produced a cartilage-specific extracellular matrix, beta1-integrins and upregulated the chondrogenic specific transcription factor Sox9. These results demonstrated the multipotency of cMSCs and thus highlight their potential therapeutic value for cell-based tissue engineering. Simon extracts are vitamin K1-rich food materials prepared from the leaves of the Simon potato. Vitamin K1, the major component of the Simon extracts, is known to stimulate bone formation. Tang et al. (2006) have examined a vitamin K1free fraction of Simon extracts and observed a remarkable inhibitory effect on osteoclastogenesis in rat bone marrow culture systems, as well as in a pure differentiation system using a murine osteoclast precursor cell line. Furthermore, the vitamin K1-free Simon extracts markedly suppressed severe bone destruction mediated by abundant osteoclasts associated with adjuvant-induced arthritis in rats. They found that caffeic acid had the most powerful inhibitory effect on osteoclastogenesis and significantly suppressed the expression of NFATc1, a key transcription factor for the induction of osteoclastogenesis. These studies demonstrate the utility of chemical components of the Simon extracts for successful suppression of bone destruction accompanied with adjuvant-induced arthritis in rats.

The activation of HSC is a common pathway leading to hepatic fibrosis. However, the molecular mechanisms underlying HSC activation remain obscure. Lim et al. (2007) have elucidated the nature of the HSC activation by investigating the expression of E-cadherin and its switch to $\mathrm{N}$-cadherin during rat HSC activation, in vivo and in vitro. E-cadherin and beta-catenin were expressed on opposing cell membranes of GFAP-positive rat HSCs and adjacent hepatocytes in vivo, and between desmin-positive rat HSCs in vitro. With the progression of rat HSC activation in tissue and in culture, E-cadherin disappeared gradually, whereas $\mathrm{N}$-cadherin appeared at the cell periphery. Thus, resting rat HSCs express E-cadherin and beta-catenin both in vivo and in vitro. E-cadherin switches to N-cadherin during HSC activation suggesting that HSC activation represents transdifferentiation from an epithelial to a mesenchymal phenotype.

In addition to HSCs, myofibroblasts are known to be involved in liver fibrogenesis (Ogawa et al. 2007). Leptin is a peptide known to play a profibrogenic role in HSCs, whereas peroxisome-proliferator activated receptor (PPAR)-gamma ligands are suggested to have an anti-fibrogenic effect on HSCs. Lee et al. (2007) investigated whether or not PPAR-gamma ligands would suppress leptin-induced HSC activation and regulate leptin receptor expression. Proliferation of human HSCs was achieved by both PDGF and leptin, and this could be suppressed by ciglitazone. PPAR-gamma mRNA expression was diminished in activated HSCs either by PDGF or leptin, and this was reversed by ciglitazone. Leptin receptor (OB-R) mRNA expression increased in activated HSCs either by PDGF or leptin, and the expression was inhibited by ciglitazone. The results of this study suggested that the regulation of leptin- 
receptor mRNA expression on HSCs was subject to the regulation by a PPAR- $\gamma$ ligand. Guyot et al. (2006) used a model of the common bile duct ligation, to investigate the connective tissue modifications occurring 3 and 5 days following ligation. They showed that the common bile duct ligation is a valuable model for investigating myofibroblast differentiation and extracellular matrix adaptation in response to mechanical stress.

The acute phase reaction mediated by the proinflammatory cytokine IL6 initiates a number of metabolic changes in the liver, which may contribute to the pathogenesis of the septic shock during prolonged exposition. Lienenluke and Christ (2007) have studied the impact of IL6 on the hepatic glucose providing capacity by monitoring glycogen degradation and the expression of the gluconeogenic phosphoenolpyruvate carboxykinase (PCK1) in rat livers during the daily feeding rhythm. PCK1 mRNA levels were decreased by IL6 to $50 \%$ of levels in untreated animals due to the reduction of PCK1 mRNA in the periportal zone of the liver as shown by ISH. PCK1 enzyme activity was not affected by IL6. Glycogen degradation was accelerated by IL6, which led to nearly complete depletion of glycogen pools in periportal areas. Thus, the depletion of glycogen stores in the liver might contribute to the impairment of hepatic glucose production during prolonged acute phase challenge.

Both hypoxia and aging affect the morphology and the function of myocardial tissue which is counteracted by activating specific signaling cascades. Di Giulio et al. (2007) reported the involvement of CREB protein in "in vivo" response to hypoxic challenge and during aging in rat hearts. CREB was activated in parallel to HIF- $1 \alpha$ nuclear translocation in the young after hypoxia exposure followed by reoxygenation. However, this response was not so dramatic in the old, neither in terms of CREB activation, nor in terms of HIF- $1 \alpha$ expression and translocation. This suggested the existence of an impaired oxygen-sensing mechanism or an adaptation of the cells to hypoxia in the old. Moreover in the young a PKC $\alpha /$ Erk pathway seems to be involved in the activation of HIF- $1 \alpha$ along with CREB, suggesting an attempt of the young to counteract the damage evoked by hypoxia. In the old a PKC $\alpha / \mathrm{p} 38$ MAPK/ CREB pathway could determine the occurrence of both aging and aged cell hypoxia response. Terada et al. (2007) evaluated hypoxic cells in live mouse liver tissues by immunohistochemistry for protein adducts of reductively activated pimonidazole (PARaPi). They used their IVCT followed by freeze-substitution fixation and paraffin embedding. In liver tissues of mice without hypoxia, almost no PARaPi immunostained cells were detected. However, in liver tissues with $30 \mathrm{~s}$ of hypoxia, some hepatocytes in the pericentral zones were strongly immunostained. With time, the number of PARaPi immunostained hepatocytes in all lobular zones increased, indicating different reactivities of pimonidazole in the hepatocytes to hypoxia. Furthermore, the general immunoreactivity appeared to be stronger around the central veins than other portal areas. Thus, IVCT is useful to detect time-dependent hypoxic states with pimonidazole treatment in living animal organs.

Chronic ethanol consumption elicits detrimental changes of liver metabolism. Zinchuk et al. (2007) investigated the effects of chronic ethanol consumption on the expression and localization of bile salt export pump (Bsep), a major canalicular exporter of bile salts, and multidrug resistance protein 2 (Mrp2), a canalicular organic anion transporter, in the rat liver. Bsep mRNA was upregulated, while Mrp2 mRNA responded by downregulation. In agreement with the mRNA results, the expression of Bsep protein increased, while Mrp2 protein decreased, suggesting that the expression of both of them is transcriptionally regulated. Quantitative colocalization analysis of Bsep and Mrp2 proteins revealed a steady decrease in the degree of colocalization and Mrp2 expression, indicating that although the properties of both transporters are affected, Mrp2 is altered more. These findings indicate that ethanol alters Bsep and Mrp2 canalicular transporters in the rat liver, at both the mRNA and protein levels.

Guilmeau et al. (2007) investigated the expression of I- and L-cytosolic fatty acid binding proteins (FABP) in two rare hereditary lipid malabsorption syndromes, Abetalipoproteinemia (ABL) and Anderson's disease (AD), as compared with normal subjects. In contrast to normal subjects, the cellular immunostaining for both FABPs was clearly decreased in patients, as the enterocytes became fat-laden. However, decreased FABP expression was not associated with decreased mRNA levels. The results suggest that enterocytes might regulate intracellular FABP content in response to intracellular fatty acids. The haemochromatosis protein (HFE) is an important regulator of body iron stores and is also present in enterocytes. Here, it is not intrinsically required, but can augment iron absorption. West et al. (2006) studied the sub-cellular location of HFE in enterocytes of iron-deficient and control rats. Furthermore, studies were conducted for the primary iron absorption protein, divalent metal transporter 1 (DMT1). HFE colocalized exclusively with the terminal web of intestinal enterocytes and its expression was increased in iron deficiency. This localization was consistent with a second regulatory role for HFE in iron absorption, independent of hepcidin from the liver. DMT1 was localized primarily on the microvillus membrane, but did partially co-localize with HFE indicating the possibility that the two proteins may interact to regulate iron absorption.

Zaman et al. (2007) have delineated mechanisms through which the lack of PAI-1 in the heart affects remodeling of the heart early after myocardial infarction (MI). 
Three days after MI induced by coronary occlusion, systolic and diastolic function was assessed with high-resolution echocardiography, infarct size was determined biochemically and histologically and accumulation of acute inflammatory cells in zones of infarction was characterized by immunocytochemistry. PAI-1 KO mice exhibited markedly thickened diastolic left ventricular anterior walls $(1.38 \pm 0.38 \mathrm{~mm}$ vs. $0.77 \pm 0.13 \mathrm{SD})$, more profound depression of global and regional cardiac function (19 vs. $22 \%$ fractional shortening), and greater evidence of diastolic dysfunction (average E wave amplitude $=568$ vs. $675 \mathrm{~mm} / \mathrm{s}$ ) all of which were significant. Markedly greater extent of infarction was demonstrated in knockout mice compared with controls (76 vs. $29 \%$ of the left ventricle, $P<0.05)$ associated with striking hemorrhage and intense inflammation. Fibrosis normalized for infarct size was markedly reduced (0.006 vs. $0.022 \mathrm{mug}$ hydroxyproline $/ \mathrm{mg}$ dry weight). In conclusion, lack of PAI-1 in the heart exerted deleterious effects mediated, at least in part, by increased inflammation and hemorrhage and attenuating of fibrosis.

Obesity is associated with an elevated incidence of cardiovascular disease. The adipokine leptin may be important for the development of cardiovascular complications associated with obesity, possibly through interaction with its receptor on vascular cells. Schroeter et al. (2007) systematically analyzed expression of the leptin receptor in normal and diseased vascular specimens as well as experimental vascular lesions induced in hypercholesterolemic mice and minipigs. Their results demonstrated presence of the leptin receptor in normal vessel wall segments as well as neointimal or atherosclerotic lesions. In the latter, leptin receptors were expressed in endothelial cells. Moreover, CD14-positive monocytes/macrophages were strongly positive for the leptin receptor. These data support a possible action of leptin on the cardiovascular system by demonstrating expression of the leptin receptor in different types of vascular lesions.

Out of the family of tissue inhibitors of matrix metalloproteinases (TIMPs), TIMP4 is primarily confined to cardiovascular structures. Koskivirta et al. (2006) demonstrated that TIMP4 is present in medial SMCs and adventitial capillaries of arteries as well as in cardiomyocytes of healthy heart tissue. They examined several human inflammatory cardiovascular disorders, such as atherosclerosis, giant cell arteritis and chronic rejection of heart allografts. TIMP4 was most clearly detectable in cardiovascular tissue areas populated by abundant inflammatory cells, mainly macrophages and $\mathrm{CD}^{3+} \mathrm{T}$ cells that produce TIMP4. In advanced atherosclerotic lesions, TIMP4 was detected around necrotic lipid cores, whereas TIMP 3 and caspase 3 resided within and around the core regions, indicating different roles for TIMP3 and TIMP4 in inflammation- induced apoptosis and in matrix turnover. The data demonstrate upregulation of TIMP4 in human cardiovascular disorders exhibiting inflammation, suggesting its future use as a novel systemic marker for vascular inflammation. The inherited stress-induced arterial hypertension (ISIAH) strain of hypertensive $(>170 \mathrm{mmHg}$ ) inbred rats reacts with increased blood pressure values upon mild emotional stress. Amstislavsky et al. (2006) aimed to characterize key parameters related to hypertension in ISIAH rats. They observed an unaltered renal morphology in ISIAH rats, whereas the hypothalamic-pituitary-adrenocortical (HPA) axis was constitutively upregulated with enlarged adrenal cortices and enhanced plasma corticosterone levels. Plasma renin activity was not different from control, but aldosterone levels were in part reduced. Juxtaglomerular NO synthase type 1 , cyclooxygenase type 2 , and renin expression were significantly reduced, whereas tubular gene products related to sodium transport (bumetanide-sensitive $\mathrm{Na}, \mathrm{K}$, $2 \mathrm{Cl}$ cotransporter type 2 ; thiazide-sensitive $\mathrm{Na}, \mathrm{Cl}$ cotransporter; epithelial Na channel- $\alpha$; $11 \beta$-hydroxysteroid dehydrogenase type 2) were increased, suggesting enhanced volume conservation by the kidney. The authors propose the ISIAH rat as an attractive model for the renal components determining salt and water homeostasis in hypertension.

Diamanti-Kandarakis et al. (2007) investigated the localization/immunohistochemical distribution of advanced glycation end-products (AGEs) and their receptor (RAGE), as well as their putative signaling mediator NF- $\kappa \mathrm{B}$ in ovaries of women with polycystic ovary syndrome (PCOS) compared to normal. In healthy women, AGE immunoreactivity was observed in follicular cell layers (granulosa and theca) and luteinized cells, but not in endothelial cells. PCOS specimens displayed AGE in theca interna and granulosa cells as well as in endothelial cells, but staining of granulosa cells was stronger than in that of normal ovaries. RAGE was highly expressed in normal and PCOS tissues. Normal tissue exhibited no staining differences between granulosa cell layer and theca interna. However, in PCOS ovaries, granulosa cells displayed stronger RAGE expression compared to theca interna cells in comparison to controls. In conclusion, these findings demonstrated that RAGE and AGE-modified proteins with activated NF- $\kappa$ B are expressed in human ovarian tissue. Furthermore, a differential qualitative distribution of AGE, RAGE and NF$\kappa \mathrm{B}$ p65 subunit was observed in women with PCOS.

DNA methylation catalyzed by DNA methyltransferases (DNMTs) and histone deacetylation catalyzed by histone deacetylases (HDACs) play an important role for the regulation of gene expression during carcinogenesis and spermatogenesis. Omisanjo et al. (2007) studied the cellular expression pattern of DNMT1 and HDAC1 in human testicular cancer and impaired human spermatogenesis. 
During normal spermatogenesis, DNMT1 and HDAC1 were colocalized in nuclei of spermatogonia. While HDAC1 was additionally present in nuclei of Sertoli cells, DNMT1 was restricted to germ cells. In infertile patients revealing round spermatid maturation arrest, round spermatids lacked DNMT1 protein, while pachytene spermatocytes became positive for DNMT1. In contrast, no changes in the expression pattern could be observed for HDAC1. HDAC1 was detectable in testicular tumors such as embryonal carcinoma, seminoma and teratoma. DNMT1 was not expressed in seminoma, but upregulated in embryonal carcinoma. Sertoli cells play a key role in spermatogenesis. It has been observed that etoposide, an efficient chemotherapeutic drug, provokes an increase in numerical density of Sertoli cells. Stumpp et al. (2006) have now investigated a possible direct action of etoposide on Sertoli cells and showed that the diminution of transferrin labeling in the seminiferous epithelium was not associated with germ cell absence but suggested that etoposide impairs Sertoli cell function.

The serrated polyp-neoplasia pathway is a novel concept that has been demonstrated to differ from the conventional adenoma-carcinoma pathway. To characterize the phenotypic patterns of differentiation in colorectal serrated polyps, Mochizuka et al. (2007) examined the expression profile of gastric (MUC5AC, TFF1, MUC6, GlcNAcalpha1 $\rightarrow$ 4Gal $\rightarrow \mathrm{R}$, and PDX1) and intestinal (MUC2, TFF3, and CDX2) epithelial markers. MUC5AC and TFF1 were upregulated in the hyperplastic polyps (HPs), sessile serrated adenomas (SSAs), and traditional serrated adenomas (TSAs). MUC6 was expressed in the HPs and SSAs. GlcNAcalpha1 $\rightarrow 4 \mathrm{Gal} \rightarrow \mathrm{R}$ was expressed only in the SSAs. Although MUC2 expression was preserved, TFF3 was downregulated in the HPs, SSAs, and TSAs. PDX1 was upregulated in the HPs, SSAs, and TSAs. On the other hand, CDX2 was downregulated in the HPs and SSAs. The colorectal serrated polyps showed higher expression of gastric makers than CAs. The HPs and SSAs showed gastric and intestinal mixed phenotype expression with gastric pyloric organoid differentiation and almost identical, but different from the TSAs, marker profile. In summary, these data elaborated the characteristics of the gastric and intestinal mixed phenotype in colorectal serrated polyps, particularly HPs and SSAs that showed organoid differentiation simulating the gastric pyloric mucosa. The PDX1 up-regulation and CDX2 down-regulation could be important for inducing a gastric pyloric pattern of cell differentiation in colorectal serrated polyps.

Recent studies suggest that the interstitial cells of Cajal (ICCs) are pacemakers in the musculature of the GI tract. Resident macrophages can be observed in the network of ICC and the myenteric nerve within the myenteric plexus. It was suggested that such macrophages play a critical role in the pathogenesis of GI dysfunction during inflammation of the GI tract. Kinoshita et al. (2007) evaluated changes in chemoattractant protein mRNA expression in macrophages and neutrophils, the ICC, nerve and macrophages in the myenteric plexus of model rats with TNBS-induced colitis. Chemoattractant proteins, MCP-1, GRO, MIP-2 and CINC2alpha were upregulated in the colonic muscle layer after inflammation. Leukocyte infiltration and MPO activity were increased in the muscle layer. Macrophages were also distributed near the ICC in the inflamed myenteric plexus. Furthermore, the ICC network and myenteric nerve system had disappeared from the inflamed region, whereas the number of resident macrophages was increased. Possibly ICC-mediated, rhythmic contractions of circular smooth muscle strips and enteric neuron-mediated TTX-sensitive peristalsis in the whole proximal colon tissue were significantly inhibited in the inflamed colon, indicating that the ICC-myenteric nerve system was dysfunctional in the inflamed muscle layer. Their accumulation around the myenteric nerve plexus and the ICC network suggests that macrophages play an important role in inducing intestinal dysmotility in gut inflammation.

Clara cells are nonciliated secretory cells implicated in lung homeostasis by the synthesis of immunomodulatory and host defense products. Roth et al. (2007) compared the effects of inhaled budesonide (BUD) on Clara cell biology and its ability to reverse morphofunctional changes induced in an allergic airway hyper-responsiveness mouse model. Their results demonstrated the wide range of stimuli that can modify Clara cell biology, and highlighted the effects of BUD as a modulator of P450 enzymes, which probably contributes to a complementary antiinflamatory activity. Barth et al. (2006) showed in the in vitro bleomycininduced injury a shift of caveolin-1 from the lipid raft/caveolae fractions to the non-caveolar fractions indicating an intracellular retention of caveolin-1. This result suggested that the translocation of caveolin- 1 could be an important event regulating the metabolism of alveolar epithelial lung cells following injury. $\alpha-1$-Antitrypsin deficiency is a disease well known to result in elastolytic damage of lung. Rishikoff et al. (2006) have induced an elastolytic injury in mouse lung by endotracheal administration of porcine pancreatic elastase (PPE). They then determined the induction of the myofibroblast phenotype in the mouse lung by $\alpha$-smooth muscle actin ( $\alpha$-SMA) immunohistochemistry and of elastin and $\alpha 1$ (I) collagen mRNA expression by in situ hybridization. Changes in airspace dimensions were assessed by determining mean linear intercept. Their data suggest that repair mechanisms following elastolytic injury are confined to overtly damaged alveolar structures and are paralleled by the induction of the myofibroblast phenotype.

The phenotype and clinical outcome of cystic fibrosis (CF) are strongly influenced by other genetic modulators 
and members of the calcium activated chloride channels (CLCA) gene family, specifically the CLCA gene (hCLCA1), have been identified as genetic modulators of the intestinal manifestation of CF. Leverkoehne et al. (2006) have analyzed the expression levels of mCLCA3 and three other murine CLCA homologs (mCLCA1, mCLCA2, mCLCA4) in four different CF mouse models. They concluded that both mCLCA 2 and mCLCA3 may act as modifiers of the intestinal phenotype in $\mathrm{CF}$.

Aspects of wound healing were investigated by Kreft et al. (2006) in primary explant cultures of mouse bladder. They evaluated the possible role leading edge cells, which are located at the forefront of a wound margin, may play in coordinating the wound healing process. Their results suggest that leading edge cells may develop into fully differentiated superficial cells.

This section will be ended by referring to work related to protein misfolding which can occur as a consequence of protein mutations. Misfolded proteins are recognized by the protein quality control and eventually degraded by the ubiquitin-proteasome system. Fan et al. (2007) have analyzed the subcellular changes in $\mathrm{CHO}$ cells expressing mutant $\mathrm{C} 96 \mathrm{Y}$ proinsulin 2 as compared to $\mathrm{CHO}$ cells expressing wild type proinsulin 2 by electron microscopic morphometry and immunogold labeling as well as serial section 3D analysis. They found a significant increase in volume density of pre-Golgi intermediates in $\mathrm{CHO}$ Ins2(C96Y) cells which was principally due to an increase of its tubular elements, and no significant changes of the ER. The average diameter of the pre-Golgi intermediates of $\mathrm{CHO}$ Ins2(C96Y) cells was about twice that of $\mathrm{CHO}$ Ins2(wt) cells. The enlarged pre-Golgi intermediates and the ER of CHO Ins2(C96Y) cells were positive for proinsulin, which was not detectable in the significantly enlarged Golgi cisternal stack. Treatment of $\mathrm{CHO}$ Ins2(C96Y) cells with proteasome inhibitors resulted in the formation of proinsulin-containing aggresomes. In conclusion, misfolded proinsulin causes enlargement of pre-Golgi intermediates which indicates their involvement in protein quality control. In some protein folding diseases such as chronic neurodegenerative diseases, typical cytosolic inclusion bodies composed of misfolded proteins can be observed. They are a hallmark of Huntington's disease (HD) and other polyglutamine repeat diseases. Wanderer and Morton (2007) have now characterized the morphological and biochemical composition of inclusions in both a transgenic mouse model (R6/2 line) and an inducibel cell culture model of HD (iPC12Q74). They could identify several morphologically distinct kinds of inclusions in different locations (nuclei, cytoplasm and cellular processes). The authors suggested that both the varying composition and structure of inclusions may be important in the pathogenesis of HD. Protein misfolding also occurs under various forms of cellular stress, and heat shock proteins (HSPs) play an important role in folding of cellular proteins. The subcellular distribution of HSP27 in various human breast cancer cell lines was investigated by Qian et al. (2006).

The conformational conversion of the cellular prion isoform $\mathrm{PrP}^{\mathrm{c}}$ into the pathological prion protein isoform $\mathrm{PrP}^{\mathrm{sc}}$ is a key step in the pathogenesis of transmissible spongiform encephalopathies (TSEs) by the widely accepted protein-only hypothesis. The GI tract is thought to be a main site of entry for the pathological isoform of the prion protein. Therefore, $\operatorname{PrP}^{\mathrm{c}}$ expression is a prerequisite for the infection and spread of the disease to the central nervous system. However, the distribution of $\operatorname{PrP}(c)$ in the gut is still a matter of controversy. Miyazawa et al. (2007) investigated the localization of $\operatorname{PrP}^{\mathrm{c}}$ in the bovine and murine small intestine. In cattle, most $\operatorname{PrP}^{\mathrm{c}}$ positive epithelial cells were detected in the duodenum and corresponded to serotonin producing cells. In bovine Peyer's patches (PP), $\operatorname{PrP}^{\mathrm{c}}$ was distributed in extrafollicular areas, but not in the germinal centre of the jejunum and ileum and expressed in myeloid lineage cells such as myeloid DCs and macrophages. In mice, $\operatorname{PrP}^{\mathrm{c}}$ was expressed in some epithelial cells throughout the small intestine as well as in FDCs in the germinal centre of PP. Therefore, this study demonstrated a number of differences in the localization of $\mathrm{PrP}^{\mathrm{c}}$ between the murine and bovine small intestines. Dendritic cells are mobile cells present within lymph organs and are suspected to carry prions through the lymphoid system and to transfer them towards the peripheral nervous system. Dorban et al. (2007) have analyzed PP in C57B1/6 mice that were orally inoculated with $\mathrm{PrP}^{\mathrm{Sc}}$ (scrapie strain 139A). In PP, dissected at day 1 and day 105 after oral exposure to scrapie, an increased population of DCs localized in the follicularassociated epithelium was observed. On day $105, \mathrm{PrP}^{\mathrm{Sc}}$ was found in the follicles inside the PP of prion-infected mice. A subset of Peyer's patches DCs, which did not express cellular prion protein on their surface in non-infected mice conditions, was prion-positive in scrapie conditions. These results are in favor of the implication of DCs in prion diseases. Bencsik et al. (2007) have studied scrapie strain transmission in ovine PrP transgenic mice and showed that this transgenic mice strain was susceptible to different murine scrapie strains. However, but that the efficacy of transmission between murine strains was dissimilar. Thus, strain typing studies after transmission of natural scrapie isolates within this new mouse referential should be feasible.

Amselgruber et al. (2006) have studied whether cellular prion protein also exists in pancreatic endocrine cells. They found that $\operatorname{PrP}^{\mathrm{c}}$ was highly expressed in all endocrine cells of fetal and adult pancreatic islets, with a particularly strong expression in glucagon cells. 


\section{The nucleus and its dynamic compartments}

Many studies have analyzed the structural organization and functional compartmentalization of the nucleus and the dynamics of its substructures (Fakan 2004; Misteli 2005; Olson and Dundr 2005; Roix and Misteli 2002). Hernandez-Verdun (2006a, b) has reviewed various structure-function aspects and dynamics of defined components of the nucleolus.

Martin et al. (2007) presented the use of a fluorescently labeled peptide for fast labeling of nucleoli in living cells of different species and origin. The short peptide with ten amino acids was able to cross cellular membranes and reach the nucleolar target sites. Here, it localized to the granular component of the nucleolus. A high stability of the label in long-term studies over $24 \mathrm{~h}$ as well as no effect on the cellular viability and proliferation and on rDNA transcription was observed. The fluorescently conjugated nucleolar marker could be used in combination with different fluorophores like fluorescent proteins or DNA dyes. Importantly, nucleolar labeling was also preserved during fixation and staining of the cells. In conclusion, this fluorescently labeled peptide represents a valuable tool that allows a fast and easy labeling of the nucleolus in living cells. Xie and Pombo (2006) have examined different phosphorylated forms of polymerase II and newly made RNA in Cajal and promyelocytic leukaemia (PML) bodies using high-resolution imaging of ultrathin cryosections. They concluded that although PML bodies are present in transcriptionally active areas of the nucleus, they are not generally sites of polymerase II assembly, transport or activity. The works of Pombo that have earned her the Robert-Feulgen-Prize in 2007 have been published in an excellent review (Pombo 2007). Smetana et al. (2006a) in early leukemic granulocytic and plasmacytic precursors in vitro and in vivo showed that in most cells, AgNORs (silver stained nucleolus organizer regions) appeared as clusters in the whole nucleolar body. They proposed that the translocation of the reduced number of AgNORs to the nucleolar periphery in some blastic leukemic hematopoietic cells might be a useful marker of aging at the single cell level. Gonzalez-Camacho and Medina (2006) studied the nucleolin-like protein NopA100 during the cell cycle in proliferating plant cells. They could establish a relationship between the increase in nucleolar activity, cell-cycle progression, nucleolar structure, the activity of NopA100, and the proteolysis of this nucleolin-like protein. The studies by Diez et al. (2006) on a reverse transcriptase in the nucleolus indicated that the putative Chironomus telomere elongation machinery and telomerase share a nucleolar localization and reinforced the idea that nucleoli are functionally linked to telomere maintenance.
The mammalian heterochromatin protein 1 (HP1alpha, HP1beta, HP1gamma subtypes) and transcriptional intermediary factor TIF1beta play an important role in the regulation of chromatin structure and function. Bartova et al. (2007) investigated the nuclear arrangement of these proteins during differentiation of embryonal carcinoma P19 cells into primitive endoderm and into the neural pathway. Additionally, the differentiation potential of trichostatin A (TSA) and 5-deoxyazacytidine (5-dAzaC) was studied. They could show that the nuclear arrangement of HP1 subtypes and TIF1beta is differentiation specific, and seems to be more important than changes in the levels of these proteins, which were relatively stable during all the induced differentiation processes.

Mathee et al. (2006) analyzed the nanostructure of specific chromatin regions (7q22 gene region) and nuclear complexes by applying spatially modulated illumination (SMI) microscopy. No correlation between the measured and genomic sizes of the various gene regions was found indicating a high variability in chromatin folding, with factors other than the sequence length contributing to the chromatin compaction. Zinner et al. (2006) investigated the 3D architecture and spatial interrelationships of different histone lysine methylation sites (tri-H3K4, mono-H4K20, mono-H3K9, tri-H3K27, tri-H4K20 and tri-H3K9) in various human cell types. A close association with centromeres was found only for histone methylation sites previously linked to constitutively repressed chromatin. By simultaneous visualization of different histone lysine methylation sites methylation patterns were found to be organized in distinct nuclear zones with little apparent intermingling. The possibility that chromatin remodeling activity is important for rapid exchange of the glucocorticoid receptor (GR) at the mouse mammary tumor virus (MMTV) promoter was studied by Stavreva and McNally (2006) using photobleaching technology in live cells. Their data suggest a role for H1 phosphorylation, and by implication chromatin remodeling, in rapid exchange of GR at MMTV. Brink et al. (2006) demonstrated that truncated heterochromatin protein 1 lacking a functional chromodomain induces heterochromatinization upon in vivo targeting. Weidtkamp-Peter et al. (2006) analyzed the replication of centromeric heterochromatin in space and time during S-phase in mouse fibroblasts. They reported that late replication is not an obligatory feature of centromeric heterochromatin in murine cells and that it does not determine their "heterochromatic state".

The presence of actin and myosin I in the nucleus is well established (Nowak et al. 1997; Pederson and Aebi 2002). In continuation of earlier studies, Kahle et al. (2007) demonstrated that nuclear myosin I (NMI) is present in cell nuclei of all mouse tissues examined except for cells in terminal stages of spermiogenesis. Quantitative PCR and 
Western blots demonstrate that the expression of NMI in tissues varies with the highest levels in the lungs. The lifespan of NMI is longer than $16 \mathrm{~h}$ as determined by cycloheximide translation block. A homologous protein is expressed in human, chicken, Xenopus, and zebrafish as shown by RACE analysis. Furthermore, the analysis of genomic sequences indicates that almost identical homologous NMI genes are expressed in mammals, and similar NMI genes in vertebrates.

In their review, Widlak et al. (2006) concentrated on the structure of chromatin as a major factor determining the rate and efficiency of DNA repair. They critically reviewed the role of various DNA damage-binding chromatin proteins and derived models. The damage shielding model postulates that binding of chromatin proteins to damaged DNA might disturb damage recognition by repair factors and impair its removal. Alternatively, the damage-recognition/signaling model proposes that the binding of specific chromatin proteins to damaged DNA could serve as a hallmark to be recognized by repair proteins. Additionally, the binding of specific chromatin proteins to damaged DNA could induce chromatin remodeling at the damage site and indirectly affect its repair. Plants possess functional homologues to most parts of the DNA-damage-repair machinery in animals and humans. Nuclear foci of $\gamma-\mathrm{H} 2 \mathrm{AX}$ represent one of the very earliest symptoms of UV- and hydroxyurea (HU)-induced checkpoint responses in root meristem cells of Vicia faba. Rybaczek et al. (2007) using alpha-phospho$\mathrm{H} 2 \mathrm{AX}$ antibodies showed that HU, an inhibitor of ribonucleotide reductase, and aphidicolin (APH), an inhibitor of DNA-polymerases alpha and delta, may promote formation of phospho-H2AX foci in late $\mathrm{S} / \mathrm{G} 2$-phase cells in root meristems of Vicia faba. Although fluorescent foci spread throughout the whole area of nucleoplasm, large phospho$\mathrm{H} 2 \mathrm{AX}$ aggregates in HU-treated cells allocate mainly in perinucleolar regions.

Aphidicolin-induced phosphorylation of H2AX exhibits little or no overlap with the areas positioned close to nucleoli. Based on observations during mitosis and caffeine-mediated premature chromosome condensation, it was suggested that functional links between the checkpoint mechanisms exist that control genome integrity and those activities which operate throughout the unperturbed mitosis in plants.

It has been reported first in the mouse and later for other mammals that the paternal DNA is rapidly and actively demethylated very soon after fertilization. Thus, it has been proposed that the demethylation of paternal genome occurring soon after fertilization is a universal process that is typical for all mammals. However, there is evidence that the time course of demethylation of parental DNA may be species different. Such aspects were investigated by Fulka et al. (2006) in pig in vivo produced embryos using 5-methylcyt- osine (5-MeC) immunostaining. In accordance with others, they found rapid demethylation of paternal DNA in onecell stage embryos.

Proteasomes are molecular assemblies for non-lysosomal protein degradation and exist in both the cytoplasm and the nucleus. Scharf et al. (2007) have addressed the subnuclear distribution of endogenous $20 \mathrm{~S}$ proteasomes and proteasomal proteolysis in correlation with signature proteins of nuclear domains/structures. They reported that during interphase endogenous proteasomes are localized diffusely throughout the nucleoplasm, in speckles, in nuclear bodies, and in nucleoplasmic foci. Proteasomes do not occur in the nuclear envelope region or the nucleolus. Likewise, proteasomal proteolysis was detected in nucleoplasmic foci, but is absent from the nuclear envelope or nucleolus. It was concluded that the ubiquitin-proteasome system is not only located, but also proteolytically active in distinct nuclear domains and thus may be directly involved in gene expression, and nuclear quality control.

Baran et al. (2006) have reviewed the localization of the nuclear DNA helicase II (NDH II), which is the bovine homolog of human RNA helicase A, in somatic cells and oocytes. The focus of their studies was on the dynamic changes in the redistribution of NDH II during the growth phase of the bovine oocytes.

The sites of DNA synthesis in HeLa cell nucleus were studied by immunoelectron microscopic detection of incorporated biotin-dUTP. Philimonenko et al. (2006) identified two types of DNA synthetic sites/replication factories by immunoelectron microscopy: (1) electron-dense structuresreplication bodies, and (2) focal replication sites with no distinct underlying structure-replication foci. Their additional data suggested possible differences in genome regions replicated by these two types of replication factories.

DADLE, D-Ala(2)-D-Leu(5)-enkephalin, can induce hibernation. Vecchio et al. (2006) studied its effects on transcription and proliferation as well as the resumption of metabolic activity after treatment. DADLE treatment of HeLa cells inhibits transcription and proliferation and induces the concomitant formation of HERDS (heterogeneous ectopic RNP-derived structures). Furthermore, nucleoli are affected by DADLE, observed as a reduction of the granular center and an increase of the nucleolus-associated chromatin. After 48-h recovery following treatment, proliferation and transcription resume and, in parallel, HERDS disappear. The HERDS formed after DADLE treatment are composed of nuclear RNPs involved in both transcription and splicing; no nucleolar RNPs were found in the HERDS. Thus, treatment with DADLE effectively reduces the synthetic activity of the cells.

The nuclear lamina is composed of lamins, nuclear intermediate filament-type proteins, that when affected by 
mutations give raise to severe disease syndroms. Gotzmann and Foisner (2006) have reviewed the numerous laminopathies caused by mutated A-type lamins and lamin-binding nuclear membrane proteins and discuss various disease models including mutation-caused defects in lamin structure and stability, the deregulation of gene expression, and impaired cell cycle control. They focus on a disease model based on an impairment of adult stem cell function and thus compromised tissue regeneration in laminopathic diseases.

In yeast cells, hypersensitive regions positioned regularly at approximately $50 \mathrm{kbp}$ loop-size intervals in the eukaryotic chromatin were investigated by Szekvolgyi et al. (2006). They reported that DNA isolated from yeast cultures (or mammalian cell lines) carry nicks or secondary structures predisposing DNA for a specific nicking activity, at non-random positions, which may be involved in the cleavage processes responsible for the en masse disassembly of chromatin to loop-size fragments upon isolation of DNA from live eukaryotic cells.

The presence of adhesion-/growth-regulatory galectins in the nuclei of normal and malignant cells of squamous epithelial origin was revealed by Smetana et al. (2006b). Expression profiling for galectins (homodimeric proto-type galectins-1, -2 and -7 and the chimera-type galectin-3) and accessible binding sites (revealed by biotinylated lectins) by histochemistry was applied as an approach to link their localization with cellular growth properties. The FaDu squamous carcinoma cell line and long-term cultured human and porcine epidermal cells served as models for malignant and normal cells of squamous cell epithelial origin. It was concluded that cytochemical expression profiling is a prerequisite for the selection of distinct proteins for targeted modulation of gene expression as a step toward functional analysis.

\section{Programmed cell death in its various forms}

Apoptosis is a physiological type of programmed cell death (PCD). In their excellent review, Penazola et al. (2006) focus on the importance of PCD in shaping and sculpting the vertebrate embryo. Larsson (2006) has studied the mechanism of cell extrusion from the tips of the villi of small intestine. The obtained results suggest that loss of beta-catenin precedes the onset of PCD, loss of Ecadherin and extrusion from the villi. The paper by Mariante et al. (2006) provides insight into cell death in trichomonads. Tritrichomonas foetus is an amitochondriate parasite that possesses hydrogenosomes, unusual anaerobic energy-producing organelles. In these organisms the "mitochondrial cell death machinery" is supposed to be absent, and the mechanisms that lead to cell demise remain enigmatic. Treatment with the fungicide griseofulvin indi- cated that other cell death pathways may exist in Tritrichomonas foetus. Besides plasma membrane and nuclear envelope blebbing, nuclear fragmentation, and an abnormal number of oversized vacuoles, the exposure of phosphatidylserine in the outer leaflet of the plasma membrane was observed. Krajci et al. (2006) observed an unusual form of apoptotic cell death in a subpopulation of cisplatin-treated C6 glioma astrocytes in culture consisting of ectopic microtubules in the nucleus. The intranuclear microtubules may represent remnants of incompletely disassembled components of the mitotic spindle trapped inside the newly formed daughter cell nuclei. Ueno et al. (2006) observed the simultaneous induction of two apoptotic pathways in brains of neural cell-specific HIF- $1 \alpha-$ deficient mice embryos. The effects of actinomycin D and vinblastine during macrophage-like differentiation induced in THP-1 monocytic cell line by the phorbol ester phorbol 12-myristate 13-acetate (PMA) were studied by Spano et al. (2007). Tardito et al. (2006) found that the $\mathrm{Cu}(\mathrm{II})$ thioxotriazole complex triggers a non-apoptotic, type $3 \mathrm{~B}$ PCD which may render the compound of particular interest in apoptosis-resistant cell models.

Photodynamic therapy is an approach to cancer treatment based on the action of photoactive drugs called photosensitizers (PS), which preferentially localize in abnormal cells, and exert a cytotoxic effect upon irradiation with light at suitable wavelengths.

The xanthene derivative rose Bengal acetate (RB-Ac), a type II PS, is highly effcient in singlet oxygen generation. Bottone, Soldani and colleagues (Bottone et al. 2007; Soldani et al. 2007) report RB-induced photodamage of several organelles including mitochondria in HeLa cells which can lead to apoptosis. Oxysterols, mainly those oxidized at the $\mathrm{C} 7$ position, induce a complex mode of cell death exhibiting some characteristics of apoptosis associated with a rapid induction of lipid rich multilamellar cytoplasmic. Vejux et al. (2007) aimed to determine the relationships between myelin figure formation, cell death, and lipid accumulation in various cell lines [U937, THP-1, MCF-7 (caspase-3 deficient), A7R5] treated either with oxysterols [7-ketocholesterol (7KC), 7beta-hydroxycholesterol, cholesterol-5alpha,6alpha-epoxide, cholesterol5beta,6beta-epoxide, 25-hydroxycholesterol] or cytotoxic drugs (etoposide, daunorubicin, tunicamycin, rapamycin). Myelin figures were only observed with cytotoxic oxysterols (7KC, 7beta-hydroxycholesterol, cholesterol-5beta, 6beta-epoxide), and their formation was not inhibited by the broad-spectrum caspase inhibitor z-VAD-fmk. These findings indicate that myelin figure formation in the studied system is a caspase-independent event closely linked with the cytotoxicity of oxysterols, and they highlight a relationship between caspase activity and polar lipid accumulation. 


\section{Aspects of cell membranes: channels, caveolins, junctional proteins and others}

Voltage-gated calcium channels play a crucial role in cell signalling as mediators of membrane depolarisationinduced calcium entry and are expressed in a large variety of cell types, including neurons and neuroendocrine cells. De Proost et al. (2007) have studied localisation of voltagegated calcium channels $(\mathrm{Ca}(\mathrm{v}))$ in lungs. They used their recently developed in situ lung slice model for molecular live-cell imaging for identification of the expression pattern of all major classes and subtypes of $\mathrm{Ca}(\mathrm{v})$ channels. The $\mathrm{Ca}(\mathrm{v}) 2.1$ (P/Q-type) was the only $\mathrm{Ca}(\mathrm{v})$ channel expressed in neuroepithelial bodies (NEB) cell membranes, and appeared to be restricted to the apical membrane of the slender NEB cell processes that reach the airway lumen. Subpopulations of the vagal but not the spinal sensory nerve fibres in contact with NEBs showed immunoreactivity for $\mathrm{Ca}(\mathrm{v}) 1.2$ (L-type) and $\mathrm{Ca}(\mathrm{v}) 2.1$. The $\mathrm{Ca}(\mathrm{v}) 2.3$ (Rtype) was selectively expressed by the so-called Clara-like cells that cover NEBs only, and appears to be a unique marker to discriminate this epithelial cell type from the much more extensive group of Clara cells. The laminar nerve endings of smooth muscle-associated airway receptors (SMARs) were reactive for both $\mathrm{Ca}(\mathrm{v}) 2.1$ and $\mathrm{Ca}(\mathrm{v}) 2.2$ (N-type). The $\mathrm{Ca}(\mathrm{v}) 1.2$ was expressed in vascular smooth muscle, $\mathrm{Ca}(\mathrm{v}) 2.3$ and $\mathrm{Ca}(\mathrm{v}) 3.1$ (T-type) in bronchial smooth muscle, $\mathrm{Ca}(\mathrm{v}) 3.1$ and $\mathrm{Ca}(\mathrm{v}) 3.2$ (T-type) in endothelial cells, and $\mathrm{Ca}(\mathrm{v}) 1.3$ (L-type) in a limited number of epithelial cells. In conclusion, the various subtypes of $\mathrm{Ca}(\mathrm{v})$ channels have distinct expression patterns in rat lungs. Brouns et al. (2006) compared the location, morphology, and neurochemical coding of subepithelial receptor-like structures with those for pulmonary NEBs. Branching laminar subepithelial receptor-like endings IC in the smooth muscle cell layer of rat conducting airways and their neurochemical coding and receptor-like appearance is very reminiscent of NEBs. Both structures may represent the morphological counterparts of at least subsets of the population of physiologically characterized myelinated vagal airway mechanoreceptors. D'Angelis et al. (2006) studied the C-type natriuretic peptide (CNP) and natriuretic peptide receptor B (NPR-B) in pulmonary epithelium of the developing fetal lamb and following transition to breathing. Their results suggested that CNP may contribute to the maintenance of the fluid-filled lung through the regulation of trans-epithelial ion flux.

Calcium channels are also involved in the regulation of secretion. Synaptotagmin (syt) isoforms function as calcium sensor in post-Golgi transport. The syt7 isoform has been proposed to operate in lysosomal exocytosis and in exocytosis of large dense core vesicles (LDCVs). Monterrat et al. (2007) have addressed the distribution of syt7 in insu- lin-secreting cells. By subcellular fractionation and quantitative confocal immunofluorescence, syt7 was not found on LDCVs or on synaptic-like microvesicles (SLMV) but colocalizes with Rab7 on endosomes and to structures near to or at the plasma membrane. Similarly, endogenous syt7 was absent from LDCVs in pheochromocytoma PC12 cells. In contrast, syt7 localized to lysosomes in both, PC12 cells and hippocampal neurons. In conclusion, endogenous syt7 shows a wide subcellular distribution, but does not qualify as vesicular calcium sensor in SLMV or LDCV exocytosis according to its localisation. Homann et al. (2006) have elucidated aspects of the cellular and molecular mechanisms of calcium secretion in human salivary glands. The expression of the epithelial calcium channel (CaT-Like), the calcium binding protein (calbindin-2), the endoplasmic reticulum pumps (SERCA-2 and -3), and the plasma membrane calcium ATPases (PMCA-1, -2, and -4) were studied in parotid and submandibular glands. They proposed a three-step model of calcium secretion in human salivary glands: (1) calcium enters the acinar cell at the basolateral side via calcium channel CaT-Like (calcium influx); (2) intracellular calcium is taken up into the endoplasmic reticulum by SERCA-2 and possibly SERCA3 or bound to calbindin-2 (intracellular calcium pool); and (3) calcium is secreted by PMCAs at the apical plasma membrane (calcium efflux).

The ATP-gated non-selective cation channels assembled from P2X(3) receptor subunits are important for transduction and neurotransmitter signaling in the peripheral sensory system and also feature prominently in the development of the central nervous system. Huang et al. (2006) have studied the expression of this receptor in the mouse cochlea during development until immediately prior to the onset of hearing. This period is characterized by considerable reorganization of the afferent innervation of the sensory hair cells. Based on their findings, they proposed that $\mathrm{P} 2 \mathrm{X}(3)$ may play a role in purinergic signaling in cochlear synaptic reorganization and establishment of neurotransmission, which occurs just prior to the onset of hearing function.

Membrane water channel aquaporin-2 (AQP2) and glucose transporter 4 (GLUT4) have in common that they are stored in intracellular storage compartments and undergo translocation to the plasma membrane upon hormonal stimulation. Hasegawa et al. (2007) compared the intracellular localization and trafficking of AQP2 and GLUT4 in polarized Madin-Darby canine kidney cells stably transfected with human AQP2 (MDCK-hAQP2). When expressed in MDCK-hAQP2 cells, GLUT4 and GLUT4-EGFP were predominantly localized in the perinuclear region close to and within the Golgi apparatus. AQP2, on the other hand, was sequestered in subapical Rab11-positive vesicles. Thus, in the basal state, the intracellular storage site of 
GLUT4 was distinct from that of AQP2. Forskolin induced translocation of AQP2 from the subapical storage vesicles to the apical plasma membrane, which did not affect GLUT4 localization. After forskolin washout, AQP2 was first retrieved to early endosomes from the apical plasma membrane, where it was partly colocalized with GLUT4. AQP2 was then transferred to Rab11-positive storage vesicles. These results show that AQP2 and GLUT4 share a common compartment after retrieval from the plasma membrane, but their storage compartments are distinct from each other in polarized MDCK-hAQP2 cells.

In an elegant study, Waschke et al. (2006b) have demonstrated that the protein kinase C-mediated endothelial barrier regulation is caveolin-1-dependent.

PKC activation reduces endothelial barrier functions at least in part by the reduction of VE-cadherin-mediated adhesion and PKC-mediated permeability regulation depends on caveolin-1. The same group (Waschke et al. 2006a) demonstrated that activation of Rac-1 and Cdc42 stabilizes microvascular endothelial barrier functions in vitro and in vivo, likely by increasing the junction-associated actin cytoskeleton. In related work, Hocke et al. (2006) found that the perturbation of endothelial junction proteins by Staphylococcus aureus $\alpha$-toxin could be stabilized by adrenomedullin.

Cho and Daniel (2006) studied caveolin-1, caveolin-2 and caveolin-3 in intestinal SMCs and ICC of Cav1(+/+) and Cav1(-/-) mouse. In Cav1(+/+) animals, caveolin-1 (cav1) was colocalized with caveolin-2 (cav2) and caveolin-3 (cav3), and cav2 with cav3. In the intestine of Cav1(-/-) animals, cav1 and cav2 were undetectable and reduced cav3 staining was observed only in outer circular muscle. Caveolae were present in cell types with cav1 in Cav1(+/+) animals, and present with cav3 in outer circular muscle of Cav1(-/-) mice. It was concluded that cav1 is necessary for the expression of cav2 in SMC and ICC of intestine and facilitates, but is not necessary for the expression of cav3. Bush et al. (2006) have used domain-specific anti-caveolin-1 antibodies to analyze caveolin-1 immunostaining in cellular locations outside caveolae in MDCK cells. Antibodies directed to the N-terminus of caveolin-1 recognized a previously undetected pool of caveolin- 1 in the subapical region of MDCK cells, characteristic of endosomal recycling compartments. Furthermore, they reported that the antibodies vary in their ability to label caveolin-1 at the cell surface, and that staining is highly fixation dependent. The authors concluded that no single caveolin antibody or staining condition is capable of detecting all the caveolin-1 in a cell simultaneously and that the subcellular distribution of caveolin-1 may be much broader than actually assumed.

Lipid rafts are specialized lipid microdomains of the plasma membrane enriched in signalling proteins. In plate- lets, they play an important role in platelet stimulation by thrombin or collagen. Type I and type III collagens are rapidly exposed to platelets after a vascular lesion and participate in early haemostasis phases. A new receptor for type III collagen, named TIIICBP, specifically recognizes an octapeptide sequence from human type III collagen. In continuation of their earlier studies, Maurice et al. (2006) show that in resting platelets TIIICBP is present on the platelet membrane and associated with the open canalicular system, and redistributes to the platelet membrane upon platelet activation. TIIICBP could be recovered in lipid raft-containing fractions and Triton X-100 insoluble fractions enriched in cytoskeletal proteins. Platelet aggregation, induced by type III collagen, was inhibited after disruption of the lipid rafts by cholesterol depletion. Therefore, TIIICBP may play a role in platelet activation and signal transduction induced by type III collagen.

Membrane-bound clathrin and associated proteins are important for a variety of transport mechanisms. Indeed, the functional capacity of the kidney for urine production depends on such transport processes. Hasse et al. (2006) have performed a detailed investigation about the distribution of clathrin and its associated proteins. Although they found clathrin and its accessory proteins AP1, AP2, Eps15, Epsin, CALM and Clint/EpsinR ubiquitously expressed in rat kidney cortex epithelia, distinct distribution patterns were noticed. Podocytes in glomeruli showed the most conspicuous labeling with clathrin, AP2 and CALM highly expressed in the foot processes, and AP1 primarily localized in the cell body. In the proximal tubule epithelia, all proteins were detected along the plasma membrane, and not unexpectedly, most conspicuously below the brush border. Remarkably, two populations of clathrin vesicles could be distinguished: one positive for clathrin and AP1 and another one labeling for clathrin and AP2. In distal tubules and cortical collecting ducts, all studied proteins were found in the apex of the cells, with AP1 and Clint/EpsinR showing additional staining in perinuclear dots. It was concluded the clathrin machinery has a center-stage position in the functioning of the nephron segments.

The newly discovered proteins hemojuvelin (Hjv) and transferrin receptor type 2 (TfR2) are involved in iron metabolism. Merle et al. (2007) have tested the hypothesis that in this iron-sensing pathway controlling iron absorption in mammals, hemojuvelin and TfR2 interact functionally. By immunolabeling, Hjv and TfR2 were found in rat liver only in hepatocytes. Furthermore, both proteins were predominantly localized to the basolateral membrane domain of hepatocytes. Thus, the localization of Hjv and TfR2 in the same membrane domain renders a functional interaction of these two proteins in iron homeostasis possible.

The epidermal growth factor (EGF) and its receptor (EGFR) are important in the pathogenesis of different 
malignant tumors and drugs inhibiting EGFR function hold a potential for treatment. The drug gefitinib is a specific inhibitor of EGFR tyrosine kinase and has been shown to suppress the activation of EGFR signaling for survival and proliferation in non-small cell lung cancer (NSCLC) cell lines. Rapid down-regulation of ligand-induced EGFR in a gefitinib-sensitive cell line could be shown and inefficient down-regulation of EGFR in a gefitinib-resistant cell line. Nishimura et al. (2007) have examined the internalization of Texas red-EGF in the absence or presence of gefitinib in both cell lines to further substantiate the effect of gefitinib on the EGFR down-regulation pathway and to understand the detailed internalization mechanism of gefitinib-sensitive PC9 and gefitinib-resistant QG56 cell lines. They showed that efficient endocytosis of EGF-EGFR occurs via the endocytic pathway in the PC9 cells and that gefitinib exerted a strong inhibitory effect on the endocytosis of EGFR in PC9 cells. In contrast, the internalization rate of ligand-induced EGFR was not significantly changed by gefitinib in QG56 cells. This suggests that their endocytic machinery for EGFR might be impaired at the level of the early/late endosomes which might confer gefitinib-resistance in NSCLC cell lines.

Claudins are the transmembrane proteins forming the backbone of TJs, and consist of over 20 members of a gene family. Claudins are expressed in a tissue- and cell-type specific fashion, and changes in their abundance and/or distribution are proposed to play important roles in the pathophysiology of numerous disorders. Sakai et al. (2007) have demonstrated that in the prostate, claudin-5, -8 and -10 are expressed in addition to claudin-1, $-3,-4$ and -7 . Claudin-3, -4, -5, -8 and -10 were primarily localized at the apicalmost sites of lateral membranes of luminal epithelial cells, whereas claudin- 1 and -7 were distributed along their basolateral membranes. These findings provide basic information for elucidating the significance of claudins in prostate diseases, including prostate cancers. Because of the important role of gap junctional intercellular communication (GJIC) in the equine gastric mucosal defense system, Fink et al. (2006) have analyzed the unknown distribution of the gap junction protein connexin 32 (Cx32) in this organ. $\mathrm{Cx} 32$ was found in the glandular regions, but was undetectable in squamous mucosa. Within the glandular epithelium, Cx32 was abundant in surface and foveolar cells and decreased towards the proliferative zone of the glands, suggesting that gap junctions develop during the maturation of surface cells. Suzaki et al. (2007) applied antibodies to $\gamma$-tubilin and observed a unique staining in mouse small intestine. The tricellular junctions of the enterocytes were labeled.

Thus in addition to tricellulin, a molecule related to $\gamma$-tubulin and perhaps to the microtubules exists in tricellular junctions. Notch family molecules are transmembrane receptors that play various roles in contact-dependent cell- cell interactions in a wide range of organs. In the brain, Notch2, but not the other members of Notch, is expressed in the choroid plexus at an exceptionally high level. Tanaka et al. (2007) have examined the cellular and subcellular localization of Notch 2 protein in the choroid plexus. Unexpectedly, Notch2 was asymmetrically localized on the microvillous surface of epithelial cells in the choroid plexus. In organotypic cultures of the choroid plexus, antiNotch2 antibodies caused deformation of microvilli suggesting a role of Notch2 in the maintenance of the microvillous structure in choroid plexus epithelial cells.

Intracellular transport in cultured cells can be inhibited by lowering temperature, but the molecular basis for this phenomen remains enigmatic. In continuation of previous studies showing that COPI complexes detach from membranes at $15^{\circ} \mathrm{C}$, Martinez-Alonso et al. (2007) analyzed the effect of this temperature condition on both COPII and clathrin coat complexes in HeLa cells. Strikingly, COPII proteins moved from membranes to the cytosol and accumulated into electron-dense areas. In contrast, clathrin coat was not affected. Together, these results demonstrate that low temperature induces both COPI and COPII dissociation from target membranes which may the basis for the observed transport blockades.

\section{The cytoskeleton: cell shape and motility}

Majoul et al. (2007) have reviewed the multiple functions of developmentally regulated brain protein (drebrin), an actin-binding protein, in the formation of cellular polarity in different cell types. Drebrin has a well-established role in the morphogenesis, patterning and maintenance of dendritic spines in neurons. Drebrin also stabilizes Connexin-43 containing gap junctions at the plasma membrane. All current evidence suggests that drebrin may be broadly involved in shaping cell processes and in the formation of stabilized plasma membrane domains, an effect that is likely to be of crucial significance for formation of cell polarity in both neuronal and non-neuronal types.

Beta-thymosins are polypeptides involved in the regulation of actin polymerization, and thymosin beta10 and beta4 have been implicated in sequestration of monomeric (G-) actin. Maelan et al. (2007) have studied the distribution of endogenously expressed thymosin beta10 in cultured human breast cancer cell lines. Both unperturbed monolayer cultures and wound-healing models were examined using double-staining for thymosin beta10 and polymerized (F-) actin. The authors showed that thymosin beta10 is expressed in all three-cancer cell lines (SK-BR-3, MCF-7 and MDAMB-231) studied. No or little staining was detected in confluent cells, whereas strong staining occurred in semiconfluent cells and in cells populating monolayer wounds. 
Importantly, the distribution of staining for thymosin beta10 was inverse of staining for F-actin. These data indicate a physiological role for thymosin beta10 in sequestration of $\mathrm{G}$-actin as well as in cancer cell motility.

Fibroblasts in subcutaneous tissue contain non-filamentous $\alpha$-SMA. The distribution of $\alpha$-SMA within these fibroblasts is dynamically responsive to changes in mechanical tissue forces. In continuation of previous studies (Langevin et al. 2006), Storch et al. (2007) have investigate the structural organization of $\alpha$-SMA in relation to the nucleus. They detected $\alpha$-SMA within nuclear invaginations in close proximity to the nuclear membrane, but not in the nucleoplasm. The authors propose that the distribution pattern of $\alpha$-SMA within the cell and its relationship to the nucleus may indicate a mechanical signal transduction from the cell periphery to the nucleus.

Vasodilator-stimulated phosphoprotein (VASP) proteins regulate actin-based motility, platelet aggregation, and growth cone guidance, although the molecular mechanisms involved essentially remain elusive. Galler et al. (2006) have studied fibroblasts derived from VASP-deficient mice and showed that they have thicker and more stable actin stress fibres as compared to fibroblasts from wilt type animals. Furthermore, focal adhesions were enlarged, myosin light chain phosphorylation was increased, and the rigidity of the filament-supported plasma membrane was elevated about three- to fourfold as determined by atomic force microscopy. Fibronectin-coated beads adhered stronger to the surface of VASP-deficient cells. Interestingly, many of these effects observed in VASP-deficient cells are recapitulated in VASP-overexpressing cells. Together, these results suggest that VASP regulates surface protrusion formation and cell adhesion through modulation of the mechanical properties of the actin cytoskeleton. Colocalization of cortactin and actin related protein 2/3 (Arp2/3) in the lamellipodia is critical to sphingosine-1-phosphate (S1P)-induced endothelial cell chemotaxis. Lee et al. (2006a) described that S1P-stimulated cortactin translocation to the cell periphery to form lamellipodia is specifically mediated by the endothelial S1P1 G-protein coupled receptor, and is regulated by G(i)mediated Akt-dependent S1P1 receptor phosphorylation and Cdc42/Rac activation pathways. Furthermore, S1P signaling, via the G(i)/Akt/S1P1 phosphorylation/Rac pathway, was observed to regulate the cortactin-Arp2/3 complex formation, which ultimately results in membrane ruffling, formation of the lamellipodia and endothelial migration.

Differentiation processes in the placental trophoblast comprise polarization, cell fusion and migration, which involve dramatic reorganizations of cytoskeletal proteins such as intermediate filaments or actin. Miehe et al. (2006) have analyzed the protein expression of an actin stress fiber-associated protein, the carboxy-terminal LIM domain protein (CLP36). In placenta, CLP36 protein was found only in the cytotrophoblast layer, where it was expressed in proliferative and early post-proliferative trophoblast cells. This is a potentially important finding since pathological pregnancy syndromes such as preeclampsia are driven by alterations of trophoblast differentiation and turnover.

Non-cytoskeletal proteins may be involved in shaping cells as shown for paralemmin-1, a phosphoprotein, lipidanchored to the cytoplasmic face of membranes studied by Kutzleb et al. (2006). Paralemmin-1 expression was highest in rat brain, adrenal gland and kidney. Paralemmin-1 staining was abundant in the neuropil-rich areas of the brain, both in axonal and dendritic processes including dendritic spines. The protein was abundant in renal distal tubule cells with their elaborate infoldings of the basolateral plasma membrane, and in extremely flattened cell types like the epithelia of the thin limbs of Henle's loops, and subpopulations of the parietal epithelial cells of Bowman's capsule and vascular endothelial cells. This discontinuous distribution of paralemmin-1 suggested an association with lipid microdomains and is consistent with a role for paralemmin1 in the formation and stabilization of plasma membrane elaborations in neurons as well as in other cell types. Elements of the cytoskeleton fulfill functions other than to help maintain the shape of a cell. Two manuscripts used MDCK cells together with cytoskeletal disruption as a model system to investigate the role of cytoskeletal elements in protein trafficking and localization. Tajika et al. (2005) investigated the involvement of cytoskeletal elements in trafficking of the aquaporin2 (AQP2) water channel. By using nocadazole or colcemid to disrupt microtubules, and cytochalasin D or latrunculin to disrupt actin filaments, they found that microtubules (together with Rab11) maintain the proper intracellular distribution of the subapical AQP2 storage compartment, and that cytoplasmic actin filaments regulate the trafficking of AQP2 from early endosomes to the storage compartment.

The localization to the centrosome of formiminotransferase cyclodeaminase (FTCD) was investigated by Hagiwara et al. (2006). FTCD immunoreactivity was localized to the centrosome, more abundantly around the mother centriole. This localization of FTCD continued throughout the cell cycle and was not disrupted after Golgi apparatus fragmentation induced by colcemid and brefeldin A. Therefore, FTCD in the centrosome may be associated with polyglutamylated residues of centriole microtubules and may play a role in providing centrioles with glutamate produced by cyclodeaminase domains of FTCD.

\section{Blood and lymph vessels, angiogenesis}

Research in lymphatic vessels has become a very active field during recent years. Unlike the blood vascular system, 
lymphatic system is an open ended, one-way transit system draining protein-rich lymph from the interstitium back into the blood. Kivelä et al. (2007) have localized lymphatic vessels and their growth factors in human and mouse skeletal muscle with specific antibodies (VEGFR-3, LYVE-1, VEGF-C and VEGF-D). The largest lymphatic vessels were found in perimysial connective tissue next to the arteries and veins, corroborating earlier electron microscopic observations. As a new finding, they observed small LYVE-1 positive vessels in the capillary bed between muscle fibres. These vessels were located next to CD31 positive blood capillaries and were of the same size, but fewer in number. In addition, the localisation of the two main lymphangiogenic growth factor proteins, vascular endothelial growth factor (VEGF)-C and -D was studied. Both proteins were expressed in skeletal muscle at mRNA and protein levels. VEGF-D was located under the sarcolemma in some of the muscle fibres, in the endothelia of larger blood vessels and in fibroblasts. VEGF-C protein was localized to the nerves and muscle spindles, to fibroblasts and surrounding connective tissue, but was not found in muscle fibres or endothelial cells. In conclusion, for the first time the presence of lymphatic capillaries throughout the skeletal muscle was described.

Brain development occurs in a specialized environment maintained by a blood-brain barrier (BBB). The endothelial $\mathrm{TJ}$ is an important structural element of the BBB. Anstrom et al. (2007) studied human premature infants to determine if amounts of the TJ proteins ZO-1, claudin and occludin increase with gestational age in vessels of germinal matrix (GM) and cortex. By 24 weeks postconception (PC), TJ proteins were detected immunohistochemically in both GM and cortical vessels, but immunoreactivity in the GM of the youngest subjects was less than in older subjects. At 24 weeks PC, TJ protein immunoreactivity in GM vessels was less than in cortical vessels suggesting that $\mathrm{TJ}$ maturation progresses along a superficial to deep brain axis. Together, these data indicate that differentiation of some functional specializations is still in progress in GM vessels during the third trimester. This maturation was suggested to be related to the pathogenesis of germinal matrix hemorrhage-intraventricular hemorrhage. Notch and Delta signaling regulates cell-fate decisions in a variety of tissues including blood vessels in diverse organisms through cellto-cell interactions. Nimmagadda et al. (2007) with the help of an isolated $696 \mathrm{bp}$ fragment of chick Delta-like 4 (Dll4) cDNA analyzed its expression pattern during chick development (from HH-stage 8-30) by in situ hybridization. cDll4 expression was seen in extraembryonic tissues and in the dorsal aorta throughout development but was absent from venules. Dll4 as expressed in the embryonic blood vessels, heart, somites, neural tube, limb, pharyngeal arches, esophagus, and in the developing eye. Thus, like in mice, mice, cDll4 is a marker of the arterial type of endothelial cells in chicken supporting a role in vascular development during chick embryogenesis.

Splenic sinus endothelial cells adhere through tight and adherens junctions and regulate the passage of blood cells through the splenic cord. Uehara and Uehara (2007) have investigated the localization of tight junctional proteins, claudin-5 and ZO-1 in the sinus endothelial cells of rat spleen and to characterized spatial and functional relationships between tight and adherens junctions. Claudin-5, ZO1 , and alpha-catenin were distinctly localized in the junctional regions of adjacent endothelial cells. By immunogold electron microscopy claudin-5 localized in the tight-junctional fused membranes of adjacent endothelial cells, whereas ZO-1 was localized not only in the tight-junctional-fused membranes of endothelial cells but also in the junctional membrane. alpha-Catenin was intermittently localized along the juxtaposed junctional membranes of adjacent endothelial cells. Double immunogold labeling demonstrated that ZO-1 was closely localized to VE-cadherin and alpha-catenin in their juxtaposed membranes of endothelial cells. It was concluded that ZO-1 might play an important role in regulating the cell-cell junctions of sinus endothelial cells for blood-cell passage through splenic cords.

Angiogenesis, the process of new vessel formation from a pre-existing vascular network, is regulated by a net balance between stimulatory and inhibitory molecules. Although various signals triggering angiogenesis have been discovered, the mechanisms that trigger angiogenesis to adapt tissue perfusion to increased metabolic demands remain unclear. Hansen-Algenstaedt et al. (2006) hypothesized a neural controlled activation of angiogenesis correlating with increased metabolic demands by NGF overexpression via activation of VEGF and VEGF receptors in tissues with sympathetic innervation such as brown adipose tissue. This was supported by their data, which suggested an activation of angiogenesis as a result of both stimulation of adipocytes and direct mitogenic effects on endothelial cells. The observed increased nerve density associated with vessels provided additionally support that tissue perfusion is regulated by neural control of vessels and that the interaction between the NGF and VEGF systems is the critical driver for the activated angiogenic process.

Onodere et al. (2006) revealed the presence of stem-like cells with vasculogenic potential in the murine endometrium. These tissue-specific vasculogenic cells were able to vascular formation even in different tissue microenvironments. The possibility of the therapeutic replacement of endothelium by endothelial progenitor cells (EPCs) in ischemic organs was investigated by Neumuller et al. (2006). They investigated whether EPCs derived from 
peripheral blood mononuclear cells (PBMNCs-derived EPCs) or EPCs propagated from $\mathrm{CD} 34^{(+)}$hematopoietic stem cells (HSCs-derived EPCs), both isolated from human cord blood, are able to differentiate into early mature endothelial cells (ECs) under in vitro conditions. PBMNCs gave rise to clusters of spindle-like EPCs that did not mature. Mature ECs could only be successfully propagated from a starting population of isolated HSCs.

In the lung, hypoxia results in various effects, which includes induction of angiogenesis, which may counteract pulmonary hypertension. Paddenberg et al. (2006) analyzed whether the anti-angiogenic factor endostatin participates in vascular alterations induced by hypoxia. Heart, aorta, brain and liver were also included in this study to discriminate pulmonary-specific from general mechanisms. In the lung, the activity of MMP, which are known to generate endostatin by cleavage of collagen XVIII, was increased (MMP-2) and decreased (proMMP-9), respectively, by hypoxia. This surprising finding was proposed to be another factor in development of pulmonary hypertension by reduction of angiogenesis.

\section{Studies on the nervous system}

Synapses, particularly those on dendritic spines, are the major sites of neuronal plasticity in the central nervous system. For learning and memory formation, synapses and plastic changes in their structure and function play an important role. In their excellent review, Frotscher et al. (2007) have critically analyzed methods to study synapses, in particular newer ones allowing for fixation artifact-free electron microscopic analysis and advanced fluorescence microscopy techniques for real-time analysis of structural changes at synapses. They first review high-pressure freezing of fresh tissue as a method that may be applied to study subtle changes in synaptic ultrastructure associated with functional synaptic plasticity. Furthermore, the authors proposed to label presynaptic mossy fiber terminals and postsynaptic complex spines on CA3 pyramidal neurons by different fluorescent dyes to allow for the real-time monitoring of these synapses in living tissue over extended periods of time. It is expected that these approaches will lead to new insights into the structure and function of central synapses.

Luziga et al. (2007) have carried out in situ hybridization studies to examine the expression pattern of cytotoxic T-lymphocyte antigen-2alpha (CTLA-2alpha) mRNA and determine the specific cell types synthesizing CTLA-2alpha in the mouse brain. CTLA-2alpha was originally discovered and expressed in mouse-activated T-cells and mast cells and shown to exhibit selective inhibition to cathepsin L-like cysteine proteinases. In the current study, CTLA- 2alpha mRNA was detected in various neuronal populations within the telencephalon in cerebral cortices, olfactory system, septum, basal ganglia, amygdala and highest levels were observed in the hippocampus. Within the diencephalon high density of positive cells was found in mediodorsal and lateral posterior thalamic nuclei and medial habenular nucleus $(\mathrm{MHb})$. In the hypothalamus, high density of CTLA-2alpha mRNA labeling was seen in the suprachiasmatic nucleus (Sch), optic tract, arcuate nucleus, and median eminence. The fasciculus retroflexus and its termination in the mesencephalic interpeduncular nucleus were also densely labeled. Other mesencephalic expression sites were the superior colliculus, periaqueductal gray, paramedian raphe nucleus, and inferior colliculus. In the rhombencephalon, strong labeling was detected in the pontine, vestibular, and reticular nuclei. Intense expression was also noted within cerebellar cortex in Purkinje neurons and at a moderate level in granule cell layer, stellate, and basket cells. The authors discuss possible function(s) of this novel inhibitor peptide in relation to learning, memory and diseases. Malatesta et al. (2007) have performed an analysis of CLOCK protein, a transcription factor that is essential for normal circadian rhythms. They compared its expression between adult and old rats, and at different phases of the daily cycle in the neurons of the medullary reticular formation. The latter are involved in the control of the sleepwake cycle. Their results demonstrate quali-quantitative modifications of CLOCK protein in the neurons of old animals which suggest that a deregulation of the intracellular clock mechanism may play a role in the degeneration of the sleep-wake circadian cycle. BK channels are involved in controlling action potential duration and the firing frequency and spike frequency adaptation for many neurons by leading to a fast after hyperpolarization after a neuronal action potential. Sausbier et al. (2006) have observed strong immunoreactivity for the BK channel $\alpha$-subunit within the telencephalon in the cerebral cortex, olfactory bulb, basal ganglia and hippocampus and lower levels in the basal forebrain region and amygdala. Other regions expressing a high amount of BK channel staining were the nuclei of the ventral and dorsal thalamus and medial habenular nucleus, the fasciculus retroflexus and its termination in the mesencephalic interpeduncular nucleus, the periaquaeductal gray and raphe nuclei, the cerebellar cortex and locus coeruleus of the rhombencephalon, and the vestibular nuclei.

A reciprocal modulation is known to exist between the central nervous system and immune system and interleukin (IL)- 1 beta has been recognized as one of the informational molecules in immune-to-brain communication. However, details of the transmission of this large molecule to the brain remained enigmatic, although cranial nerves, especially the vagus, have been proposed to play a pivotal role in this regard. Zhang et al. (2007b) based on their previous 
findings of functional IL-1 receptor type I (IL-1RI) in carotid body, studied changes in expression of IL-1RI and tyrosine hydroxylase $(\mathrm{TH})$, a rate-limiting enzyme for catecholamine synthesis, in the glomus cells of the rat carotid body following intraperitoneal injection of IL-1beta. Their data provided additional evidence for the response of the carotid body to proinflammatory cytokine stimulation. Ciliary neurotrophic factor (CNTF) is a member of the interleukin-6 (IL-6) cytokine family and is abundantly expressed in Schwann cells in adult mammalian peripheral nerves, but not in neurons. After peripheral nerve injury, CNTF released from disrupted Schwann cells is likely to promote neuronal survival and axonal regeneration. Sango et al. (2007) have examined the expression and histochemical localization of CNTF in adult rat dorsal root ganglia (DRG) neurons in vivo and in vitro. In contrast to the restricted expression in Schwann cells in vivo, they observed abundant CNTF mRNA and protein expression in DRG neurons after $3 \mathrm{~h}, 2,7$, and 15 days in dissociated cell culture. At later stages ( 7 and 15 days) of culture, CNTF immunoreactivity was detected in both neuronal cell bodies and regenerating neurites. The authors interpreted their findings in that CNTF is synthesized and transported to neurites in cultured DRG neurons and that the culture condition itself, may be an inducible factor for localization of CNTF in the neurons.

Barclay et al. (2007) have studied the expression of peripherin in mouse hindbrain, including the inferior colliculus, pons, medulla and cerebellum. Peripherin, a $57 \mathrm{kDa}$ type III intermediate filament protein, was associated with neurite extension, neuropathies such as amyotrophic lateral sclerosis, and cranial nerve and dorsal root projections. Peripherin immunolabeling was observed in the nerve fibres and nuclei that are associated with all cranial nerves $[(\mathrm{CN}) \mathrm{V}-$ $\mathrm{XII}]$ in the hindbrain. Peripherin expression was prominent in the cell bodies and axons of the mesenchephalic trigeminal nucleus and the pars compacta region of nucleus ambiguus, and in the fibres that comprise the solitary tract, the descending spinal trigeminal tract and the trigeminal and facial nerves. A small proportion of peripherin positive fibres in CN VIII likely arise from cochlear type II spiral ganglion neurons. Peripherin positive fibres were also observed in the inferior cerebellar peduncle and folia in the intermediate zone of the cerebellum. These results demonstrate that in the adult mouse hindbrain, peripherin is expressed in discrete neuronal subpopulations that have sensory, motor and autonomic functions.

The enteric nervous system consists of three main groups of neurons, intrinsic primary afferent neurons (IPANs), interneurons and effector neurons. Weidmann et al. (2007) have estimated the proportion of human myenteric Dogiel type II neurons, putative IPANs in relation to the entire myenteric neuron population. Because of lack of a single marker for these neurons, they identified the most appropriate marker combination by immunostaining for calretinin (CALR), somatostatin (SOM), neurofilaments (NF), substance P (SP), SOM and NF.The authors found that the majorities of neurons co-reactive for CALR/SOM and SP/SOM, respectively, were type II neurons which was not the case for neurons that were reactive for only one of the two markers. The positive predictive value that a neuron displaying CALR/SOM- or SP/SOM-co-reactivity was a type II neuron was $97 \%$ in case of CALR/SOM- and $95 \%$ in case of SP/SOM-co-staining. Although the difference of the statistical parameters between the two stainings was not significant, CALR and SOM were used to estimate indirectly the proportion of type II neurons. From the results obtained, it seemed that the proportion of myenteric type II neurons in the human small intestine was related to the proportion of CALR/SOM-co-reactive neurons and may represent about one tenth of the total myenteric neuronal population. Brehmer et al. (2006) characterized human myenteric neurons co-reactive for neuronal nitric oxide synthase (nNOS) and vasoactive intestinal peptide (VIP) with respect to the entire myenteric neuronal population. By neurofilament, VIP and nNOS immunostaining, they identified spiny neurons, which differed morphologically in the small intestine compared with the large. Combined with neuronal tracing data, human myenteric spiny neurons displaying both VIP and nNOS seem to represent either inhibitory motor or descending interneurons. Ewald et al. (2006) studied the patterns of vesicular glutamate transporter 1 (VGLUT1) and the intraganglionic laminar endings markers calretinin and VGLUT2 in rat esophagus. VGLUT1 immunoreactivity was detected in both extrinsic and intrinsic innervation of the rat esophagus. Continuing previous studies, Burnstock's group investigated $\mathrm{P}_{2} \mathrm{Y}_{6}$ and $\mathrm{P} 2 \mathrm{Y}_{12}$ receptor-immunoreactive neurons and fibers and their relationship with calbindin, calretinin and nitric oxide synthase (Xiang and Burnstock 2006). Almost half of the ganglion cells in the myenteric and submucosal plexuses show $\mathrm{P}_{2} \mathrm{Y}_{12}$ receptor-immunoreactivity, which were also immunopositive for calbindin.

Maznychenko et al. (2007) have examined c-fos gene expression in the cervical spinal cord and amygdala in rats following muscle fatigue caused by intermittent high-rate $\left(100 \mathrm{~s}^{-1}\right)$ electrical stimulation of the dorsal neck muscles. Fatigue-related increases in c-fos expression were observed on the stimulated muscle side in the cervical C2-C4 (layers 1, 3-5, 7 and 10) spinal segments, bilaterally in the lumbar L4-L6 (layer 1) segments and in contralateral central (Ce), medial (Me), and basomedial (BM) amygdaloid nuclei. The rostro-caudal extent of c-fos expression in the spinal cord supported functional coupling of the cervical and lumbar regions during the neck muscle fatigue development. The distinct $\mathrm{c}$-fos expression in the $\mathrm{Ce}$ and $\mathrm{Me}$ amygdaloid 
nuclei was interpreted as evidence that they may contribute to mediate the neck muscle fatigue-related nociception, autonomic and behavioural responses.

Dubovy et al. (2006) have examined various basal lamina molecules in the DRG in the Wistar rat following constriction nerve injury. Their results suggest that nerve ligature caused an altered content of basal laminae surrounding the bodies of primary sensory neurons and their satellite glial cell units. Chen et al. (2006) have provided evidence that leptin receptor (OB-R) expression may be regulated by estradiol in an ER $\alpha$-dependent pathway. Subsequent to earlier work Schwarzenbacher and co-workers identifed a novel population of olfactory marker protein (OMP)-expressing neurons found bilaterally in the anterior/ dorsal region of each nasal cavity at the septum of the mouse (Fleischer et al. 2006). Their arrangement was considerably changed during development with appearance at stage E13; formation of ganglion-shaped clusters in the mesenchyme during the perinatal phase, and formation of a filiform layer beneath the nasal epithelium by adulthood.

Tsukagoshi et al. (2006) examined the expression of transient receptor potential (TRP) V1 and TRPV2 in calcitonin gene-related peptide (CGRP) positive sensory neurons projecting to the skin and skeletal muscles of the rat dorsum. They showed that the percentage of CGRP-positive neurons projecting to the trapezius was higher than that to the longissimus, and that the co-localization percentage of CGRP and TRPV1 on the sensory nerves was also higher in the trapezius than in the longissimus and the skin. Avendano et al. (2006) used lectins as anterograde tracers to investigate whether the lateral intermediate (LI) and posterior (Po) groups of the thalamus also project to the striatum in the cat.

Sphingolipids are major structural components of eukaryotic membranes and fulfill important functions in signal transduction and intracellular transport. A key step in the synthesis of sphingolipids is the synthesis of dihydroceramide by (dihydro)ceramide synthases (CerS). Becker et al. (2007) have examined expression of CerS genes during post-natal development in mouse brain by means of Northern blot analysis, real-time RT-PCR, and in situhybridization. In situ-hybridization experiments showed that CerS1 was the predominant CerS in neurons throughout the brain. A similar distribution, but lower expression levels, was found for CerS4 and CerS6. Only low or undetectable amounts of CerS1, CerS4 and CerS6 were, however, present in white matter. In contrast, CerS5 mRNA was detected in most cells within gray and white matter of all brain regions, suggesting ubiquitous expression of this palmitoyl-CoA specific CerS. Expression of CerS2 was transiently increased during the period of active myelination. Furthermore, expression of CerS2 was specifically localized to white matter tracts of the brain. Furthermore,
CerS2 was the predominant CerS in Schwann cells of sciatic nerves. These data suggest that CerS2 is important for the synthesis of dihydroceramide used for synthesis of myelin sphingolipids. They also show that expression levels of CerS appear to be cell-type specific and differentiation dependent.

\section{Hormone cell biology}

Andropause is a situation of partial androgen deficiency and defined as an age-related decline in serum testosterone levels. One of the symptoms of Low testosterone levels result in decreased bone mass. Filipovic et al. (2007) have evaluated the effect of androgen deficiency on thyroid immunoreactive C-cells, and on bone structure and function in the male orchidectomized middle-aged rat model Orx. In the Orx group significant decreases $(P<0.05)$ were found in the volume of $\mathrm{C}$ cells (by 14\%), their relative volume density (by 13\%) and serum calcitonin concentration (by $54 \%$ ) compared to the controls. Analyses of trabecular microarchitecture of the proximal tibia metaphysis showed that Orx induced marked decreases of cancellous bone area, trabecular thickness and trabecular number (by 52, 20 and $19 \%$ respectively; $P<0.05)$, whereas trabecular separation was increased by $27 \%(P<0.05)$. In Orx rats, serum osteocalcin concentration was increased by $119 \%(P<0.05)$, while serum calcium and phosphorus were 6 and $14 \%$ $(P<0.05)$ lower, respectively, compared to the levels in shame operated animals. In addition, urine calcium content was considerably higher (by $129 \% ; P<0.05$ ) in Orx animals. These findings indicate that the androgen deficiency caused by orchidectomy in middle-aged rats modulates the structure of $\mathrm{C}$ cells and diminished secretion of calcitonin and results in a decrease of cancellous bone mass and increased bone turnover. Type I diabetes has been shown to be associated with bone loss and increased marrow adiposity in the tibia. Martin and McCabe (2007) have tested if this response exhibits gender and location dependency by examining femur, vertebrae and calvaria of male and female, control and diabetic BALB/c mice. Non-diabetic male mice exhibited larger body, muscle, and fat mass, and increased femur BMD compared to female mice, while vertebrae and calvarial bone parameters did not exhibit gender differences. Streptozotocin-induced diabetes caused a reduction in BMD at all sites examined irrespective of gender. Increased marrow adiposity was evident in diabetic femurs and calvaria (endochondrial and intramembranous formed bones, respectively), but not in vertebrae. Leptindeficient mice also exhibit location dependent bone responses and serum leptin levels were significantly lower in diabetic compared to control mice. However, in contrast to leptin-deficient mice, the vertebrae of T1-diabetic mice 
exhibit bone loss, not gain. Taken together, these findings indicate that type I-diabetic bone loss in mice is not gender, bone location or bone type dependent, whereas increased marrow adiposity is location dependent.

It has been reported that mammotropes in a rodent pituitary gland are derived from somatotropes via somatomammotropes (SMTs), cells that produce both growth hormone (GH) and prolactin (Prl). Zheng et al. (2006) have studied the transdifferentiation of somatotropes in the embryonic chicken pituitary gland. However, their results suggest that chicken somatotropes and mammotropes independently appear in different lobes of pituitary gland and that transdifferentiation from somatotropes to mammotropes is not the central route for differentiation of mammotropes in the embryonic chicken pituitary gland.

Ghrelin is the endogenous ligand of the growth hormone secretagogue receptor (GHS-R), which is primarily involved in the central neuroregulation of GH secretion and food intake. Although primarily produced in neuroendocrine X/A-like cells of the oxyntic glands in the gastric fundus, ghrelin has been shown to have a more widespread tissue expression. Raghay et al. (2006) could detect ghrelin in thyroid $\mathrm{C}$ cells and in parathyroid cells. In addition, thyroid carcinomas (medullar, follicular and papillary) and parathyroid adenomas showed intense and diffuse immunostaining for ghrelin. Yabuki et al. (2006) reported presence of ghrelin in kidney of mice, rats and hamsters of both sexes. Immunostaining was observed on the basolateral membrane in the epithelium of the distal tubules and collecting ducts, with the other parts of the nephron or interstitial cells, including juxtaglomerular cells, being unreactive.

\section{Immune system and adipocytes}

Innate immunity as the first line of host defence is a nonspecific response against pathogens and is mainly mediated by macrophages and neutrophils. The recognition of pathogen-associated molecular pattern by these cells during the innate immune response involves a variety of receptors, termed toll-like receptors (TLRs). Interestingly, it has recently been demonstrated that adipose tissue can secrete a large array of molecules, including inflammatory cytokines. Other recent studies have suggested that adipose cells can behave as immune cells. Bes-Houtmann et al. (2007) have determined the presence of the two most prominent "pattern recognition receptors" for bacterial and fungal cell wall components, TLR2 and TLR4 on human adipose cells and have assessed their functionality. They could demonstrate relatively high levels of TLR2 and TLR4 on the surface of human adipose cells. Stimulation of human adipocytes with lipopolysaccharide (LPS), or with lipoteichoic acid (LTA), two specific ligands of TLR4 and TLR2, respectively, induced a strong increase in TNFalpha production. The specificity of the response was demonstrated by the use of anti-TLR4 and anti-TLR2 blocking antibodies. The presence of functional TLRs in human adipocytes indicates that adipocytes play a role in innate immunity.

Ohkawara et al. (2006) have investigated the effect of macrophage migration inhibitory factor (MIF) on the expression of the Toll-like receptor TLR4 (which recognizes LPS) in the colon of MIF-deficient mice. The expressions of TLR4 mRNA and protein were drastically decreased in colon tissues of MIF-deficient mice compared with wild-type mice, and upregulated by treatment with recombinant MIF. TLR4 immunostaining was observed in mononuclear cells in the lamina propria and intraepithelial, as well as weak staining in epithelial cells and crypts of wild-type mice. In contrast, no TLR4 staining was seen in the colon of MIF-deficient mice, except after treatment with recombinant MIF. Administration of dextran sulfate sodium led to an up-regulation of TLR4 expression in the colon of wild-type mice, but not in MIF-deficient mice; however, the expression of TLR4 was rescued in dextran sulfate sodium treated MIF-deficient mice by treatment with recombinant MIF. These results indicate that MIF affects the expression of TLR4 in mouse colon in both normal and colitic conditions.

Spleen tyrosine kinase (Syk) is found in hematopoietic and non-hematopoietic cells, and thought to be involved in a variety of host defense and allergic reactions. Duta et al. (2006) have investigated the influence of microbial exposure on Syk expression in mouse tissues. Total Syk expression was similar comparing germ-free with conventional mice. When they compared the expression of Syk isoforms, they found that $\operatorname{Syk}(\mathrm{S})$ was increased in the lung and spleen from germ-free animals. Indeed, they found broad tissue expression of $\operatorname{Syk}(\mathrm{S})$, but not of $\operatorname{Syk}(\mathrm{L})$. Their results demonstrate broad tissue expression of Syk isoforms, and that the lack of microbial flora results in an increased expression of $\operatorname{Syk}(\mathrm{S})$ isoform in lung and spleen.

Despite a rather widespread use of gold in medicine, for instance in the treatment of diseases expressing autoimmune elements in their pathogenesis, the definitive mechanisms of gold compounds are not yet known in detail. However, it is recognized that gold ions influence the number and function of macrophages. Larsen et al. (2007) now demonstrate that cultured macrophages are able to liberate gold ions from metallic gold surfaces in a way analogous to the release taking place when metallic implants are placed in a body. Using the ultra-sensitive autometallographic (AMG) technique, they show that murine macrophages grown on a surface of metallic gold liberate gold ions. Ultra-structural AMG reveals that the gold ions are located in an ultra-thin membrane-like structure, "the dissolution membrane", intervened between the macrophages and the 
metal surface. The dissolution membrane is most likely secreted and chemically controlled by the "dissolucytes", here macrophages, and the membrane is essential for the dissolution of metal implants and particles, which cannot be phagocytozed. As gold ions can suppress the inflammatory process, it is reasonable to expect that when dissolucytosis takes place in the living organism the liberated gold ions will cause local immunosuppression.

\section{References}

Amselgruber WM, Buttner M, Schlegel T, Schweiger M, Pfaff E (2006) The normal cellular prion protein $(\operatorname{PrP}(c))$ is strongly expressed in bovine endocrine pancreas. Histochem Cell Biol 125:441-448

Amstislavsky S, Welker P, Fruhauf JH, Maslova L, Ivanova L, Jensen B, Markel AL, Bachmann S (2006) Renal and endocrine changes in rats with inherited stress-induced arterial hypertension (ISIAH). Histochem Cell Biol 125:651-659

Anstrom JA, Thore CR, Moody DM, Brown WR (2007) Immunolocalization of tight junction proteins in blood vessels in human germinal matrix and cortex. Histochem Cell Biol 127:205-213

Asano Y, Meguro R, Odagiri S, Li C, Iwatsuki H, Shoumura K (2006) Visualization of non-heme ferric and ferrous iron by highly sensitive non-heme iron histochemistry in the stress-induced acute gastric lesions in the rat. Histochem Cell Biol 125:515-525

Avendano C, de Las Heras S, Gimenez-Amaya JM (2006) Striatal projections from the lateral and posterior thalamic complexes. An anterograde tracer study in the cat. Histochem Cell Biol 125:265271

Baran V, Kovarova H, Klima J, Hozak P, Motlik J (2006) Re-localization of nuclear DNA helicase II during the growth period of bovine oocytes. Histochem Cell Biol 125:155-164

Barclay M, Noakes PG, Ryan AF, Julien JP, Housley GD (2007) Neuronal expression of peripherin, a type III intermediate filament protein, in the mouse hindbrain. Histochem Cell Biol

Barth K, Blasche R, Kasper M (2006) Lack of evidence for caveolin-1 and CD147 interaction before and after bleomycin-induced lung injury. Histochem Cell Biol 126:563-573

Bartova E, Pachernik J, Kozubik A, Kozubek S (2007) Differentiationspecific association of HP1alpha and HP1beta with chromocentres is correlated with clustering of TIF1beta at these sites. Histochem Cell Biol 127:375-388

Becker I, Wang-Eckhardt L, Yaghootfam A, Gieselmann V, Eckhardt M (2007) Differential expression of (dihydro)ceramide synthases in mouse brain: oligodendrocyte-specific expression of CerS2/ Lass2. Histochem Cell Biol

Bencsik A, Philippe S, Debeer S, Crozet C, Calavas D, Baron T (2007) Scrapie strain transmission studies in ovine PrP transgenic mice reveal dissimilar susceptibility. Histochem Cell Biol 127:531539

Bender FL, Fischer M, Funk N, Orel N, Rethwilm A, Sendtner M (2007) High-efficiency gene transfer into cultured embryonic motoneurons using recombinant lentiviruses. Histochem Cell Biol 127:439-448

Bes-Houtmann S, Roche R, Hoareau L, Gonthier MP, Festy F, Caillens H, Gasque P, Lefebvre d'Hellencourt C, Cesari M (2007) Presence of functional TLR2 and TLR4 on human adipocytes. Histochem Cell Biol 127:131-137

Bette S, Zimmermann U, Wissinger B, Knipper M (2007) OPA1, the disease gene for optic atrophy type Kjer, is expressed in the inner ear. Histochem Cell Biol 128:421-430
Bloch K, Shichman E, Vorobeychik M, Bloch D, Vardi P (2007) Catalase expression in pancreatic alpha cells of diabetic and non-diabetic mice. Histochem Cell Biol 127:227-232

Borisov AB, Sutter SB, Kontrogianni-Konstantopoulos A, Bloch RJ, Westfall MV, Russell MW (2006) Essential role of obscurin in cardiac myofibrillogenesis and hypertrophic response: evidence from small interfering RNA-mediated gene silencing. Histochem Cell Biol 125:227-238

Bottone MG, Soldani C, Fraschini A, Alpini C, Croce AC, Bottiroli G, Pellicciari C (2007) Enzyme-assisted photosensitization with rose Bengal acetate induces structural and functional alteration of mitochondria in HeLa cells. Histochem Cell Biol 127:263-271

Bouchet-Marquis C, Dubochet J, Fakan S (2006) Cryoelectron microscopy of vitrified sections: a new challenge for the analysis of functional nuclear architecture. Histochem Cell Biol 125:43-51

Brehmer A, Schrodl F, Neuhuber W (2006) Morphology of VIP/ nNOS-immunoreactive myenteric neurons in the human gut. Histochem Cell Biol 125:557-565

Brink MC, van der Velden Y, de Leeuw W, Mateos-Langerak J, Belmont AS, van Driel R, Verschure PJ (2006) Truncated HP1 lacking a functional chromodomain induces heterochromatinization upon in vivo targeting. Histochem Cell Biol 125:53-61

Brouns I, Pintelon I, De Proost I, Alewaters R, Timmermans JP, Adriaensen D (2006) Neurochemical characterisation of sensory receptors in airway smooth muscle: comparison with pulmonary neuroepithelial bodies. Histochem Cell Biol 125:351-367

Bush WS, Ihrke G, Robinson JM, Kenworthy AK (2006) Antibodyspecific detection of caveolin-1 in subapical compartments of MDCK cells. Histochem Cell Biol 126:27-34

Bystrom B, Virtanen I, Rousselle P, Miyazaki K, Linden C, Pedrosa Domellof F (2007) Laminins in normal, keratoconus, bullous keratopathy and scarred human corneas. Histochem Cell Biol 127:657-667

Chen HP, Fan J, Cui S (2006) Detection and estrogen regulation of leptin receptor expression in rat dorsal root ganglion. Histochem Cell Biol 126:363-369

Chiu CC, Huang GT, Chou SH, Chien CT, Chiou LL, Chang MH, Lee HS, Chen DS (2007) Characterization of cytokeratin 19-positive hepatocyte foci in the regenerating rat liver after $2-\mathrm{AAF} / \mathrm{CCl}(4)$ injury. Histochem Cell Biol 128:217-226

Cho WJ, Daniel EE (2006) Colocalization between caveolin isoforms in the intestinal smooth muscle and interstitial cells of Cajal of the Cav1(+/+) and Cav1 (-/-) mouse. Histochem Cell Biol 126:9-16

Claassen H, Monig H, Sel S, Werner JA, Paulsen F (2006) Androgen receptors and gender-specific distribution of alkaline phosphatase in human thyroid cartilage. Histochem Cell Biol 126:381-388

Csaki C, Matis U, Mobasheri A, Ye H, Shakibaei M (2007) Chondrogenesis, osteogenesis and adipogenesis of canine mesenchymal stem cells: a biochemical, morphological and ultrastructural study. Histochem Cell Biol

D'Angelis CA, Nickerson PA, Ryan RM, Swartz DD, Holm BA (2006) C-type natriuretic peptide and its receptor are downregulated in pulmonary epithelium following birth. Histochem Cell Biol 126:317-324

Dahan M (2006) From analog to digital: exploring cell dynamics with single quantum dots. Histochem Cell Biol 125:451-456

De Proost I, Brouns I, Pintelon I, Timmermans JP, Adriaensen D (2007) Pulmonary expression of voltage-gated calcium channels: special reference to sensory airway receptors. Histochem Cell Biol 128:301-316

Di Giulio C, Rapino M, Zingariello M, Antonucci A, Cataldi A (2007) PKC alpha-mediated CREB activation is oxygen and age-dependent in rat myocardial tissue. Histochem Cell Biol 127:327-333

Diamanti-Kandarakis E, Piperi C, Patsouris E, Korkolopoulou P, Panidis D, Pawelczyk L, Papavassiliou AG, Duleba AJ (2007) Immunohistochemical localization of advanced glycation end-products 
(AGEs) and their receptor (RAGE) in polycystic and normal ovaries. Histochem Cell Biol 127:581-589

Diez JL, Vilarino VR, Medina FJ, Morcillo G (2006) Nucleolar localization of a reverse transcriptase related to telomere maintenance in Chironomus (Diptera). Histochem Cell Biol 126:445-452

Dorban G, Defaweux V, Levavasseur E, Demonceau C, Thellin O, Flandroy S, Piret J, Falisse N, Heinen E, Antoine N (2007) Oral scrapie infection modifies the homeostasis of Peyer's patches' dendritic cells. Histochem Cell Biol 128:243-251

Dubovy P, Jancalek R, Klusakova I (2006) A heterogeneous immunofluorescence staining for laminin-1 and related basal lamina molecules in the dorsal root ganglia following constriction nerve injury. Histochem Cell Biol 125:671-680

Dudas J, Elmaouhoub A, Mansuroglu T, Batusic D, Tron K, Saile B, Papoutsi M, Pieler T, Wilting J, Ramadori G (2006) Prospero-related homeobox 1 (Prox1) is a stable hepatocyte marker during liver development, injury and regeneration, and is absent from "oval cells". Histochem Cell Biol 126:549-562

Duta F, Ulanova M, Seidel D, Puttagunta L, Musat-Marcu S, Harrod KS, Schreiber AD, Steinhoff U, Befus AD (2006) Differential expression of spleen tyrosine kinase Syk isoforms in tissues: effects of the microbial flora. Histochem Cell Biol 126:495-505

Elmaouhoub A, Dudas J, Ramadori G (2007) Kinetics of albumin- and alpha-fetoprotein-production during rat liver development. Histochem Cell Biol 128:431-443

Eriksson A, Lindstrom M, Carlsson L, Thornell LE (2006) Hypertrophic muscle fibers with fissures in power-lifters; fiber splitting or defect regeneration? Histochem Cell Biol 126:409-417

Ewald P, Neuhuber WL, Raab M (2006) Vesicular glutamate transporter 1 immunoreactivity in extrinsic and intrinsic innervation of the rat esophagus. Histochem Cell Biol 125:377-395

Fakan S (2004) The functional architecture of the nucleus as analysed by ultrastructural cytochemistry. Histochem Cell Biol 122:83-93

Fan JY, Roth J, Zuber C (2007) Expression of mutant Ins2(C96Y) results in enhanced tubule formation causing enlargement of pre-Golgi intermediates of CHO cells. Histochem Cell Biol 128:161-173

Faulk W, Taylor G (1971) An immunocolloid method for the electron microscope. Immunochemistry 8:1081-1083

Filipovic B, Sosic-Jurjevic B, Ajdzanovic V, Trifunovic S, Manojlovic-Stojanoski M, Ristic N, Nestorovic N, Milosevic V, Sekulic M (2007) The effect of orchidectomy on thyroid C cells and bone histomorphometry in middle-aged rats. Histochem Cell Biol 128:153-159

Fink C, Hembes T, Brehm R, Weigel R, Heeb C, Pfarrer C, Bergmann M, Kressin M (2006) Specific localisation of gap junction protein connexin 32 in the gastric mucosa of horses. Histochem Cell Biol 125:307-313

Fiolka R, Stemmer A, Belyaev Y (2007) Virtual slit scanning microscopy. Histochem Cell Biol

Fleischer J, Hass N, Schwarzenbacher K, Besser S, Breer H (2006) A novel population of neuronal cells expressing the olfactory marker protein (OMP) in the anterior/dorsal region of the nasal cavity. Histochem Cell Biol 125:337-349

Frederikse PH, Donnelly R, Partyka LM (2006) miRNA and Dicer in the mammalian lens: expression of brain-specific miRNAs in the lens. Histochem Cell Biol 126:1-8

Frotscher M, Zhao S, Graber W, Drakew A, Studer D (2007) New ways of looking at synapses. Histochem Cell Biol 128:91-96

Fujinaga R, Yanai A, Nakatsuka H, Yoshida K, Takeshita Y, Uozumi K, Zhao C, Hirata K, Kokubu K, Nagano M, Shinoda K (2007) Anti-human placental antigen complex X-P2 (hPAX-P2) anti-serum recognizes $\mathrm{C}$-terminus of huntingtin-associated protein $1 \mathrm{~A}$ common to $1 \mathrm{~B}$ as a determinant marker for the stigmoid body. Histochem Cell Biol 128:335-348

Fujita A, Fujimoto T (2007) Quantitative retention of membrane lipids in the freeze-fracture replica. Histochem Cell Biol 128:385-389
Fujita K, Komatsu K, Tanaka K, Ohshima S, Asami Y, Murata E, Akita $M$ (2006) An in vitro model for studying vascular injury after laser microdissection. Histochem Cell Biol 125:509-514

Fujiwara K, Shin M, Hougaard DM, Larsson LI (2007) Distribution of anticancer antibiotic daunomycin in the rat heart and kidney revealed by immunocytochemistry using monoclonal antibodies. Histochem Cell Biol 127:69-77

Fulka J, Fulka H, Slavik T, Okada K, Fulka J Jr (2006) DNA methylation pattern in pig in vivo produced embryos. Histochem Cell Biol 126:213-217

Galler AB, Garcia Arguinzonis MI, Baumgartner W, Kuhn M, Smolenski A, Simm A, Reinhard M (2006) VASP-dependent regulation of actin cytoskeleton rigidity, cell adhesion, and detachment. Histochem Cell Biol 125:457-474

Ganchrow D, Ganchrow J, Witt M, Arki-Burstyn E (2006) The effect of beta-bungarotoxin, or geniculate ganglion lesion on taste bud development in the chick embryo. Histochem Cell Biol 126:419 435

Gealy EC, Kerr BC, Young RD, Tudor D, Hayes AJ, Hughes CE, Caterson B, Quantock AJ, Ralphs JR (2007) Differential expression of the keratan sulphate proteoglycan, keratocan, during chick corneal embryogenesis. Histochem Cell Biol

Gebhard S, Hattori T, Bauer E, Bosl MR, Schlund B, Poschl E, Adam $\mathrm{N}$, de Crombrugghe B, von der Mark K (2007) BAC constructs in transgenic reporter mouse lines control efficient and specific LacZ expression in hypertrophic chondrocytes under the complete Col10a1 promoter. Histochem Cell Biol 127:183-194

Gomes RR Jr, Van Kuppevelt TH, Farach-Carson MC, Carson DD (2006) Spatiotemporal distribution of heparan sulfate epitopes during murine cartilage growth plate development. Histochem Cell Biol 126(6):713-722

Gonzalez-Camacho F, Medina FJ (2006) The nucleolar structure and the activity of NopA100, a nucleolin-like protein, during the cell cycle in proliferating plant cells. Histochem Cell Biol 125:139-153

Gorbe A, Becker DL, Dux L, Krenacs L, Krenacs T (2006) In differentiating prefusion myoblasts connexin43 gap junction coupling is upregulated before myoblast alignment then reduced in post-mitotic cells. Histochem Cell Biol 125:705-716

Gotzmann J, Foisner R (2006) A-type lamin complexes and regenerative potential: a step towards understanding laminopathic diseases? Histochem Cell Biol 125:33-41

Guilmeau S, Niot I, Laigneau JP, Devaud H, Petit V, Brousse N, Bouvier R, Ferkdadji L, Besmond C, Aggerbeck LP et al (2007) Decreased expression of Intestinal I- and L-FABP levels in rare human genetic lipid malabsorption syndromes. Histochem Cell Biol 128:115-123

Guyot C, Combe C, Desmouliere A (2006) The common bile duct ligation in rat: a relevant in vivo model to study the role of mechanical stress on cell and matrix behaviour. Histochem Cell Biol 126:517-523

Hagiwara H, Tajika Y, Matsuzaki T, Suzuki T, Aoki T, Takata K (2006) Localization of Golgi 58K protein (formiminotransferase cyclodeaminase) to the centrosome. Histochem Cell Biol 126:251-259

Han J, Cao S, Jin H, Liu Y, Wang M, Song J, Li N (2006) Localization of putative stem cells and four cell populations with different differentiation degree in mouse mammary anlagen. Histochem Cell Biol 126:35-43

Hansen-Algenstaedt N, Algenstaedt P, Schaefer C, Hamann A, Wolfram L, Cingoz G, Kilic N, Schwarzloh B, Schroeder M, Joscheck $\mathrm{C}$ et al (2006) Neural driven angiogenesis by overexpression of nerve growth factor. Histochem Cell Biol 125:637-649

Hasegawa T, Matsuzaki T, Tajika Y, Ablimit A, Suzuki T, Aoki T, Hagiwara H, Takata K (2007) Differential localization of aquaporin-2 and glucose transporter 4 in polarized MDCK cells. Histochem Cell Biol 127:233-241 
Hass N, Schwarzenbacher K, Breer H (2007) A cluster of gustducinexpressing cells in the mouse stomach associated with two distinct populations of enteroendocrine cells. Histochem Cell Biol 128:457-471

Hasse S, Ungewickell EJ, Groos S (2006) Clathrin and clathrin-accessory proteins in rat kidney cortex epithelia. Histochem Cell Biol 126:219-229

Hausser HJ, Ruegg MA, Brenner RE, Ksiazek I (2007) Agrin is highly expressed by chondrocytes and is required for normal growth. Histochem Cell Biol 127:363-374

Hermann M, Pirkebner D, Draxl A, Berger P, Untergasser G, Margreiter R, Hengster P (2007) Dickkopf-3 is expressed in a subset of adult human pancreatic beta cells. Histochem Cell Biol 127:513521

Hernandez-Verdun D (2006a) The nucleolus: a model for the organization of nuclear functions. Histochem Cell Biol 126:135-148

Hernandez-Verdun D (2006b) Nucleolus: from structure to dynamics. Histochem Cell Biol 125:127-137

Higashiyama H, Billin AN, Okamoto Y, Kinoshita M, Asano S (2007) Expression profiling of peroxisome proliferator-activated receptor-delta (PPAR-delta) in mouse tissues using tissue microarray. Histochem Cell Biol 127:485-494

Hocke AC, Temmesfeld-Wollbrueck B, Schmeck B, Berger K, Frisch EM, Witzenrath M, Brell B, Suttorp N, Hippenstiel S (2006) Perturbation of endothelial junction proteins by Staphylococcus aureus alpha-toxin: inhibition of endothelial gap formation by adrenomedullin. Histochem Cell Biol 126:305-316

Homann V, Kinne-Saffran E, Arnold WH, Gaengler P, Kinne RK (2006) Calcium transport in human salivary glands: a proposed model of calcium secretion into saliva. Histochem Cell Biol 125:583-591

Horobin RW, Stockert JC, Rashid-Doubell F (2006) Fluorescent cationic probes for nuclei of living cells: why are they selective? A quantitative structure-activity relations analysis. Histochem Cell Biol 126:165-175

Huang LC, Ryan AF, Cockayne DA, Housley GD (2006) Developmentally regulated expression of the $\mathrm{P} 2 \mathrm{X}(3)$ receptor in the mouse cochlea. Histochem Cell Biol 125:681-692

Inghilleri S, Morbini P, Oggionni T, Barni S, Fenoglio C (2006) In situ assessment of oxidant and nitrogenic stress in bleomycin pulmonary fibrosis. Histochem Cell Biol 125:661-669

Jacob M, Mannherz HG, Napirei M (2007) Chromatin breakdown by deoxyribonuclease1 promotes acetaminophen-induced liver necrosis: an ultrastructural and histochemical study on male CD1 mice. Histochem Cell Biol 128:19-33

Jager K, Wu G, Sel S, Garreis F, Brauer L, Paulsen FP (2007) MUC16 in the lacrimal apparatus. Histochem Cell Biol 127:433-438

Jaszai J, Janich P, Farkas LM, Fargeas CA, Huttner WB, Corbeil D (2007) Differential expression of Prominin-1 (CD133) and Prominin-2 in major cephalic exocrine glands of adult mice. Histochem Cell Biol 128:409-419

Jeschke U, Karsten U, Wiest I, Schulze S, Kuhn C, Friese K, Walzel H (2006) Binding of galectin-1 (gal-1) to the Thomsen-Friedenreich (TF) antigen on trophoblast cells and inhibition of proliferation of trophoblast tumor cells in vitro by gal-1 or an anti-TF antibody. Histochem Cell Biol 126:437-444

Jouvion G, Rouger K, Fornasari B, Bougras G, Leroux I, Segalen J, Cherel Y (2006) Functional properties of muscle-derived cells related to morphological characteristics. Histochem Cell Biol 126:603-616

Kadi F, Charifi N, Henriksson J (2006) The number of satellite cells in slow and fast fibres from human vastus lateralis muscle. Histochem Cell Biol 126:83-87

Kahle M, Pridalova J, Spacek M, Dzijak R, Hozak P (2007) Nuclear myosin is ubiquitously expressed and evolutionary conserved in vertebrates. Histochem Cell Biol 127:139-148
Kalbe C, Mau M, Wollenhaupt K, Rehfeldt C (2007) Evidence for estrogen receptor alpha and beta expression in skeletal muscle of pigs. Histochem Cell Biol 127:95-107

Kallijarvi J, Hamalainen RH, Karlberg N, Sainio K, Lehesjoki AE (2006) Tissue expression of the mulibrey nanism-associated Trim37 protein in embryonic and adult mouse tissues. Histochem Cell Biol 126:325-334

Kasajima-Akatsuka N, Maeda K (2006) Development, maturation and subsequent activation of follicular dendritic cells (FDC): immunohistochemical observation of human fetal and adult lymph nodes. Histochem Cell Biol 126:261-273

Kase M, Houtani T, Sakuma S, Tsutsumi T, Sugimoto T (2007) Laser microdissection combined with immunohistochemistry on serial thin tissue sections: a method allowing efficient mRNA analysis. Histochem Cell Biol 127:215-219

King GL, Loeken MR (2004) Hyperglycemia-induced oxidative stress in diabetic complications. Histochem Cell Biol 122:333-338

Kinoshita K, Horiguchi K, Fujisawa M, Kobirumaki F, Yamato S, Hori M, Ozaki H (2007) Possible involvement of muscularis resident macrophages in impairment of interstitial cells of Cajal and myenteric nerve systems in rat models of TNBS-induced colitis. Histochem Cell Biol 127:41-53

Kishimoto K, Kitazawa R, Kurosaka M, Maeda S, Kitazawa S (2006) Expression profile of genes related to osteoclastogenesis in mouse growth plate and articular cartilage. Histochem Cell Biol 125:593-602

Kivelä R, Havas E, Vihko V (2007) Localisation of lymphatic vessels and vascular endothelial growth factors-C and -D in human and mouse skeletal muscle with immunohistochemistry. Histochem Cell Biol 127:31-40

Kobayashi T, Ogawa Y, Watanabe Y, Furuya M, Kataoka S, Garcia del Saz E, Tsunawaki S, Dinauer MC, Seguchi H (2004) Mitochondrial transmembrane potential is diminished in phorbol myristate acetate-stimulated peritoneal resident macrophages isolated from wild-type mice, but not in those from gp91-phox-deficient mice. Histochem Cell Biol 122:323-332

König S, Probst I, Becker H, Krause P (2006) Zonal hierarchy of differentiation markers and nestin expression during oval cell mediated rat liver regeneration. Histochem Cell Biol 126(6):723-734

König S, Aurich H, Schneider C, Krause P, Haftendorn R, Becker H, Christ B (2007) Zonal expression of hepatocytic marker enzymes during liver repopulation. Histochem Cell Biol 128:105-114

Korgun ET, Celik-Ozenci C, Acar N, Cayli S, Desoye G, Demir R (2006) Location of cell cycle regulators cyclin B1, cyclin A, PCNA, Ki67 and cell cycle inhibitors p21, p27 and p57 in human first trimester placenta and deciduas. Histochem Cell Biol 125:615-624

Koskivirta I, Rahkonen O, Mayranpaa M, Pakkanen S, Husheem M, Sainio A, Hakovirta H, Laine J, Jokinen E, Vuorio E et al (2006) Tissue inhibitor of metalloproteinases 4 (TIMP4) is involved in inflammatory processes of human cardiovascular pathology. Histochem Cell Biol 126:335-342

Krajci D, Mares V, Lisa V, Bottone MG, Pellicciari C (2006) Intranuclear microtubules are hallmarks of an unusual form of cell death in cisplatin-treated C6 glioma cells. Histochem Cell Biol 125:183-191

Kreft ME, Sterle M, Jezernik K (2006) Distribution of junction- and differentiation-related proteins in urothelial cells at the leading edge of primary explant outgrowths. Histochem Cell Biol 125:475-485

Kutzleb C, Petrasch-Parwez E, Kilimann MW (2006) Cellular and subcellular localization of paralemmin-1, a protein involved in cell shape control, in the rat brain, adrenal gland and kidney. Histochem Cell Biol 127(1):13-30

Langevin HM, Storch KN, Cipolla MJ, White SL, Buttolph TR, Taatjes DJ (2006) Fibroblast spreading induced by connective tissue 
stretch involves intracellular redistribution of alpha- and beta-actin. Histochem Cell Biol 125:487-495

Langhorst MF, Genisyuerek S, Stuermer CA (2006) Accumulation of FlAsH/Lumio Green in active mitochondria can be reversed by beta-mercaptoethanol for specific staining of tetracysteine-tagged proteins. Histochem Cell Biol 125:743-747

Larsen A, Stoltenberg M, Danscher G (2007) In vitro liberation of charged gold atoms: autometallographic tracing of gold ions released by macrophages grown on metallic gold surfaces. Histochem Cell Biol 128:1-6

Larsson LI (2006) Distribution of E-cadherin and beta-catenin in relation to cell maturation and cell extrusion in rat and mouse small intestines. Histochem Cell Biol 126:575-582

Lee JF, Ozaki H, Zhan X, Wang E, Hla T, Lee MJ (2006a) Sphingosine-1-phosphate signaling regulates lamellipodia localization of cortactin complexes in endothelial cells. Histochem Cell Biol 126:297-304

Lee JH, Oh CS, Mun GH, Kim JH, Chung YH, Hwang YI, Shin DH, Lee WJ (2006b) Immunohistochemical localization of sodiumdependent $\mathrm{L}$-ascorbic acid transporter 1 protein in rat kidney. Histochem Cell Biol 126:491-494

Lee JI, Paik YH, Lee KS, Lee JW, Kim YS, Jeong S, Kwon KS, Lee DH, Kim HG, Shin YW, Kim MA (2007) A peroxisome-proliferator activated receptor-gamma ligand could regulate the expression of leptin receptor on human hepatic stellate cells. Histochem Cell Biol 127:495-502

Leverkoehne I, Holle H, Anton F, Gruber AD (2006) Differential expression of calcium-activated chloride channels (CLCA) gene family members in the small intestine of cystic fibrosis mouse models. Histochem Cell Biol 126:239-250

Li Z, Ohno N, Terada N, Ohno S (2006) Immunolocalization of serum proteins in living mouse glomeruli under various hemodynamic conditions by "in vivo cryotechnique". Histochem Cell Biol 126:399-406

Lienenluke B, Christ B (2007) Impact of interleukin-6 on the glucose metabolic capacity in rat liver. Histochem Cell Biol 128:371-377

Lim YS, Lee HC, Lee HS (2006) Switch of cadherin expression from E- to N-type during the activation of rat hepatic stellate cells. Histochem Cell Biol

Lim YS, Lee HC, Lee HS (2007) Switch of cadherin expression from E- to N-type during the activation of rat hepatic stellate cells. Histochem Cell Biol 127:149-160

Lin WL, Pang VF, Liu CH, Chen JY, Shen KF, Lin YY, Yu CY, Hsu YH, Jou TS (2007) Pleomorphic extra-renal manifestation of the glomerular podocyte marker podocalyxin in tissues of normal beagle dogs. Histochem Cell Biol 127:399-414

Liu G, Amin S, Okuhama NN, Liao G, Mingle LA (2006a) A quantitative evaluation of peroxidase inhibitors for tyramide signal amplification mediated cytochemistry and histochemistry. Histochem Cell Biol 126:283-291

Liu J, Fu YY, Sun XY, Li FX, Li YX, Wang YL (2006b) Expression of SWAP-70 in the uterus and feto-maternal interface during embryonic implantation and pregnancy in the rhesus monkey (Macaca mulatta). Histochem Cell Biol 126(6):695-704

Lourenco SV, Coutinho-Camillo CM, Buim ME, Uyekita SH, Soares FA (2007) Human salivary gland branching morphogenesis: morphological localization of claudins and its parallel relation with developmental stages revealed by expression of cytoskeleton and secretion markers. Histochem Cell Biol 128:361-369

Luers GH, Thiele S, Schad A, Volkl A, Yokota S, Seitz J (2006) Peroxisomes are present in murine spermatogonia and disappear during the course of spermatogenesis. Histochem Cell Biol 125:693-703

Luziga C, Nakamura O, Deshapriya RM, Usui M, Miyaji M, Wakimoto M, Wada N, Yamamoto Y (2007) Expression mapping of cytotoxic T-lymphocyte antigen-2alpha gene transcripts in mouse brain. Histochem Cell Biol 127:569-579
Macarak EJ, Schulz J, Zderic SA, Sado Y, Ninomiya Y, Polyak E, Chacko S, Howard PS (2006) Smooth muscle trans-membrane sarcoglycan complex in partial bladder outlet obstruction. Histochem Cell Biol 126:71-82

Maelan AE, Rasmussen TK, Larsson LI (2007) Localization of thymosin beta 10 in breast cancer cells: relationship to actin cytoskeletal remodeling and cell motility. Histochem Cell Biol 127:109-113

Majoul I, Shirao T, Sekino Y, Duden R (2007) Many faces of drebrin: from building dendritic spines and stabilizing gap junctions to shaping neurite-like cell processes. Histochem Cell Biol 127:355-361

Malatesta M, Fattoretti P, Baldelli B, Battistelli S, Balietti M, BertoniFreddari C (2007) Effects of ageing on the fine distribution of the circadian CLOCK protein in reticular formation neurons. Histochem Cell Biol 127:641-647

Mariante RM, Vancini RG, Benchimol M (2006) Cell death in trichomonads: new insights. Histochem Cell Biol 125:545-556

Martin LM, McCabe LR (2007) Type I diabetic bone phenotype is location but not gender dependent. Histochem Cell Biol 128:125133

Martin RM, Tunnemann G, Leonhardt H, Cardoso MC (2007) Nucleolar marker for living cells. Histochem Cell Biol 127:243-251

Martinez-Alonso E, Tomas M, Ballesta J, Martinez-Menarguez JA (2007) Low temperature (15 degrees C) induces COPII dissociation from membranes and slow exit from the endoplasmic reticulum in HeLa cells. Histochem Cell Biol 128:379-384

Mathee H, Baddeley D, Wotzlaw C, Fandrey J, Cremer C, Birk U (2006) Nanostructure of specific chromatin regions and nuclear complexes. Histochem Cell Biol 125:75-82

Maurice P, Waeckel L, Pires V, Sonnet P, Lemesle M, Arbeille B, Vassy J, Rochette J, Legrand C, Fauvel-Lafeve F (2006) The platelet receptor for type III collagen (TIIICBP) is present in platelet membrane lipid microdomains (rafts). Histochem Cell Biol 125:407-417

Maznychenko AV, Pilyavskii AI, Kostyukov AI, Lyskov E, Vlasenko OV, Maisky VA (2007) Coupling of c-fos expression in the spinal cord and amygdala induced by dorsal neck muscles fatigue. Histochem Cell Biol 128:85-90

Merle U, Theilig F, Fein E, Gehrke S, Kallinowski B, Riedel HD, Bachmann S, Stremmel W, Kulaksiz H (2007) Localization of the iron-regulatory proteins hemojuvelin and transferrin receptor 2 to the basolateral membrane domain of hepatocytes. Histochem Cell Biol 127:221-226

Miehe U, Kadyrov M, Neumaier-Wagner P, Bartz C, Rath W, Huppertz B (2006) Expression of the actin stress fiber-associated protein CLP36 in the human placenta. Histochem Cell Biol 126:465-471

Milicevic NM, Nohroudi K, Labudovic-Borovic M, Milicevic Z, Pfeffer K, Westermann J (2006) Metallophilic macrophages are lacking in the thymus of lymphotoxin-beta receptor-deficient mice. Histochem Cell Biol 126(6):687-693

Minas V, Mylonas I, Schiess1 B, Mayr D, Schulze S, Friese K, Jeschke U, Makrigiannakis A (2007) Expression of the blood-group-related antigens Sialyl Lewis a, Sialyl Lewis $\mathrm{x}$ and Lewis y in term placentas of normal, preeclampsia, IUGR- and HELLP-complicated pregnancies. Histochem Cell Biol 128:55-63

Misteli T (2005) Concepts in nuclear architecture. Bioessays 27:477487

Mitani H, Takahashi I, Onodera K, Bae JW, Sato T, Takahashi N, Sasano Y, Igarashi K (2006) Comparison of age-dependent expression of aggrecan and ADAMTSs in mandibular condylar cartilage, tibial growth plate, and articular cartilage in rats. Histochem Cell Biol 126:371-380

Miyazawa K, Kanaya T, Tanaka S, Takakura I, Watanabe K, Ohwada S, Kitazawa H, Rose MT, Sakaguchi S, Katamine S et al (2007) Immunohistochemical characterization of cell types expressing 
the cellular prion protein in the small intestine of cattle and mice. Histochem Cell Biol 127:291-301

Mochizuka A, Uehara T, Nakamura T, Kobayashi Y, Ota H (2007) Hyperplastic polyps and sessile serrated 'adenomas' of the colon and rectum display gastric pyloric differentiation. Histochem Cell Biol 128:445-455

Moldovan L, Moldovan NI (2004) Oxygen free radicals and redox biology of organelles. Histochem Cell Biol 122:395-412

Monterrat C, Grise F, Benassy MN, Hemar A, Lang J (2007) The calcium-sensing protein synaptotagmin 7 is expressed on different endosomal compartments in endocrine, neuroendocrine cells or neurons but not on large dense core vesicles. Histochem Cell Biol 127:625-632

Muller D, Davidoff MS, Bargheer O, Paust HJ, Pusch W, Koeva Y, Jezek D, Holstein AF, Middendorff R (2006) The expression of neurotrophins and their receptors in the prenatal and adult human testis: evidence for functions in Leydig cells. Histochem Cell Biol 126:199-211

Myatt L, Cui X (2004) Oxidative stress in the placenta. Histochem Cell Biol 122:369-382

Nauseef WM (2004) Assembly of the phagocyte NADPH oxidase. Histochem Cell Biol 122:277-291

Neumuller J, Neumuller-Guber SE, Lipovac M, Mosgoeller W, Vetterlein M, Pavelka M, Huber J (2006) Immunological and ultrastructural characterization of endothelial cell cultures differentiated from human cord blood derived endothelial progenitor cells. Histochem Cell Biol 126(6):649-664

Nilsson M (2006) Lock and roll: single-molecule genotyping in situ using padlock probes and rolling-circle amplification. Histochem Cell Biol 126:159-164

Nimmagadda S, Geetha-Loganathan P, Prols F, Scaal M, Christ B, Huang R (2007) Expression pattern of D114 during chick embryogenesis. Histochem Cell Biol 128:147-152

Nishimura Y, Bereczky B, Ono M (2007) The EGFR inhibitor gefitinib suppresses ligand-stimulated endocytosis of EGFR via the early/ late endocytic pathway in non-small cell lung cancer cell lines. Histochem Cell Biol 127:541-553

Nowak G, Pestic-Dragovich L, Hozak P, Philimonenko A, Simerly C, Schatten G, de Lanerolle P (1997) Evidence for the presence of myosin I in the nucleus. J Biol Chem 272:17176-17181

Ogawa T, Tateno C, Asahina K, Fujii H, Kawada N, Obara M, Yoshizato $\mathrm{K}$ (2007) Identification of vitamin A-free cells in a stellate cell-enriched fraction of normal rat liver as myofibroblasts. Histochem Cell Biol 127:161-174

Ohara K, Shin M, Larsson LI, Fujiwara K (2007a) Improved immunocytochemical detection of daunomycin. Histochem Cell Biol 127:603-608

Ohara K, Shin M, Nakamuta H, Larsson LI, Hougaard DM, Fujiwara $\mathrm{K}$ (2007b) Immunocytochemical studies on the distribution pattern of daunomycin in rat gastrointestinal tract. Histochem Cell Biol 128:285-290

Ohkawara T, Takeda H, Miyashita K, Nishiwaki M, Nakayama T, Taniguchi M, Yoshiki T, Takana J, Imamura M, Sugiyama T et al (2006) Regulation of Toll-like receptor 4 expression in mouse colon by macrophage migration inhibitory factor. Histochem Cell Biol 125:575-582

Ohno N, Terada N, Ohno S (2006) Histochemical analyses of living mouse liver under different hemodynamic conditions by "in vivo cryotechnique". Histochem Cell Biol 126:389-398

Okamura K, Asahina K, Fujimori H, Ozeki R, Shimizu-Saito K, Tanaka Y, Teramoto K, Arii S, Takase K, Kataoka M et al (2006) Generation of hybrid hepatocytes by cell fusion from monkey embryoid body cells in the injured mouse liver. Histochem Cell Biol 125:247-257

Olson MO, Dundr M (2005) The moving parts of the nucleolus. Histochem Cell Biol 123:203-216
Omisanjo OA, Biermann K, Hartmann S, Heukamp LC, Sonnack V, Hild A, Brehm R, Bergmann M, Weidner W, Steger K (2007) DNMT1 and HDAC1 gene expression in impaired spermatogenesis and testicular cancer. Histochem Cell Biol 127:175-181

Onodera N, Tamaki T, Okada Y, Akatsuka A, Aoki D (2006) Identification of tissue-specific vasculogenic cells originating from murine uterus. Histochem Cell Biol 125:625-635

Osawa M, Kenmotsu S, Masuyama T, Taniguchi K, Uchida T, Saito C, Ohshima H (2007) Rat wct mutation prevents differentiation of maturation-stage ameloblasts resulting in hypo-mineralization in incisor teeth. Histochem Cell Biol 128:183-193

Ota H, Hayama M, Momose M, El-Zimaity HM, Matsuda K, Sano K, Maruta F, Okumura N, Katsuyama T (2006) Co-localization of TFF2 with gland mucous cell mucin in gastric mucous cells and in extracellular mucous gel adherent to normal and damaged gastric mucosa. Histochem Cell Biol 126:617-625

Paddenberg R, Faulhammer P, Goldenberg A, Kummer W (2006) Hypoxia-induced increase of endostatin in murine aorta and lung. Histochem Cell Biol 125:497-508

Pederson T, Aebi U (2002) Actin in the nucleus: what form and what for? J Struct Biol 140:3-9

Penaloza C, Lin L, Lockshin RA, Zakeri Z (2006) Cell death in development: shaping the embryo. Histochem Cell Biol 126:149-158

Philimonenko AA, Hodny Z, Jackson DA, Hozak P (2006) The microarchitecture of DNA replication domains. Histochem Cell Biol 125:103-117

Pombo A (2007) Advances in imaging the interphase nucleus using thin cryosections. Histochem Cell Biol 128:97-104

Punkt K, Fritzsche M, Stockmar C, Hepp P, Josten C, Wellner M, Schering S, Buchwalow IB (2006) Nitric oxide synthase in human skeletal muscles related to defined fibre types. Histochem Cell Biol 125:567-573

Qian L, Zhang Z, Shi M, Yu M, Hu M, Xia Q, Shen B, Guo N (2006) Expression and distribution of HSP27 in response to G418 in different human breast cancer cell lines. Histochem Cell Biol 126:593-601

Raghay K, Garcia-Caballero T, Nogueiras R, Morel G, Beiras A, Dieguez C, Gallego R (2006) Ghrelin localization in rat and human thyroid and parathyroid glands and tumours. Histochem Cell Biol 125:239-246

Rajas F, Jourdan-Pineau H, Stefanutti A, Mrad EA, Iynedjian PB, Mithieux G (2007) Immunocytochemical localization of glucose 6phosphatase and cytosolic phosphoenolpyruvate carboxykinase in gluconeogenic tissues reveals unsuspected metabolic zonation. Histochem Cell Biol 127:555-565

Rishikof DC, Lucey EC, Kuang PP, Snider GL, Goldstein RH (2006) Induction of the myofibroblast phenotype following elastolytic injury to mouse lung. Histochem Cell Biol 125:527-534

Robinson JM, Ohira T, Badwey JA (2004a) Regulation of the NAD$\mathrm{PH}$-oxidase complex of phagocytic leukocytes. Recent insights from structural biology, molecular genetics, and microscopy. Histochem Cell Biol 122:293-304

Robinson JM, Seguchi H, Badwey JA (2004b) Active oxygen and nitrogen species in biology: from cytocidal agents to signaling intermediates. Histochem Cell Biol 122:273-275

Roche R, Hoareau L, Bes-Houtmann S, Gonthier MP, Laborde C, Baron JF, Haffaf Y, Cesari M, Festy F (2006) Presence of the cannabinoid receptors, $\mathrm{CB} 1$ and $\mathrm{CB} 2$, in human omental and subcutaneous adipocytes. Histochem Cell Biol 126:177-187

Roix J, Misteli T (2002) Genomes, proteomes, and dynamic networks in the cell nucleus. Histochem Cell Biol 118:105-116

Roth FD, Quintar AA, Uribe Echevarria EM, Torres AI, Aoki A, Maldonado CA (2007) Budesonide effects on Clara cell under normal and allergic inflammatory condition. Histochem Cell Biol 127:55-68 
Roth J, Bendayan M, Orci L (1978) Ultrastructural localization of intracellular antigens by the use of protein A-gold complex. J Histochem Cytochem 26:1074-1081

Roth J (1983) The colloidal gold marker system for light and electron microscopic cytochemistry. In: Bullock GR, Petrusz P (eds) Techniques in immunocytochemistry, vol 2, pp 217-284. Academic, London

Rybaczek D, Bodys A, Maszewski J (2007) H2AX foci in late S/G2and M-phase cells after hydroxyurea- and aphidicolin-induced DNA replication stress in Vicia. Histochem Cell Biol 128:227241

Sakai N, Chiba H, Fujita H, Akashi Y, Osanai M, Kojima T, Sawada N (2007) Expression patterns of claudin family of tight-junction proteins in the mouse prostate. Histochem Cell Biol 127:457-462

Sakurada Y, Shirota M, Inoue K, Uchida N, Shirota K (2006) New approach to in situ quantification of ovarian gene expression in rat using a laser microdissection technique: relationship between follicle types and regulation of inhibin-alpha and cytochrome P450aromatase genes in the rat ovary. Histochem Cell Biol 126(6):735-741

Sango K, Yanagisawa H, Takaku S (2007) Expression and histochemical localization of ciliary neurotrophic factor in cultured adult rat dorsal root ganglion neurons. Histochem Cell Biol 128:35-43

Sausbier U, Sausbier M, Sailer CA, Arntz C, Knaus HG, Neuhuber W, Ruth $\mathrm{P}(2006) \mathrm{Ca}(2+)$-activated $\mathrm{K}(+)$ channels of the BK-type in the mouse brain. Histochem Cell Biol 125:725-741

Saussez S, Lorfevre F, Nonclercq D, Laurent G, Andre S, Journe F, Kiss R, Toubeau G, Gabius HJ (2006) Towards functional glycomics by localization of binding sites for tissue lectins: lectin histochemical reactivity for galectins during diethylstilbestrolinduced kidney tumorigenesis in male Syrian hamster. Histochem Cell Biol 126:57-69

Scharf A, Rockel TD, von Mikecz A (2007) Localization of proteasomes and proteasomal proteolysis in the mammalian interphase cell nucleus by systematic application of immunocytochemistry. Histochem Cell Biol 127:591-601

Schierack P, Nordhoff M, Pollmann M, Weyrauch KD, Amasheh S, Lodemann U, Jores J, Tachu B, Kleta S, Blikslager A et al (2006) Characterization of a porcine intestinal epithelial cell line for in vitro studies of microbial pathogenesis in swine. Histochem Cell Biol 125:293-305

Schlormann W, John M, Steiniger F, Westermann M, Richter W (2007) Improved antigen retrieval in freeze-fracture cytochemistry by evaporation of carbon as first replication layer. Histochem Cell Biol 127:633-639

Schmidt T, Wahl P, Wuthrich RP, Vogetseder A, Picard N, Kaissling B, Le Hir M (2007) Immunolocalization of phospho-S6 kinases: a new way to detect mitosis in tissue sections and in cell culture. Histochem Cell Biol 127:123-129

Schrader M, Fahimi HD (2004) Mammalian peroxisomes and reactive oxygen species. Histochem Cell Biol 122:383-393

Schroeter MR, Schneiderman J, Schumann B, Gluckermann R, Grimmas P, Buchwald AB, Tirilomis T, Schondube FA, Konstantinides SV, Schafer K (2007) Expression of the leptin receptor in different types of vascular lesions. Histochem Cell Biol 128:323-333

Schwab W, Harada H, Goetz W, Nowicki M, Witt M, Kasper M, Barth K (2007) Immunocytochemical and biochemical detection of EMMPRIN in the rat tooth germ: differentiation-dependent coexpression with MMPs and co-localization with caveolin-1 in membrane rafts of dental epithelial cells. Histochem Cell Biol 128:195-203

Serhan CN (2004) A search for endogenous mechanisms of antiinflammation uncovers novel chemical mediators: missing links to resolution. Histochem Cell Biol 122:305-321

Seta Y, Kataoka S, Toyono T, Toyoshima K (2007) Immunohistochemical localization of aromatic L-amino acid decarboxylase in mouse taste buds and developing taste papillae. Histochem Cell Biol 127:415-422

Sgambati E, Marini M, Vichi D, Zappoli Thyrion GD, Parretti E, Mello G, Gheri G (2007) Distribution of the glycoconjugate oligosaccharides in the human placenta from pregnancies complicated by altered glycemia: lectin histochemistry. Histochem Cell Biol 128:263-273

Shin M, Larsson LI, Fujiwara K (2007) Polyamines in spermatocytes and residual bodies of rat testis. Histochem Cell Biol 127:649655

Smetana K, Klamova H, Pluskalova M, Stockbauer P, Hrkal Z (2006a) To the intranucleolar translocation of AgNORs in leukemic early granulocytic and plasmacytic precursors. Histochem Cell Biol 125:165-170

Smetana K Jr, Dvorankova B, Chovanec M, Boucek J, Klima J, Motlik J, Lensch M, Kaltner H, Andre S, Gabius HJ (2006b) Nuclear presence of adhesion-/growth-regulatory galectins in normal/ malignant cells of squamous epithelial origin. Histochem Cell Biol 125:171-182

Soldani C, Croce AC, Bottone MG, Fraschini A, Biggiogera M, Bottiroli G, Pellicciari C (2007) Apoptosis in tumour cells photosensitized with Rose Bengal acetate is induced by multiple organelle photodamage. Histochem Cell Biol 128:485-495

Spano A, Monaco G, Barni S, Sciola L (2007) Expression of cell kinetics and death during monocyte-macrophage differentiation: effects of Actinomycin D and Vinblastine treatments. Histochem Cell Biol 127:79-94

Stavreva DA, McNally JG (2006) Role of H1 phosphorylation in rapid GR exchange and function at the MMTV promoter. Histochem Cell Biol 125:83-89

Steiniger B, Stachniss V, Schwarzbach H, Barth PJ (2007a) Phenotypic differences between red pulp capillary and sinusoidal endothelia help localizing the open splenic circulation in humans. Histochem Cell Biol 128:391-398

Steiniger B, Ulfig N, Risse M, Barth PJ (2007b) Fetal and early postnatal development of the human spleen: from primordial arterial B cell lobules to a non-segmented organ. Histochem Cell Biol 128:205-215

Stenzinger A, Kajosch T, Tag C, Porsche A, Welte I, Hofer HW, Steger K, Wimmer M (2005) The novel protein PTPIP51 exhibits tissue- and cell-specific expression. Histochem Cell Biol 123:19-28

Storch KN, Taatjes DJ, Bouffard NA, Locknar S, Bishop NM, Langevin HM (2007) Alpha smooth muscle actin distribution in cytoplasm and nuclear invaginations of connective tissue fibroblasts. Histochem Cell Biol 127:523-530

Stumpp T, Freymuller E, Miraglia SM (2006) Sertoli cell function in albino rats treated with etoposide during prepubertal phase. Histochem Cell Biol 126:353-361

Sugiyama Y, Koike T, Shiojiri N (2007) Immunohistochemical analyses of cell-cell interactions during hepatic organoid formation from fetal mouse liver cells cultured in vitro. Histochem Cell Biol

Suzaki E, Nomura R, Horio T, Mineyuki Y, Kataoka K (2007) gammaTubulin-like molecules in the mouse duodenal epithelium. Histochem Cell Biol 128:175-182

Suzuki-Yamamoto T, Sugimoto Y, Ichikawa A, Ishimura K (2007) Co-localization of prostaglandin F synthase, cyclooxygenase-1 and prostaglandin $\mathrm{F}$ receptor in mouse Leydig cells. Histochem Cell Biol 128:317-322

Szekvolgyi L, Hegedus E, Molnar M, Bacso Z, Szarka K, Beck Z, Dombradi V, Austin C, Szabo G (2006) Nick-forming sequences may be involved in the organization of eukaryotic chromatin into approximately $50 \mathrm{kbp}$ loops. Histochem Cell Biol 125:63-73

Taatjes DJ, Wadsworth MP, Zaman AK, Schneider DJ, Sobel BE (2007) A novel dual staining method for identification of apoptotic cells reveals a modest apoptotic response in infarcted mouse myocardium. Histochem Cell Biol 128:275-283 
Tajika Y, Matsuzaki T, Suzuki T, Ablimit A, Aoki T, Hagiwara H, Kuwahara M, Sasaki S, Takata K (2005) Differential regulation of AQP2 trafficking in endosomes by microtubules and actin filaments. Histochem Cell Biol 124:1-12

Tamaki T, Okada Y, Uchiyama Y, Tono K, Masuda M, Wada M, Hoshi A, Akatsuka A (2007) Synchronized reconstitution of muscle fibers, peripheral nerves and blood vessels by murine skeletal muscle-derived CD34(-)/45 (-) cells. Histochem Cell Biol 128:349-360

Tanaka M, Kokubo M, Marunouchi T (2007) Asymmetric localization of Notch 2 on the microvillous surface in choroid plexus epithelial cells. Histochem Cell Biol 127:449-456

Tang QY, Kukita T, Ushijima Y, Kukita A, Nagata K, Sandra F, Watanabe T, Toh K, Okuma Y, Kawasaki S et al (2006) Regulation of osteoclastogenesis by Simon extracts composed of caffeic acid and related compounds: successful suppression of bone destruction accompanied with adjuvant-induced arthritis in rats. Histochem Cell Biol 125:215-225

Tardito S, Bussolati O, Gaccioli F, Gatti R, Guizzardi S, Uggeri J, Marchio L, Lanfranchi M, Franchi-Gazzola R (2006) Non-apoptotic programmed cell death induced by a Copper(II) complex in human fibrosarcoma cells. Histochem Cell Biol 126:473-482

Terada N, Ohno N, Murata S, Katoh R, Stallcup WB, Ohno S (2006) Immunohistochemical study of NG2 chondroitin sulfate proteoglycan expression in the small and large intestines. Histochem Cell Biol 126:483-490

Terada N, Ohno N, Saitoh S, Ohno S (2007) Immunohistochemical detection of hypoxia in mouse liver tissues treated with pimonidazole using "in vivo cryotechnique". Histochem Cell Biol 128:253-261

Teramae H, Fujimoto W, Seino S, Iwanaga T (2007) Cellular expression of Noc2, a Rab effector protein, in endocrine and exocrine tissues in the mouse. Histochem Cell Biol 127:1-11

Toriya N, Takuma T, Arakawa T, Abiko Y, Sasano Y, Takahashi I, Sakakura Y, Rahemtulla F, Mizoguchi I (2006) Expression and localization of versican during postnatal development of rat temporomandibular joint disc. Histochem Cell Biol 125:205214

Tsukagoshi M, Goris RC, Funakoshi K (2006) Differential distribution of vanilloid receptors in the primary sensory neurons projecting to the dorsal skin and muscles. Histochem Cell Biol 126:343-352

Tsukamoto Y, Hijiya N, Yano S, Yokoyama S, Nakada C, Uchida T, Matsuura K, Moriyama M (2007) Arpp/Ankrd2, a member of the muscle ankyrin repeat proteins (MARPs), translocates from the Iband to the nucleus after muscle injury. Histochem Cell Biol

Uehara K, Uehara A (2007) Localization of claudin-5 and ZO-1 in rat spleen sinus endothelial cells. Histochem Cell Biol

Ueno M, Tomita S, Ueki M, Iwanaga Y, Huang CL, Onodera M, Maekawa N, Gonzalez FJ, Sakamoto H (2006) Two pathways of apoptosis are simultaneously induced in the embryonal brains of neural cell-specific HIF-1alpha-deficient mice. Histochem Cell Biol 125:535-544

Unger NJ, Odorfer KI, Weber K, Sandgren EP, Erben RG (2007) Utility of human placental alkaline phosphatase as a genetic marker for cell tracking in bone and cartilage. Histochem Cell Biol 127:669-674

Vecchio L, Soldani C, Bottone MG, Malatesta M, Martin TE, Rothblum LI, Pellicciari C, Biggiogera M (2006) DADLE induces a reversible hibernation-like state in HeLa cells. Histochem Cell Biol 125:193-201

Vejux A, Kahn E, Menetrier F, Montange T, Lherminier J, Riedinger JM, Lizard G (2007) Cytotoxic oxysterols induce caspase-independent myelin figure formation and caspase-dependent polar lipid accumulation. Histochem Cell Biol 127:609-624

Voetsch B, Jin RC, Loscalzo J (2004) Nitric oxide insufficiency and atherothrombosis. Histochem Cell Biol 122:353-367
Wakabayashi Y, Chua J, Larkin JM, Lippincott-Schwartz J, Arias IM (2007) Four-dimensional imaging of filter-grown polarized epithelial cells. Histochem Cell Biol 127:463-472

Walter EL, Spreng D, Schmockel H, Schawalder P, Tschudi P, Friess AE, Stoffel MH (2007) Distribution of lactate dehydrogenase in healthy and degenerative canine stifle joint cartilage. Histochem Cell Biol 128:7-18

Wanderer J, Morton AJ (2007) Differential morphology and composition of inclusions in the R6/2 mouse and PC12 cell models of Huntington's disease. Histochem Cell Biol 127:473-484

Wang BG, Koenig K, Riemann I, Krieg R, Halbhuber KJ (2006) Intraocular multiphoton microscopy with subcellular spatial resolution by infrared femtosecond lasers. Histochem Cell Biol 126:507515

Wang J, Olin M, Rozell B, Bjorkhem I, Einarsson C, Eggertsen G, Gafvels M (2007) Differential hepatocellular zonation pattern of cholesterol 7alpha-hydroxylase (Cyp7a1) and sterol 12alphahydroxylase (Cyp8b1) in the mouse. Histochem Cell Biol 127:253-261

Waschke J, Burger S, Curry FR, Drenckhahn D, Adamson RH (2006a) Activation of Rac-1 and Cdc42 stabilizes the microvascular endothelial barrier. Histochem Cell Biol 125:397-406

Waschke J, Golenhofen N, Kurzchalia TV, Drenckhahn D (2006b) Protein kinase $\mathrm{C}$-mediated endothelial barrier regulation is caveolin-1-dependent. Histochem Cell Biol 126:17-26

Wehrli P, Loffing-Cueni D, Kaissling B, Loffing J (2007) Replication of segment-specific and intercalated cells in the mouse renal collecting system. Histochem Cell Biol 127:389-398

Weidmann S, Schrodl F, Neuhuber W, Brehmer A (2007) Quantitative estimation of putative primary afferent neurons in the myenteric plexus of human small intestine. Histochem Cell Biol 128:399 407

Weidtkamp-Peters S, Rahn HP, Cardoso MC, Hemmerich P (2006) Replication of centromeric heterochromatin in mouse fibroblasts takes place in early, middle, and late $\mathrm{S}$ phase. Histochem Cell Biol 125:91-102

Welle MM, Reichler IM, Barth A, Forster U, Sattler U, Arnold S (2006) Immunohistochemical localization and quantitative assessment of GnRH-, FSH-, and LH-receptor mRNA Expression in canine skin: a powerful tool to study the pathogenesis of side effects after spaying. Histochem Cell Biol 126:527-535

West AR, Thomas C, Sadlier J, Oates PS (2006) Haemochromatosis protein is expressed on the terminal web of enterocytes in proximal small intestine of the rat. Histochem Cell Biol 125:283-292

Widlak P, Pietrowska M, Lanuszewska J (2006) The role of chromatin proteins in DNA damage recognition and repair. Histochem Cell Biol 125:119-126

Winter H, Braig C, Zimmermann U, Engel J, Rohbock K, Knipper M (2007) Thyroid hormone receptor alpha1 is a critical regulator for the expression of ion channels during final differentiation of outer hair cells. Histochem Cell Biol 128:65-75

Xiang Z, Burnstock G (2006) Distribution of P2Y(6) and P2Y(12) receptor: their colocalization with calbindin, calretinin and nitric oxide synthase in the guinea pig enteric nervous system. Histochem Cell Biol 125:327-336

Xie SQ, Pombo A (2006) Distribution of different phosphorylated forms of RNA polymerase II in relation to Cajal and PML bodies in human cells: an ultrastructural study. Histochem Cell Biol 125:21-31

Yabuki A, Taharaguchi S, Ichii O, Kojima M, Nishi Y, Mifune H, Kamimura R, Matsumoto M, Suzuki S (2006) Immunohistochemical localization of ghrelin in rodent kidneys. Histochem Cell Biol 126:231-238

Yamamoto T, Domon T, Takahashi S, Anjuman KA, Fukushima C, Wakita M (2007) Mineralization process during acellular cementogenesis in rat molars: a histochemical and immunohistochemi- 
cal study using fresh-frozen sections. Histochem Cell Biol 127:303-311

Ye W, Mairet-Coello G, DiCicco-Bloom E (2007) DNAse I pre-treatment markedly enhances detection of nuclear cyclin-dependent kinase inhibitor p57Kip2 and BrdU double immunostaining in embryonic rat brain. Histochem Cell Biol 127:195-203

Young RD, Akama TO, Liskova P, Ebenezer ND, Allan B, Kerr B, Caterson B, Fukuda MN, Quantock AJ (2007) Differential immunogold localisation of sulphated and unsulphated keratan sulphate proteoglycans in normal and macular dystrophy cornea using sulphation motif-specific antibodies. Histochem Cell Biol 127:115-120

Yuan X, He Y, Liu J, Luo H, Zhang J, Cui S (2007) Expression of androgen receptor and its co-localization with estrogen receptoralpha in the developing pituitary gland of sheep fetus. Histochem Cell Biol 127:423-432

Zaman AK, Fujii S, Schneider DJ, Taatjes DJ, Lijnen HR, Sobel BE (2007) Deleterious effects of lack of cardiac PAI-1 after coronary occlusion in mice and their pathophysiologic determinants. Histochem Cell Biol 128:135-145

Zarnani AH, Moazzeni SM, Shokri F, Salehnia M, Dokouhaki P, Shojaeian J, Jeddi-Tehrani M (2006) The efficient isolation of murine splenic dendritic cells and their cytochemical features. Histochem Cell Biol 126:275-282

Zhang HB, Ren CP, Yang XY, Wang L, Li H, Zhao M, Yang H, Yao KT (2007a) Identification of label-retaining cells in nasopharyn- geal epithelia and nasopharyngeal carcinoma tissues. Histochem Cell Biol 127:347-354

Zhang XJ, Wang X, Xiong LZ, Fan J, Duan XL, Wang BR (2007b) Up-regulation of IL-1 receptor type I and tyrosine hydroxylase in the rat carotid body following intraperitoneal injection of IL1beta. Histochem Cell Biol

Zheng J, Nakamura K, Maseki Y, Geelissen SM, Berghman LR, Sakai $T$ (2006) Independent differentiation of mammotropes and somatotropes in the chicken embryonic pituitary gland analysis by cell distribution and attempt to detect somatomammotropes. Histochem Cell Biol 125:429-439

Zhou HD, Fan SQ, Zhao J, Huang DH, Zhou M, Liu HY, Zeng ZY, Yang YX, Huang H, Li XL et al (2006) Tissue distribution of the secretory protein, SPLUNC1, in the human fetus. Histochem Cell Biol 125:315-324

Zinchuk V, Zinchuk O, Akimaru K, Moriya F, Okada T (2007) Ethanol consumption alters expression and colocalization of bile salt export pump and multidrug resistance protein 2 in the rat. Histochem Cell Biol 127:503-512

Zinner R, Albiez H, Walter J, Peters AH, Cremer T, Cremer M (2006) Histone lysine methylation patterns in human cell types are arranged in distinct three-dimensional nuclear zones. Histochem Cell Biol 125:3-19 